\title{
DR. 556
}

$178 / 78$ MISTLR
ONE-HALF-SCALE, TWO-DIMENSIONAL,
TWO-AXIS SEISMIC TESTS

by

L. WALDMAN and B. E. OLSEN

Work supported in part by

Contract EY-76-C-03-0167

Project Agreement No. 65

for the San Francisco Operations Office

Department of Energy

\section{DATE PUBLISHED: JUNE 1978}

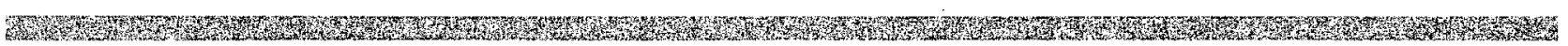

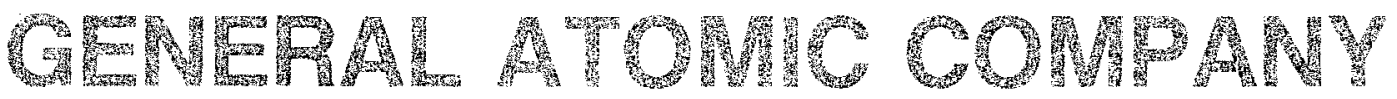




\section{DISCLAIMER}

This report was prepared as an account of work sponsored by an agency of the United States Government. Neither the United States Government nor any agency Thereof, nor any of their employees, makes any warranty, express or implied, or assumes any legal liability or responsibility for the accuracy, completeness, or usefulness of any information, apparatus, product, or process disclosed, or represents that its use would not infringe privately owned rights. Reference herein to any specific commercial product, process, or service by trade name, trademark, manufacturer, or otherwise does not necessarily constitute or imply its endorsement, recommendation, or favoring by the United States Government or any agency thereof. The views and opinions of authors expressed herein do not necessarily state or reflect those of the United States Government or any agency thereof. 


\section{DISCLAIMER}

Portions of this document may be illegible in electronic image products. Images are produced from the best available original document. 
This report was prepared as an account of work sponsored by the United States Government. Neither the United States nor the Department of Energy, nor any of their employees, nor any of their contractors, subcontractors, or their employees, makes any warranty, express or implied, or assumes any legal liability or responsibility for the accuracy, completeness or usefulness of any information, apparatus, product or process disclosed, or represents that its use would not infringe privately owned rights.

Printed in the United States of America Available from

National Technical Information Service

U.S. Department of Commerce

5285 Port Royal Road

Springfield, Virginia 22161

Price: Printed Copy $\$ 6.50$; Microfiche $\$ 3.00$ 
GA-A14548

UC-77

\section{ONE-HALF-SCALE, TWO-DIMENSIONAL, TWO-AXIS SEISMIC TESTS}

by

L. WALDMAN and B. E. OLSEN

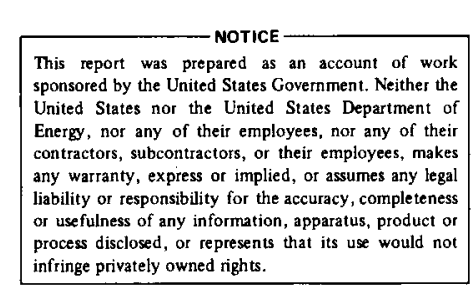

Work supported in part by

Contract EY-76-C-03-0167

Project Agreement No. 65

for the San Francisco Operations Office

Department of Energy

GENERAL ATOMIC PROJECT 3273

DATE PUBLISHED: JUNE 1978

\section{GENERAL ATOMIC COMPANY}


4 


\begin{abstract}
Uni-axial seismic tests were performed on a $1 / 2$-scale, two-dimensional model of the HTGR core consisting of 73 graphite elements in a hexagonal array. Core displacement and velocity, boundary support force, and in-core element force were measured. Behavior of the core using single-axis excitation was compared with its behavior when subjected to two-axis excitation.
\end{abstract}


$+$ 
1. SUMMARY AND CONCLUSIONS . . . . . . . . . . . . . . . . . . 1

2. INTRODUCTION . . . . . . . . . . . . . . . . . . 3

3. TEST RIG AND CORE MODEL DESCRIPTIONS . . . . . . . . . . . 4

3.1. Core Model . . . . . . . . . . . . . . 4

3.2. Test Rig . . . . . . . . . . . . . . 4

3.3. Actuators ................. 9

4. INSTRUMENTATION AND CONTROL . . . . . . . . . . . . . 10

4.1. Rig Contro1 Systems . . . . . . . . . . . . 10

4.1.1. Sinusoidal Vibration ........... 10

4.1.2. Time History Tests .......... . 15

4.2. Instrumentation . . . . . . . . . . . 20

4.2.1. Boundary Support Instrumentation ....... 20

4.2.2. In-Core Instrumentation .......... 20

4.3. Data Acquisition System . . . . . . . . . . . 25

4.4. Instrument and System Calibrations and Verification . . 29

4.4.1. Test Equipment ............. 29

4.4.2. ILMD Calibration ........... 30

4.4.3. End-to-End Calibration . . . . . . . . 32

4.4.4. Insert Calibrations . . . . . . . . . . 34

4.4.5. Other Calibrations .......... . 34

4.5. Coefficient of Restitution Tests . . . . . . . . . 35

5. TEST PLAN . . . . . . . . . . . . . . . . . 38

5.1. Sine Sweep and Sine Dwe11 Input ........... . 38

5.2. Time History Input . . . . . . . . . . . . . . . 44

5.3. Instrument Locations . . . . . . . . . . . . 47

6. DATA REDUCTION METHODS ................. . . 49

7. TEST RESULTS . . . . . . . . . . . . . . . . . 51

7.1. Pretest and System Verification . . . . . . . . 51 
7.2. Core Dynamic Characteristics . . . . . . . . . 51

7.2.1. Frequency Response ........... 54

7.2.2. Phase Dependence of Forces and Relative
Velocities................. 64

7.3. Time History Response . . . . . . . . . . . . . 73

7.4. Comparison Between Single-Axis and Two-Axis Tests . . . 73

8. ERRORS IN TEST DATA . . . . . . . . . . . . . . . 92

9. REFERENCES . . . . . . . . . . . . . . . . 98

\section{FIGURES}

3-1. One-half-scale, two-dimensional test rig and core model . . 5

3-2. One-half-scale shakers and shaker tables . . . . . . . 7

3-3. Layout of shakers and shaker tables . . . . . . . . . . 8

4-1. Hydraulic test system . . . . . . . . . . . . . . . 11

4-2. Sinusoidal vibration - phase lag definition . . . . . . 12

4-3. Sinusoidal and time history vibration control system, first method .................. 13

4-4. Rig control accelerometer instrumentation, first method . . 14

4-5. Sinusoidal and time history vibration control system, second method.................. . 16

4-6. Rig control accelerometer instrumentation, second method . 17

4-7. Time history vibration - phase lag definition . . . . . . . 19

4-8. Core displacement instrumentation . . . . . . . . . . . . 21

4-9. Boundary support load instruments and in-core load measuring devices................. . . 22

4-10. In-core instrument position 1. . . . . . . . . . 23

4-11. In-core instrument position 1a . . . . . . . . . . . . . 24

4-12. In-core load measuring device (ILMD) . . . . . . . . 26

4-13. ILMD load cell instrumentation . . . . . . . . . . . 28

4-14. ILMD mass moment of inertia test setup . . . . . . . . . . 31

4-15. ILMD dynamic calibration test setup . . . . . . . . . 33

4-16. ILMD coefficient of restitution test setup . . . . . . . 36

4-17. ILMD coefficient of restitution . . . . . . . . . . 37

5-1. Time history of shock 9................ . . 45

5-2. Time history of shock 3................ 46 


\section{FIGURES (Continued)}

5-3. Core instrumentation positions . . . . . . . . . . . . .

7-1. Frequency response curve (peak average core velocity, DX003), $\phi=90^{\circ}$. . . . . . . . . . . . . . . .

7-2. Frequency response curve (peak average core velocity, DY003),

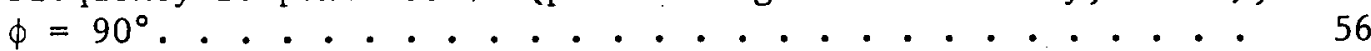

7-3. Frequency response curve (peak average element velocity, CD057), $\phi=90^{\circ}$. . . . . . . . . . . . . 57

7-4. Frequency response curve (peak average force, LC002), $\phi=90^{\circ}$. . . . . . . . . . . . . . . 58

7-5. Frequency response curve (peak average force, LL057-1), $\phi=90^{\circ}$. . . . . . . . . . . . . . . . .

7-6. Frequency response curve (peak average core velocity, DX003), $\phi=0^{\circ}$..................... . . . 60

7-7. Frequency response curve (peak average force, LC002), $\phi=0^{\circ}$....................... 61

7-8. Two-axis excitation modes for different phase angles . . . 62

7-9. Resonant frequency as a function of phase angle . . . . . 63

7-10. Distribution of force (peak average) at resonance, $\phi=0^{\circ} .65$

7-11. Distribution of velocity (peak average) at resonance, $\phi=0^{\circ}$. . . . . . . . . . . . . . . . 66

7-12. Distribution of force (peak average) at resonance, $\phi=90^{\circ}$. 67

7-13. Distribution of velocity (peak average) at resonance, $\phi=90^{\circ}$. . . . . . . . . . . . . . . . 68

7-14. Boundary support force, LC002 (peak average) versus phase angle . . . . . . . . . . . . . . . 69

7-15. In-core force, ILMD-1 (peak average), versus phase angle . . 70

7-16. In-core force, IL-C1 (peak average), versus phase angle . . 71

7-17. In-core force, ILMD-2 (peak average), versus phase angle . . 72

7-18. Distribution of maximum force, shock 3 , correlation $=1.0$. 74

7-19. Distribution of maximum velocity, shock 3 , correlation $=1.0 \quad 75$

7-20. Distributio- of maximum force, shock 9, correlation $=1.0$. 76

7-21. Distribution of maximum velocity, shock 9, correlation $=1.0 \quad 77$

7-22. Distribution of maximum force, shock 3 , correlation $=0.0$. 78

7-23. Distribution of maximum velocity, shock 3, correlation $=0.0 \quad 79$

7-24. Distribution of maximum force, shock 3, correlation $=0.25$. 80

7-25. Distribution of maximum velocity, shock 3 , correlation $=0.2581$ 
FIGURES (Continued)

7-26. Distribution of maximum force, shock 3 , correlation $=0.50$.

7-27. Distribution of maximum velocity, shock 3, correlation $=0.50$. . . . . . . . . . . . . . 83

7-28. Distribution of maximum force, shock 3, correlation $=0.75 .84$

7-29. Distribution of maximum velocity, shock 3 , correlation $=0.75$. . . . . . . . . . . . . . .

7-30. Distribution of maximum force $0.1775 \mathrm{~g}$, shock 3 , correlation $=0.0$. . . . . . . . . . . . . . . 86

7-31. Distribution of maximum velocity, $0.1775 \mathrm{~g}$, shock 3 , correlation $=0.0$. . . . . . . . . . . . . . . .

7-32. Comparison between 1/2-scale single-axis and two-axis tests, sine sweep. . . . . . . . . . . . . . . . . . . .

7-33. Comparison between 1/2-scale, single-axis and two-axis tests, E1 Centro earthquake No. 9 . . . . . . . . . . 90

7-34. Comparison between 1/2-scale single-axis and two-axis tests, GA design earthquake No. 3 . . . . . . . . . . 91

8-1. Error diagram for ILMD . . . . . . . . . . . . 97

\section{TABLES}

3-1. Summary of 1/2-scale, two-dimensional, two-axis test drawings 6

4-1. Comparison between specified and actual phase angle input . 18

5-1. Test plan ...................... . 39

7-1. Sumnary of $1 / 2$-scale two-axis test data . . . . . . . . 52

8-1. Total random errors in the 1/2-scale, two-dimensional, two-axis test data. . . . . . . . . . . . . . . 93

8-2. Error in ILMD load verification test data . . . . . . . 94

8-3. Errors in boundary support force and core velocity data . . 95

8-4. Error in core resonant frequency . . . . . . . . . . 96 


\section{SUMMARY AND CONCLUSIONS}

Simultaneous two-axis seismic tests on a 1/2-scale, two-dimensional model of the HTGR core consisting of 73 graphite elements in a hexagonal array were performed. This model is the same model that previously was tested with single axis input. The two-axis tests consisted of sinusoidal sweep, dwell, and time history earthquake type inputs conducted with several shifts in phase between the two inputs. Measured parameters included core displacement and velocity, boundary support force, and incore element force. A comparison of core behavior between single axis and two-axis excitation was performed. This test report contains a description and analysis of typical test data; the bulk of the data is contained in Ref. 1 .

The following is a summary of the more important test results and conclusions :

1. When subjected to out-of-phase, two-axis input excitation, the core describes elliptical motion. The core stays tightly lumped as for single-axis motion.

2. Two-axis motion gives the same resonance characteristics as single-axis motion. A slight decrease in resonant frequency occurs with increasing phase shifts up to $90^{\circ}$.

3. Boundary support and in-core forces at any core position are strongly dependent on the phase relationship between the two-axis inputs. The boundary forces generally show a maximum for a $0^{\circ}$ phase shift.

4. The new in-core load measuring devices (ILMD) with crystal load washers for measuring in-core element forces were very successful. 
5. The errors in the two-axis test data were larger than for singleaxis data due to the added inaccuracies associated with the second input axis. The input constituted the largest single error source. The error in the ILMD response was estimated as $18 \%$ on the basis of one standard deviation. 


\section{INTRODUCTION}

The two-dimensional, 1/2-scale two-axis test is part of an on-going seismic program to verify the adequacy of the reactor core and support structures according to NRC licensing requirements. This program consists of concurrent analytical and experimental tasks in which test data are correlated with analysis in an effort to verify the analytical models.

The two-axis tests are designed to provide simultaneous excitation along two horizontal directions $90^{\circ}$ apart and succeeded the single-axis tests on the same 1/2-scale core configuration of 73 elements. The results from the single-axis tests are reported in Ref. 2. Both tests were conducted at the Approved Engineering Test Laboratories (AETL), Los Angeles.

The specific objectives of the two-axis tests were as follows:

1. To ascertain the behavior of the core model in terms of resonant frequency, boundary forces, and interelement forces and velocities to simultaneous two-axis input excitation.

2. To obtain data for correlation with results from analytical core models under development.

A secondary objective was to obtain better core element collision forces by introducing new Instrumentation since the method of using strain gages for this purpose in the single-axls test largely failed. 


\section{TEST RIG AND CORE MODEL DESCRIPTIONS}

The core model and test rig were basically the same structures described in Ref. 2 for the 1/2-scale single-axis tests. They are shown in Fig. 3-1.

3.1. CORE MODEL

The core model consisted of 73 fuel elements scaled to one-half the HTGR prototype size. Each block had a hole pattern of seven holes to match the 1/1-scale coefficient of restitution. The blocks contained lead weights symmetrically located in six of the holes such that the proper scaled weight of $32.4 \mathrm{lb}$ could be achieved. Element design details are given in the drawings listed in Table 3-1. Three of the elements were instrumented for measuring in-core response and could be relocated to any position in the core. For further discussion of the element scaling, see Ref. 2.

The 73 core elements were assembled in a hexagonal pattern as described in the AETL test procedure (Ref. 3). To determine in-core and boundary support positions, the numbering system shown in F1g. 5-3 was used. The total core gap was adjusted to 0.5 in. and was kept constant throughout the tests.

\subsection{TEST RIG}

Some modifications to the existing single-axis test rig were made to provide two-axis capability. Figures 3-2 and 3-3 show the final two-axis design; details of this deslgn are contained in the drawings listed in Table 3-1. In this design, two core support floor plates were riding on 


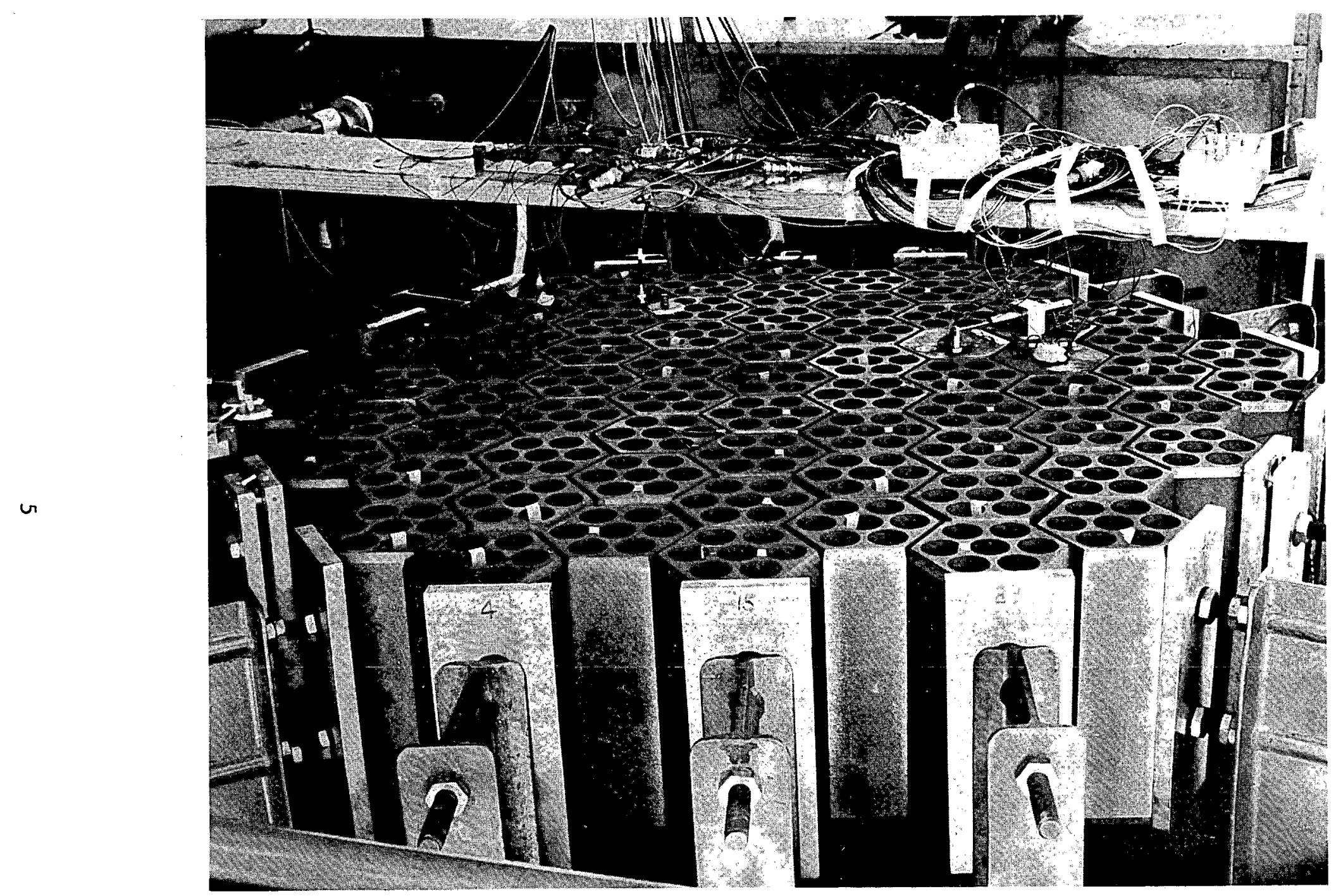

Fig. 3-1. One-half-scale, two-dimensional test rig and core model 
TABLE 3-1

SUMMARY OF 1/2-SCALE, TWO-DIMENSIONAL, TWO-AXIS TEST DRAWINGS

\begin{tabular}{|c|c|c|}
\hline $\begin{array}{l}\text { AETL Drawing } \\
\text { Number }\end{array}$ & $\begin{array}{l}\text { GA Foreign } \\
\text { Print Number }\end{array}$ & Title \\
\hline & 010750B & Fuel element $1 / 2$-size model \\
\hline $5430-5486-04$ & & Boundary support-assembly \\
\hline $5430-5486-G 4$ & & Core floor support \\
\hline $5430-5486-05$ & & Core floor support \\
\hline $5430-5486-06$ & & Core floor support \\
\hline $5430-5486-10$ & & Boundary support-detail \\
\hline $5430-5486-11$ & & Boundary support-detail \\
\hline $5430-5486-12$ & & Boundary support-detail \\
\hline $5430-5486-13$ & & Seismic test stand-off \\
\hline $5430-5486-14$ & & Lower insert \\
\hline $5430-5486-15$ & & Upper insert \\
\hline $5430-.5486-16$ & & Boundary support-detail \\
\hline $5430-5486-21$ & & Instrument graphite \\
\hline $5430-5486-22$ & & Boundary support-detail \\
\hline $5430-5486-18$ & & Boundary LVDT \\
\hline $5430-5486-19$ & & Eddy current gage \\
\hline $5430-5486-G 1$ & & In-core load measuring device \\
\hline $5430-5486-G 2$ & & Boundary LVDT installation \\
\hline $5430-5486-G 3$ & & Velocity coll insta1lation \\
\hline
\end{tabular}




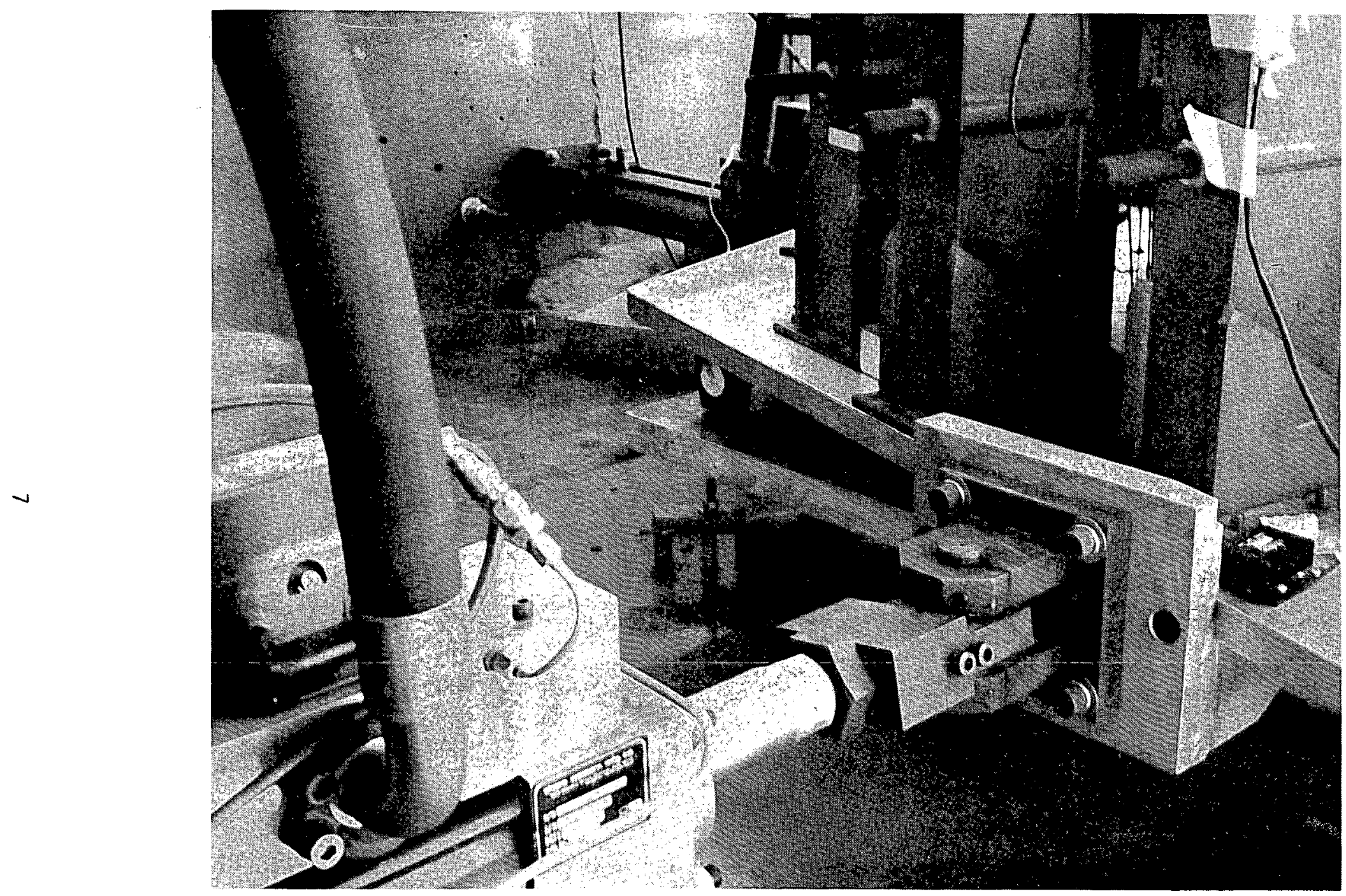

Fig. 3-2. One-half-scale shakers and shaker tables 


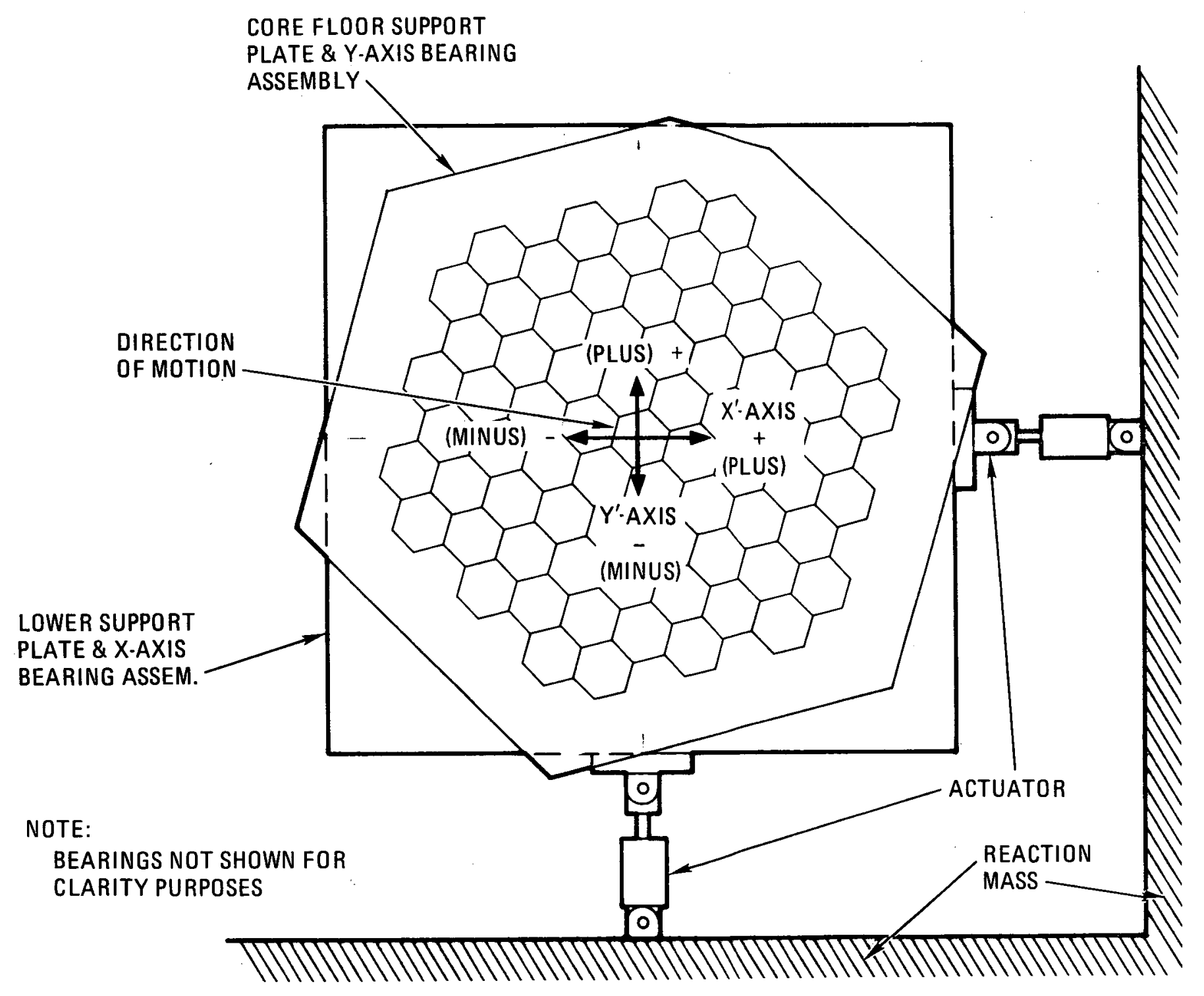

Fig. 3-3. Layout of shakers and shaker tables 
two orthogonal sets of bearings. One set of bearings connected the core support floor to an intermediate plate, termed the bottom axis plate, and allowed motion in what is defined as the $X^{\prime}$ direction. The second set of bearings attached the bottom axis plate to the foundation plate and permitted motion in the $\mathrm{Y}^{\prime}$ direction.

Each set of bearings consisted of 16 Thomson ball bushings that ride on four 2-in. diameter shafts mounted in parallel fashion. These shafts tended to increase the stiffness of the plates on which they were mounted and thereby minimized rig vibrations.

The core support floor contained adjustable core support brackets for horizontal core support. Each element in the core was also supported vertically by three stand-off pins located in spherical sockets in the element and in the support floor. The pins provided unconstrained block motion in any horizontal direction and maintained parallelism between core blocks at al1 times. The stand-offs were designed to tight tolerances such that block-to-block collisions occurred within vertical misalignments of $0.10^{\circ}$, which represents a limit value for flat-to-flat impacts.

\subsection{ACTUATORS}

Two Shore and Western hydraulic actuators were fixed to the core support plate and bottom axis plate, respectively, as shown in F1g. 3-2. Their performance characteristics were as follows:

$\begin{array}{lll} & \underline{X^{\prime} \text { Axis }} & \underline{Y^{\prime} \text { Axis }} \\ \begin{array}{l}\text { Force } \\ \begin{array}{l}\text { Max. double } \\ \text { amplitude }\end{array}\end{array} & 10,000 \mathrm{lb} & 20,000 \mathrm{lb} \\ \begin{array}{l}\text { Max. velocity } \\ \text { Frequency range }\end{array} & 60 \mathrm{in.} / \mathrm{sec} & 9 \mathrm{in} . \\ & \text { dc to } 50 \mathrm{~Hz} & 60 \mathrm{in.} / \mathrm{sec}\end{array}$




\section{INSTRUMENTATION AND CONTROL}

\subsection{RIG CONTROL SYSTEMS}

The hydraulic control system for the shaker units consisted of two parallel systems, one of which is illustrated in Fig. 4-1. The control loop for the electromechanical hydraulic system consisted of a linear motion displacement transducer (LVDT) providing a voltage to the servoamplifier proportional to the actual rig displacement. The servoamplifier compared the displacement feedback voltage to the command signal voltage (input) and produced a corrected signal to the servo valve, which controlled the flow to the actuator. This variation in the pressure/flow produced the prescribed motion in the test rig.

\subsubsection{Sinusoidal Vibration}

Sinusoidal vibrations (sine sweeps and dwe11s) were applied to the $X^{\prime}-$ and $Y^{\prime}$-axes simultaneously. Phase shifts between the two inputs were obtained as 11lustrated in Fig. 4-2. Amplitude and phase control for the two shakers were achieved by two different methods as discussed below.

The first method of phase/amplitude control, which was used for approximately half of the sine sweep tests, is shown in Figs. 4-3 and 4-4. This scheme employed fixed phase control, proceeding under the assumption that the phase set at the beginning of the sweep would be maintained as the frequency of both actuators was varfed identically. It was later found that the phase drifted approximately $15^{\circ}$ to a higher value for a sweep from 1.5 to $15 \mathrm{~Hz}$. The same shift occurred in the opposite direction on a sweep down. 


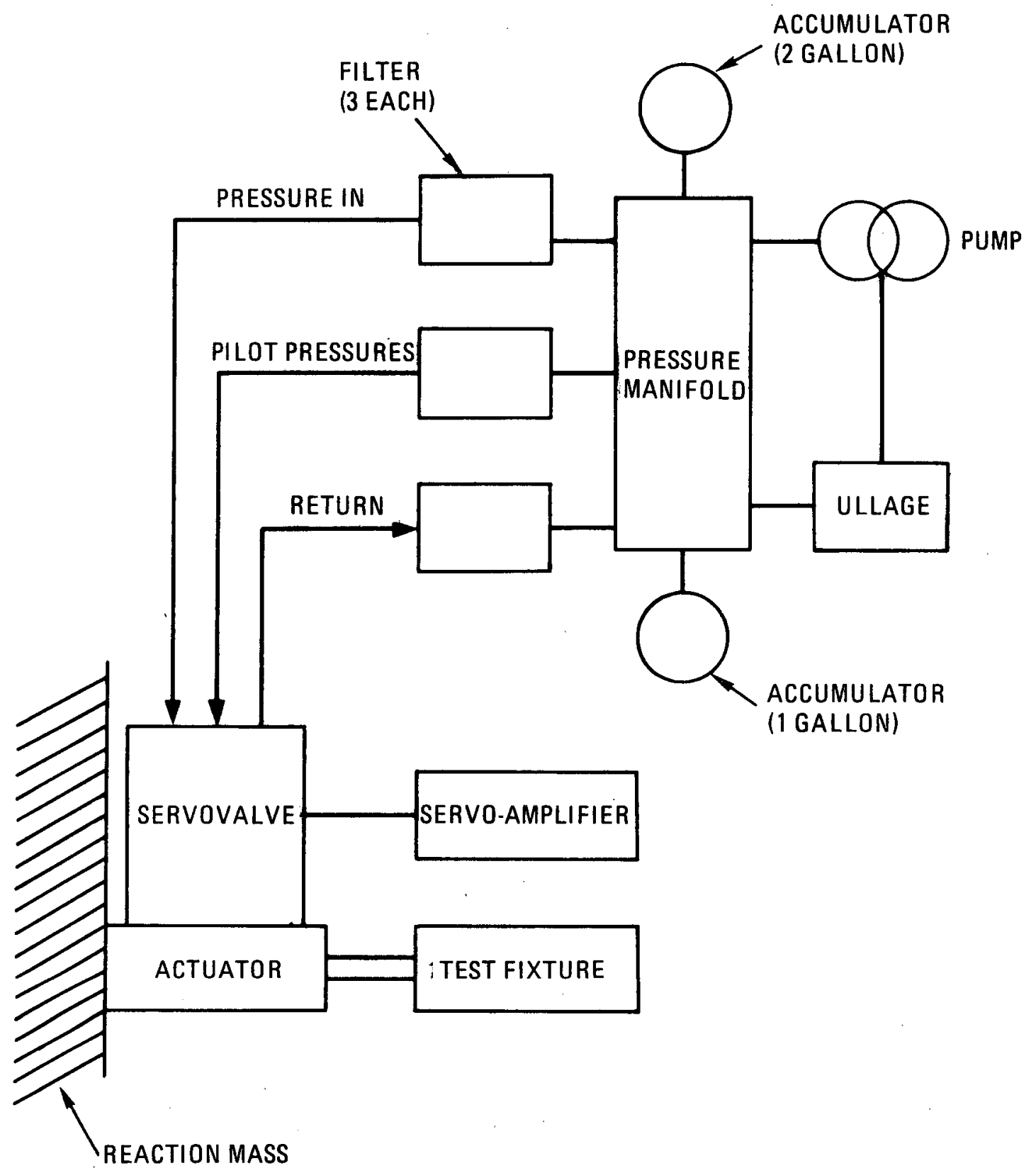

Fig. 4-1. Hydraulic test system (one channe1) 


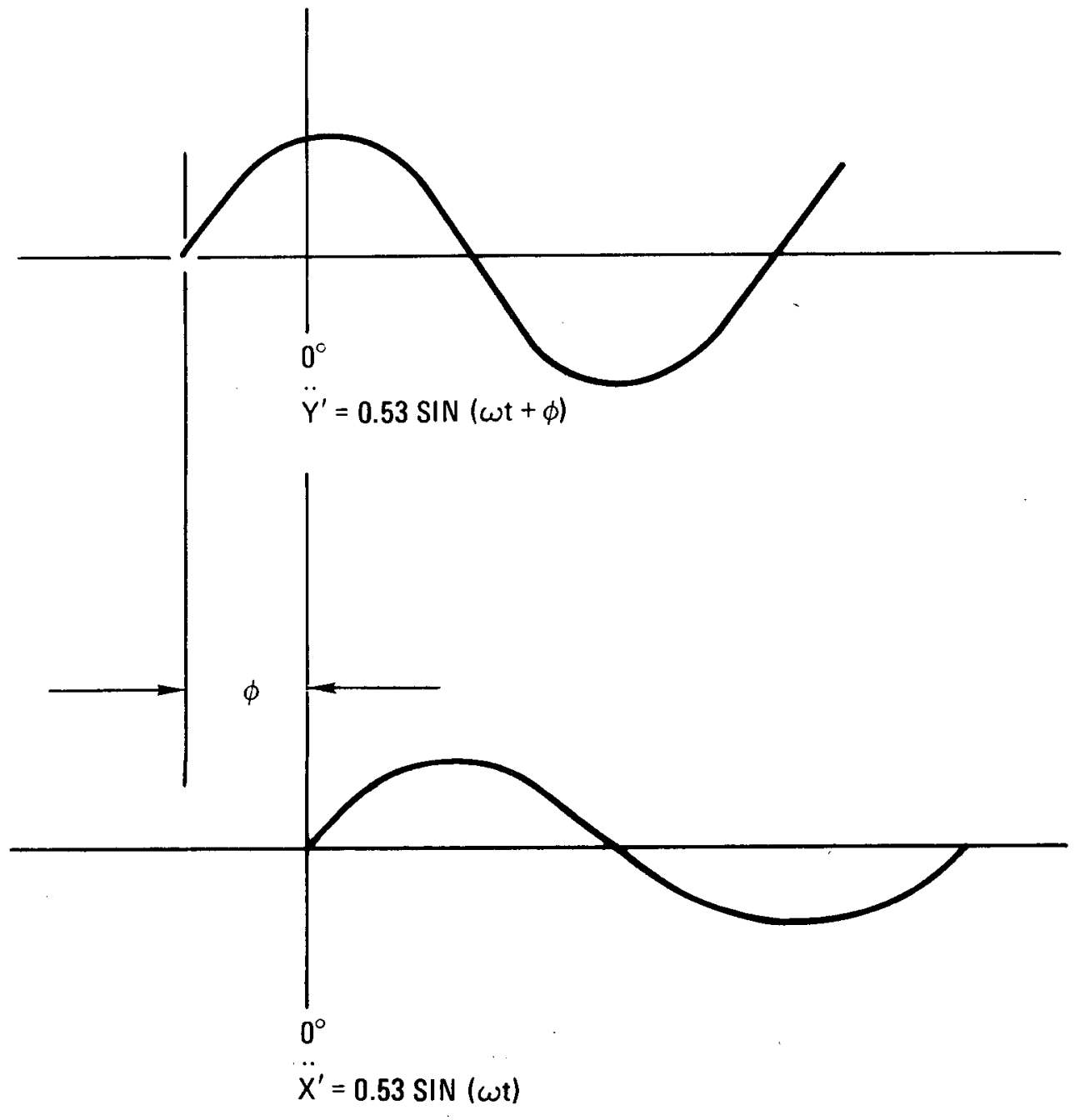

DEFINITION: $\ddot{Y}^{\prime}$ LEADS $\ddot{X}^{\prime}$

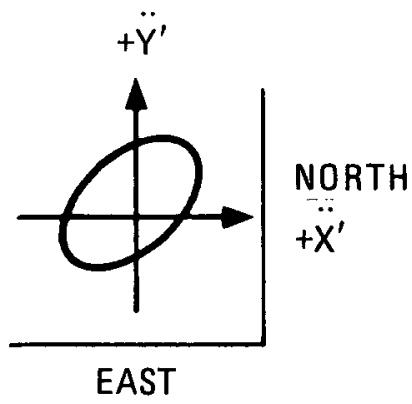

Fig. 4-2. Sinusoidal vibration - phase lag definition 


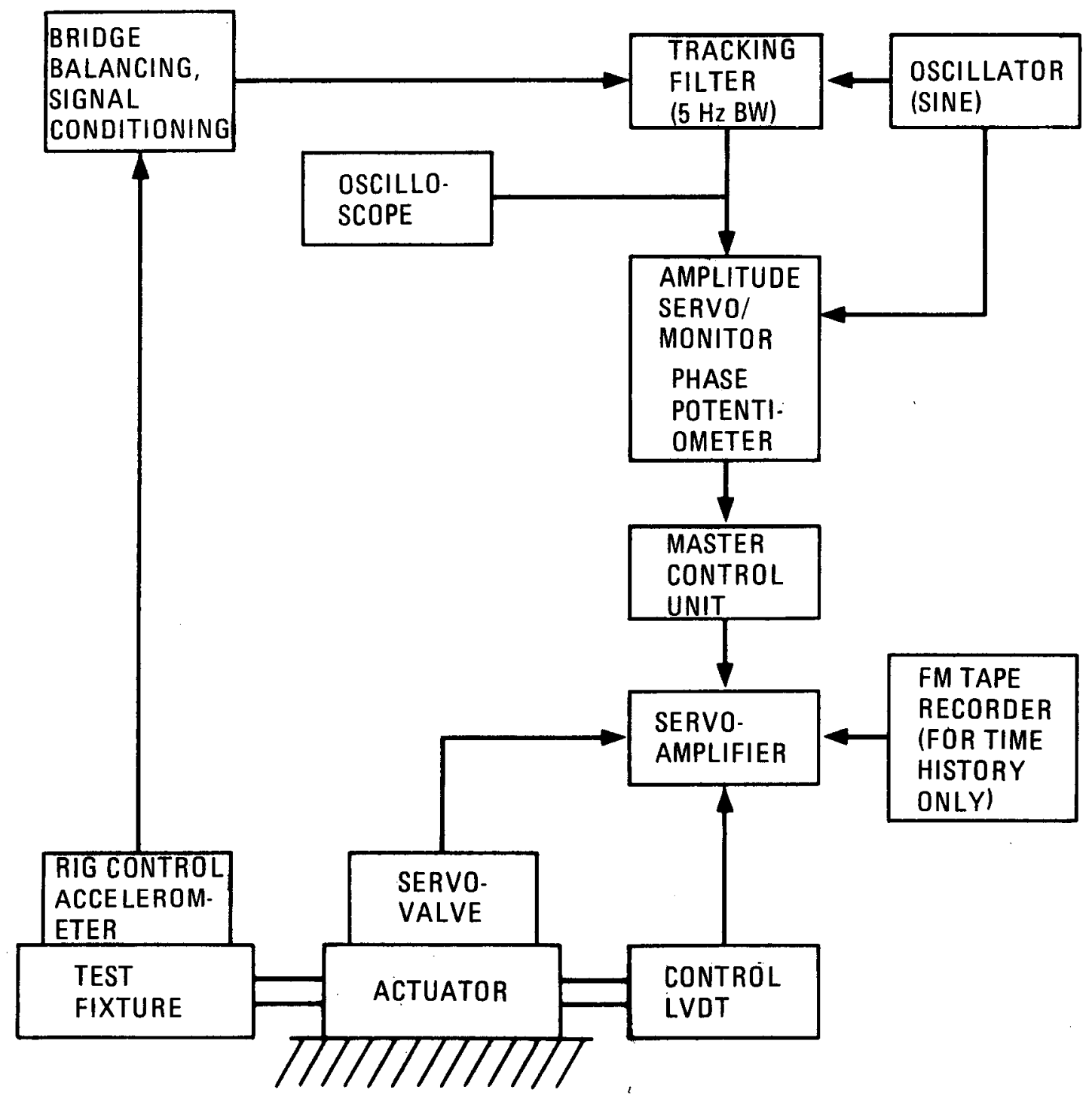

Fig. 4-3. Sinusoidal and time history vibration control system (one channe1), first method 


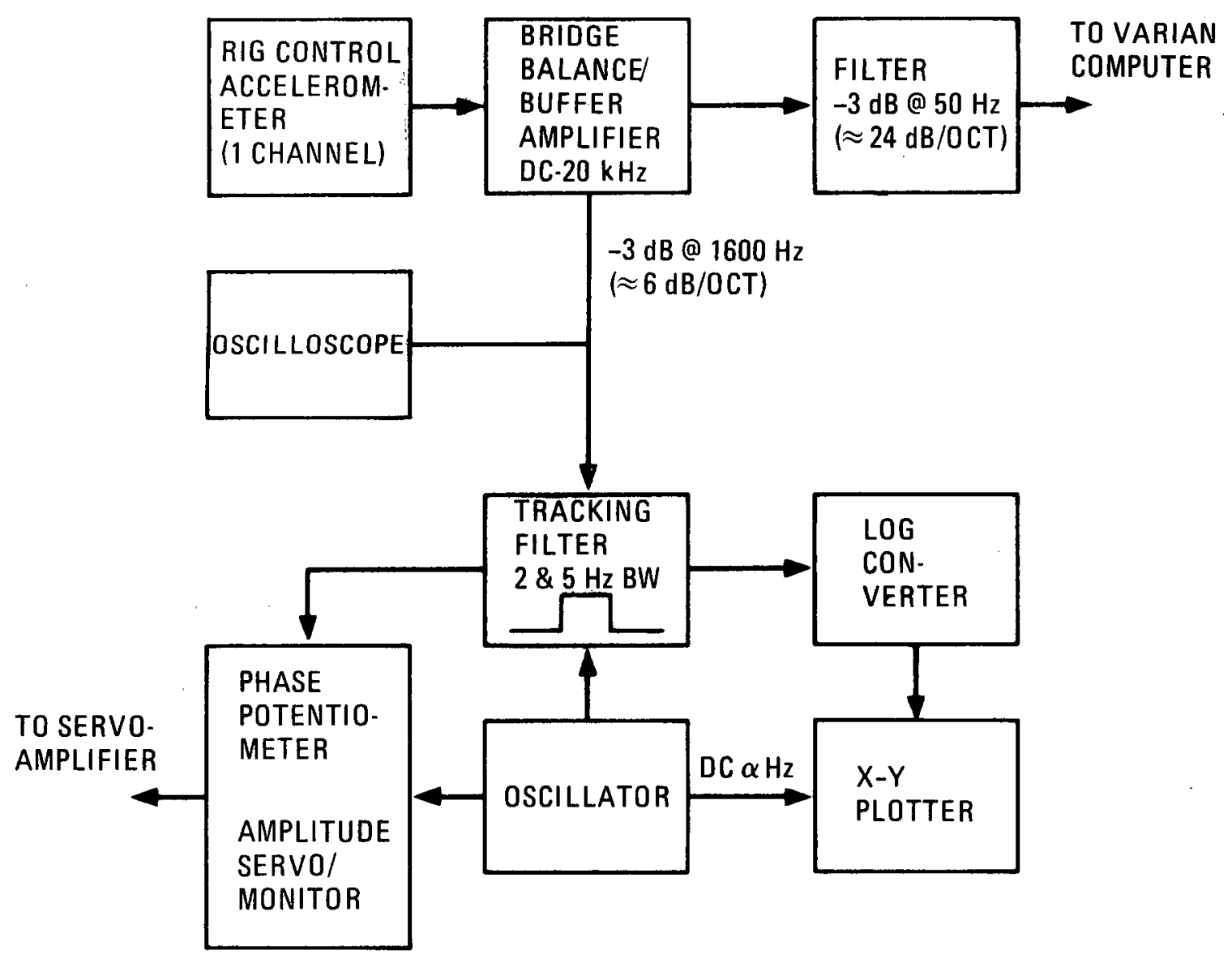

Fig. 4-4. Rig control accelerometer instrumentation, first method 
The second and more successful means of phase control was utilized as illustrated in Figs. 4-5 and 4-6. In this procedure, a phase angle meter monitored the phase between the two filtered control signals from the rig accelerometers. The phase between the inputs was then manually adjusted, achieving an accuracy within approximately $\pm 5^{\circ}$ of the specified value.

Table 4-1 contains both the nominal and the actual phase differences between input excitations. The actual values were obtained by inspecting the displacement-versus-time traces of the rig motion.

The instrumentation for sinusoidal sweep control was calibrated periodically. The strain gage rig control accelerometer was reoriented with its sensitive axis in the vertical direction and was calibrated with the known value of gravitational acceleration. The LVDT was checked by displacing the test $\mathrm{rig}$ precisely $\pm 4 \mathrm{in}$, and noting the instrument readout. The phase control was checked by subjecting the test rig to pure two-axis translational motion at $0^{\circ}$ phase.

If a straight line lissajous figure appeared on the oscilloscope, the phase angle meter reading of $0^{\circ}$ was verified. This demonstrated that there was no phase shift introduced into the system due to the signal conditioning and tracking filters utilized.

\subsubsection{Time History Tests}

The time history random motion was provided by GA on computer card decks. Each time history was applied to the $X^{\prime}$ and $Y^{\prime}$ axes simultaneously. The time delays were adjusted such that the $X^{\prime}$ motion led the $Y^{\prime}$ axis motion as illustrated in Fig. 4-7. The time history traces and the time delays employed are discussed in detail in Section 5. 


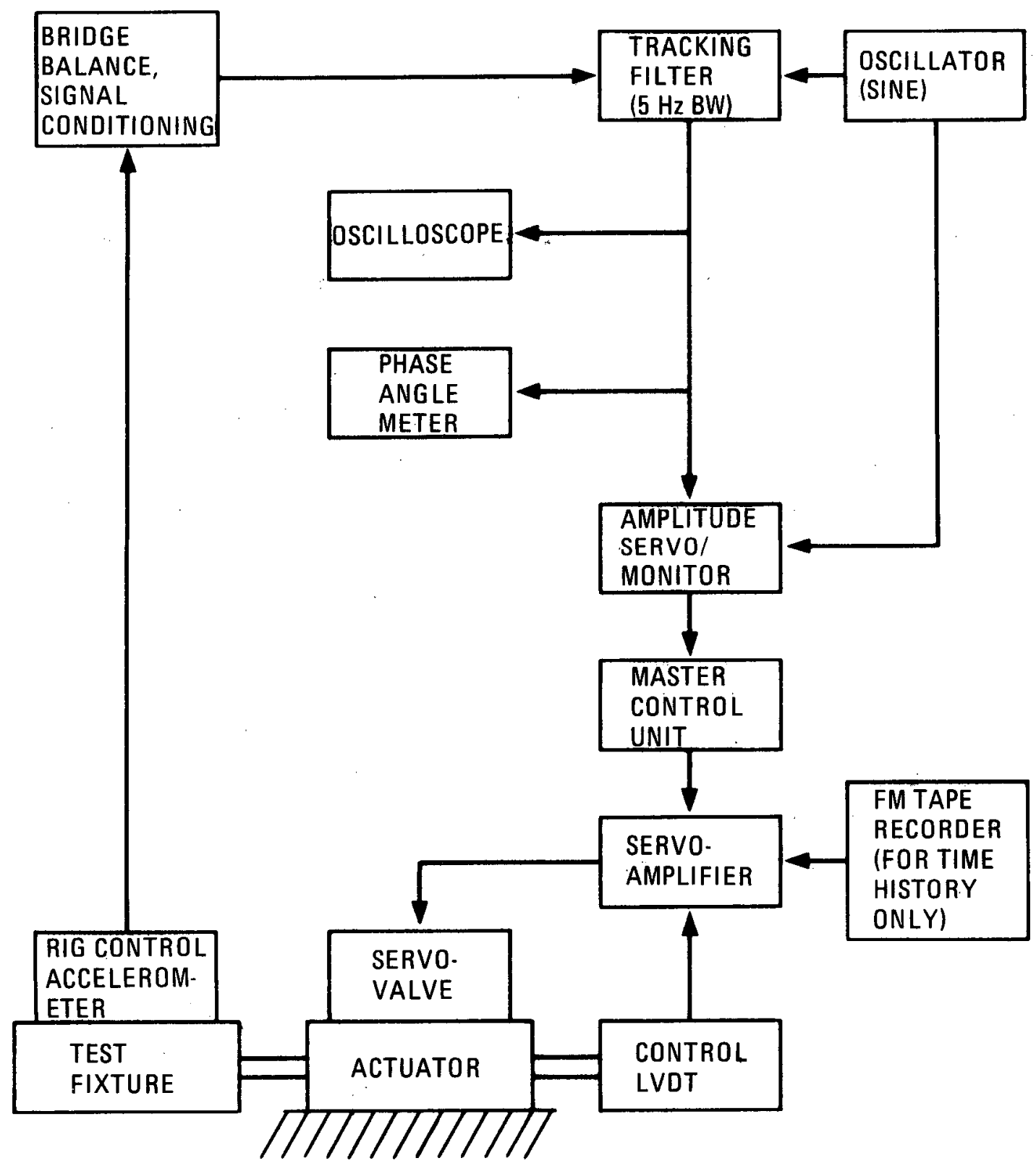

Fig. 4-5. Sinusoidal and tịme history vibration control system (one channe1), second method 


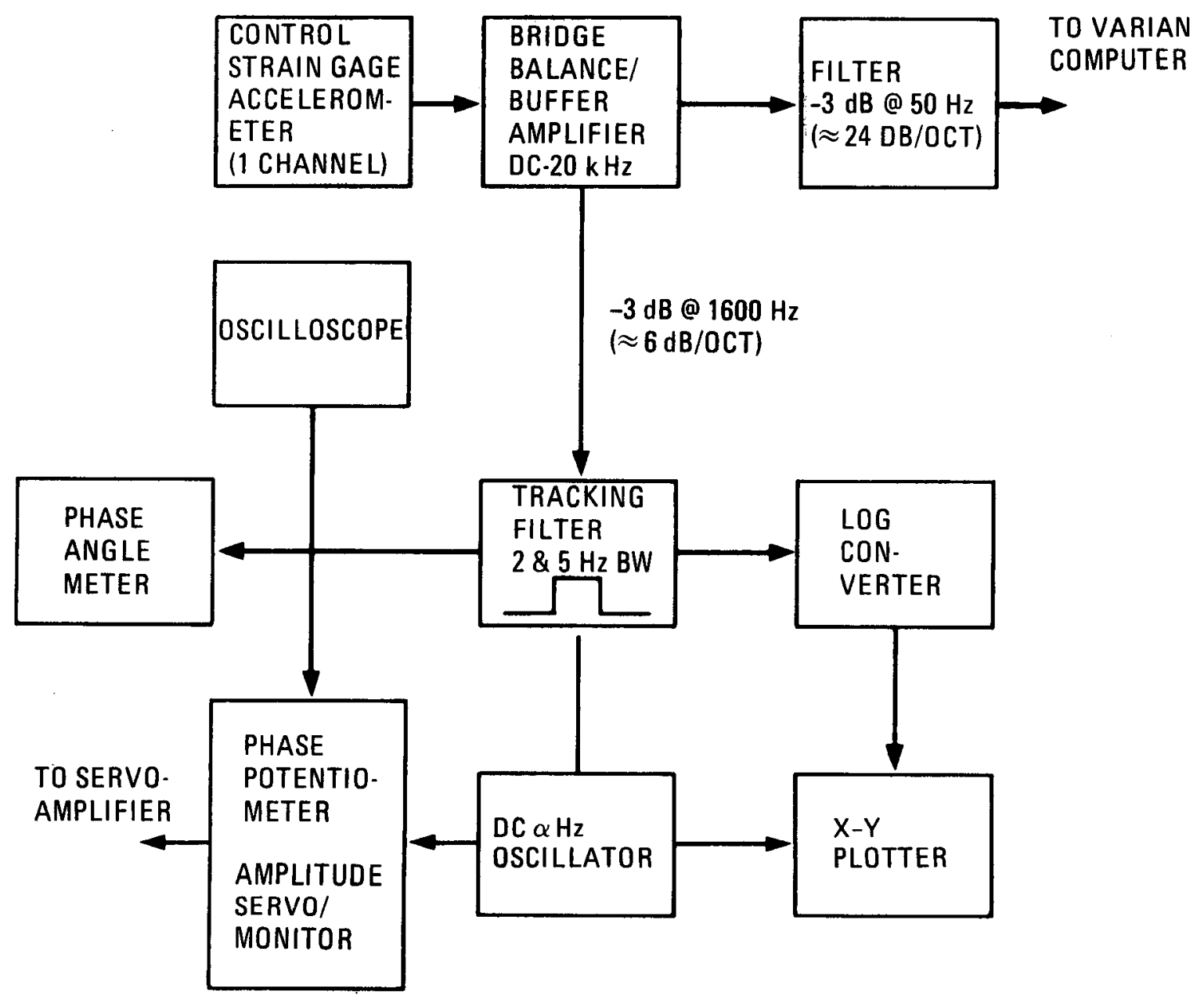

Fig. 4-6. Rig control accelerometer instrumentation, second method 
TABLE 4-1

COMPARISON BETWEEN SPECIFIED AND ACTUAL

PHASE ANGLE INPUT

\begin{tabular}{c|c|c}
\hline Test Number & Specified $\phi$ & Actual $\phi($ at $\sim 5 \mathrm{~Hz})$ \\
\hline 1 & $41^{\circ}$ & $55^{\circ}$ \\
4 & 60 & $65^{\circ}$ \\
6 & $75^{\circ}$ & $85^{\circ}$ \\
10 & $90^{\circ}$ & $100^{\circ}$ \\
14 & $41^{\circ}$ & $65^{\circ}$ \\
19 & $60^{\circ}$ & $79^{\circ}$ \\
22 & $90^{\circ}$ & $80^{\circ}$ \\
25 & $41^{\circ}$ & $60^{\circ}$ \\
27 & $60^{\circ}$ & $90^{\circ}$ \\
29 & $75^{\circ}$ & $90^{\circ}$ \\
32 & $90^{\circ}$ & $100^{\circ}$ \\
35 & $41^{\circ}$ & $41^{\circ}$ \\
37 & $60^{\circ}$ & $60^{\circ}$ \\
39 & $75^{\circ}$ & $80^{\circ}$ \\
42 & $90^{\circ}$ & $90^{\circ}$ \\
101 & $0^{\circ}$ & $0^{\circ}$ \\
102 & $0^{\circ}$ & $0^{\circ}$ \\
\hline
\end{tabular}




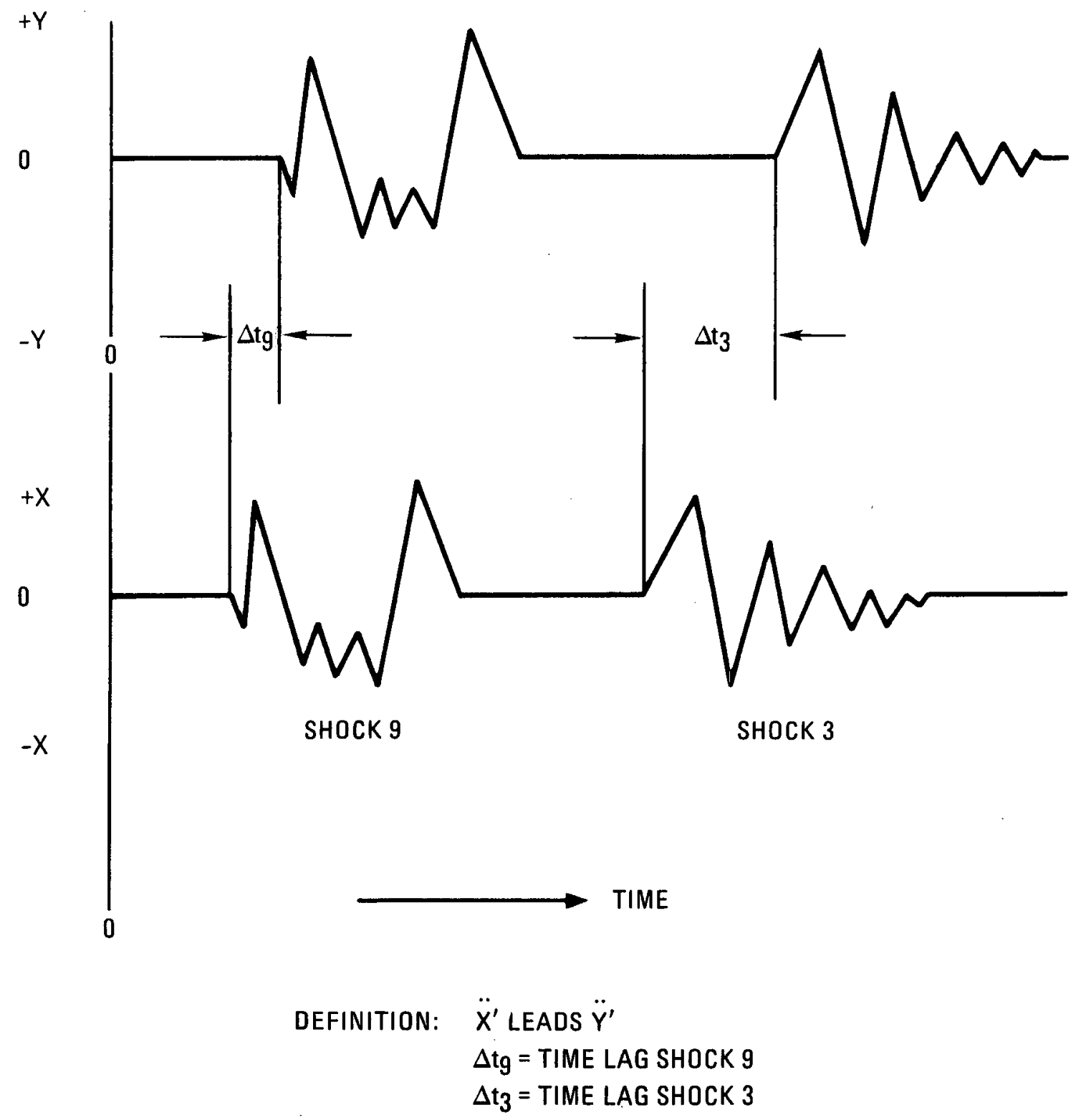

Fig. 4-7. Time history vibration - phase lag definition 
Each of the time history shocks was electrically transmitted to the test system on a prerecorded analog tape. The signal was fed into the servoamplifier, as illustrated in Figs. 4-2 and 4-4. Two channels of the tape recorder incorporated shock No, 9 and shock No. 3, time-displaced in accordance with the specification requirements. In addition to the time histories, there was also a recorded dc signal proportional to displacement in the range \pm 2 . in. This dc signal was introduced for each of the $X^{\prime}$ and $Y^{\prime}$ axes to ensure the gain of the system was correct prior to application of the specified time histories.

\subsection{INSTRUMENTATION}

\subsubsection{Boundary Support Instrumentation}

Boundary instrumentation consisted of LVDTs for measuring relative displacement between the boundary support and the core elements and crystal load washers for measuring collision forces between the core and the boundary supports. Details of the boundary instrumentation are shown in Figs. 4-8 and 4-9. These instruments, which are identical to those used in the $1 / 2$-scale single-axis test, are discussed in Ref. 2.

The locations of the boundary instrumentation are shown in Fig. 5-3. The LVDTs were mounted, parallel to each of the shaker axes, on core block No. 3.

\subsubsection{In-Core Instrumentation}

The in-core instrumentation consisted of an accelerometer, eddy current displacement probes, a Collins velocity transducer, and two IIMDs all incorporated into three adjacent fuel blocks (Fig. 4-10). These three instrumented blocks were located in one of seven specified core positions, shown in Fig. 5-3. Examples of the layout of the instrumented blocks are illustrated in Figs. 4-10 and 4-11. 


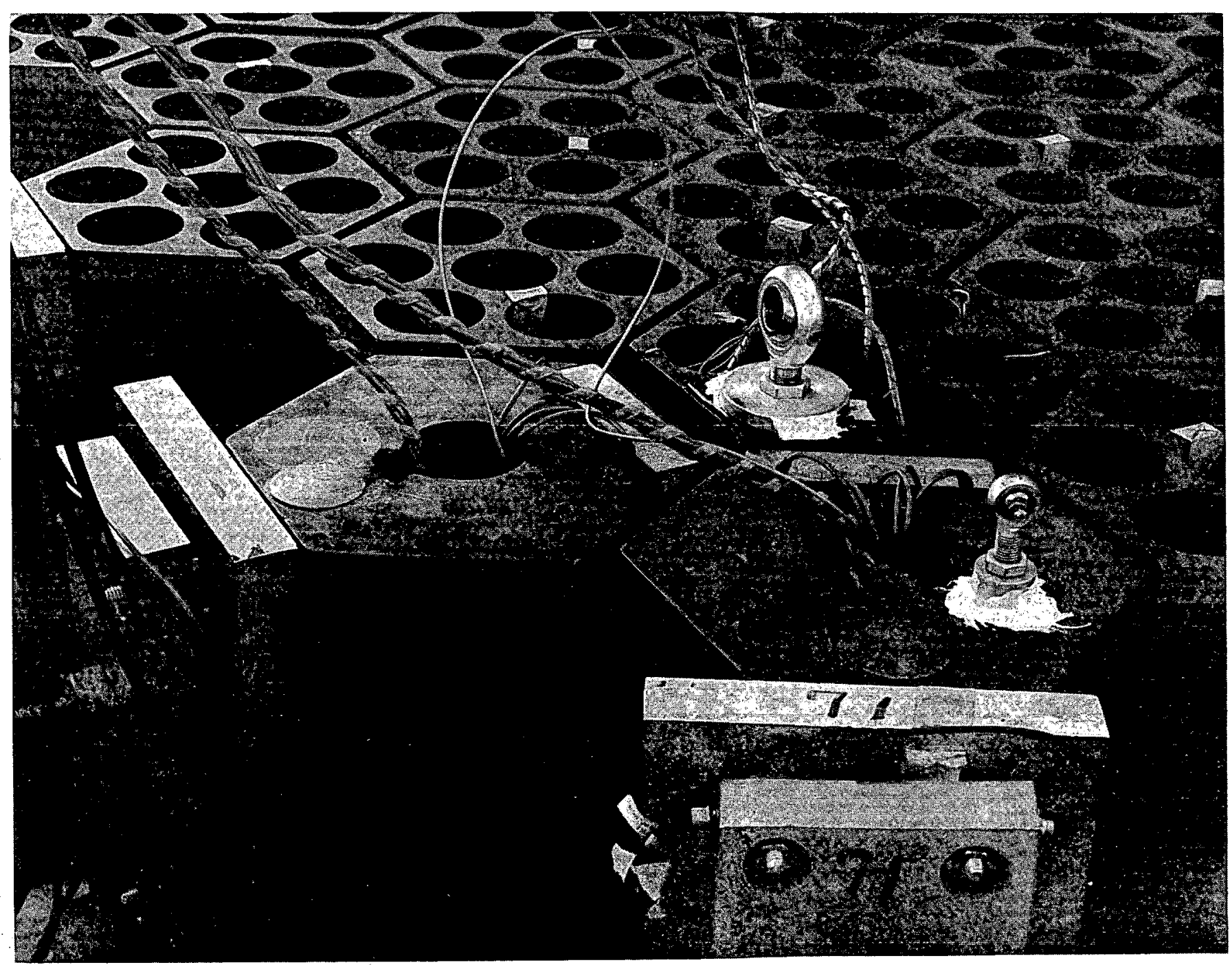

Fig. 4-9. Boundary support load instruments and in-core load measuring devices 


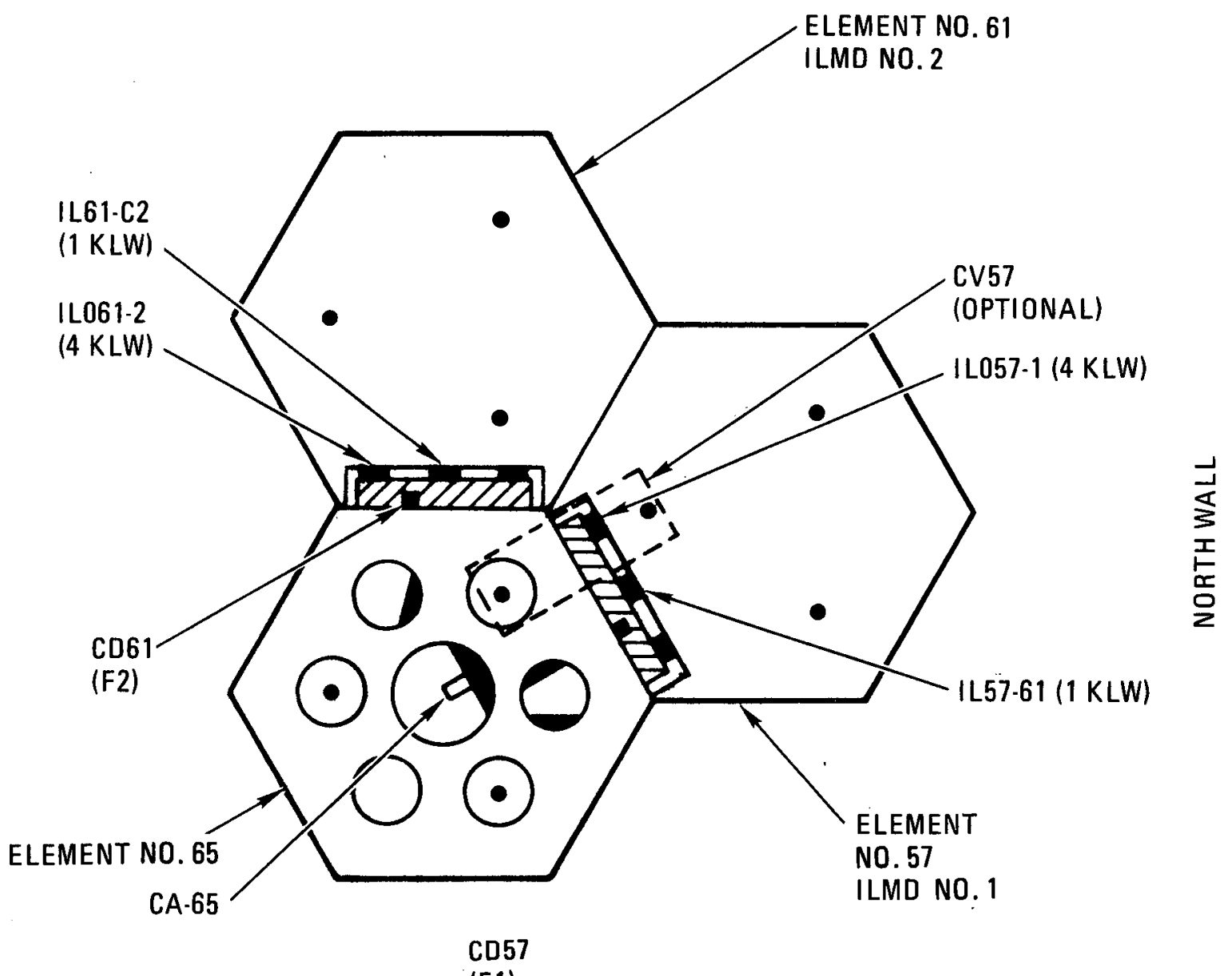

(F1)

Fig. 4-10. In-core instrument position 1 


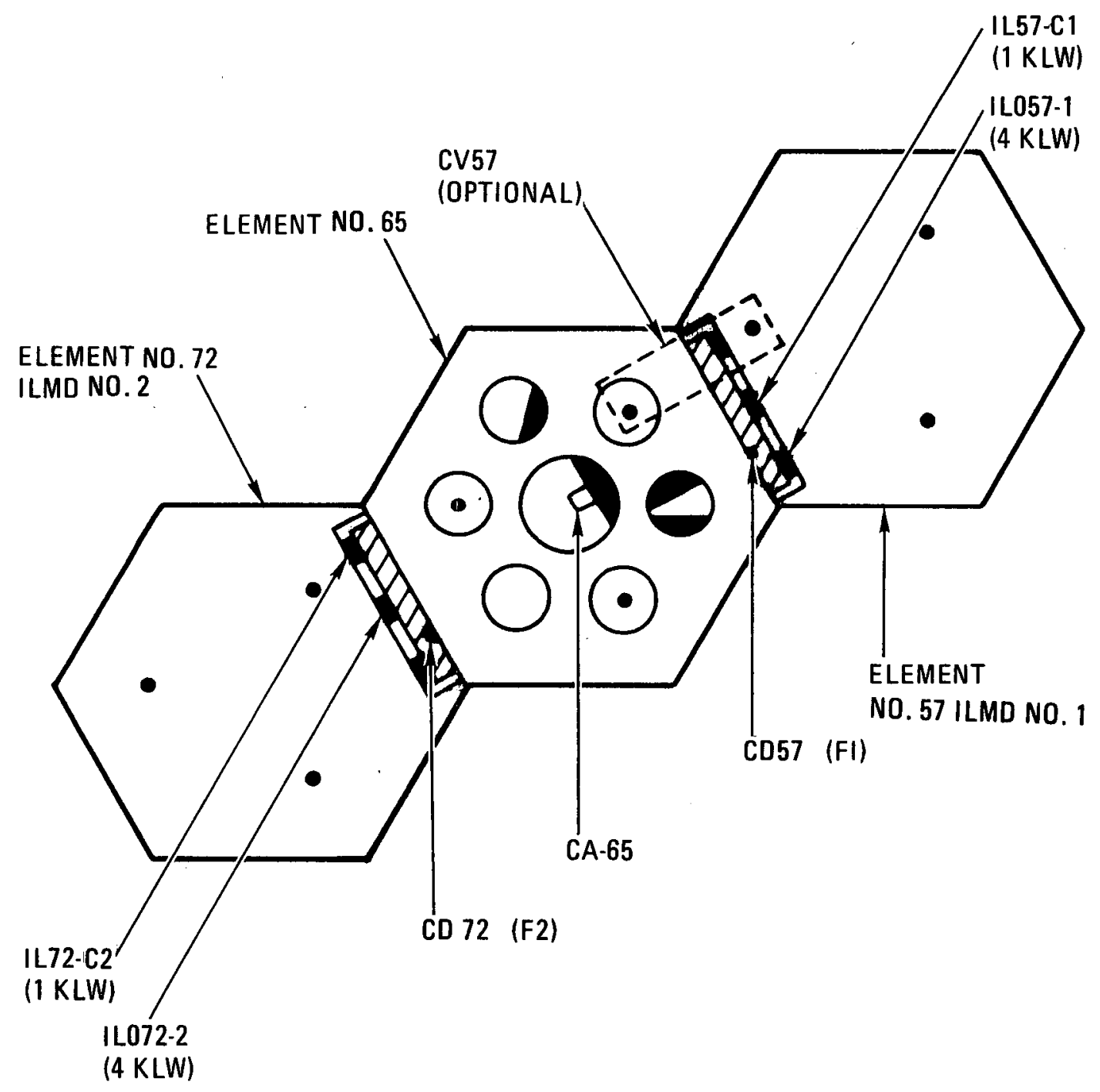

Fig. 4-11. In-core instrument position 1a 
The accelerometer was included for convenience in case acceleration response was needed in the data analysis process.

The Collins velocity transducer was introduced to see whether interblock velocities could be measured directly. As it turned out, the instrument's resolution was not good enough for the high collision frequencies involved, causing only a velocity average to be obtained.

The displacement measurements with eddy current probes between the center block and the adjacent blocks were instead used to generate interblock velocities. As for the single-axis test, velocities were obtained from data reduction software techniques.

The ILMD consisted of five crystal load washers mounted on a face of an in-core element (Fig. 4-12). A trough equal to the width of a face and the entire block length was cut to a depth of approximately $1 \mathrm{in.}$ This cutout accommodated a magnesium plate covered with a graphite sheet. This plate was bolted to the block body with the five load washers sandwiched in between. The load cells were situated at the four corners of the face and at the center, making it possible to measure the distribution of load on the face.

The signals from the five load washers were electronically summed to represent the total impact load. The outputs from the center load washer and the sum of the four corner load washers were also separately monitored in an attempt to gain information about the flatness of the impacts.

Extensive calibration tests were performed on the ILMDs; they are discussed at length in Section 4.2.4.

\subsection{DATA ACQUISITION SYSTEM}

The data acquisition system consisted of a high speed, real-time Varian 620 computer, which is capable of digitizing and recording up to 80 

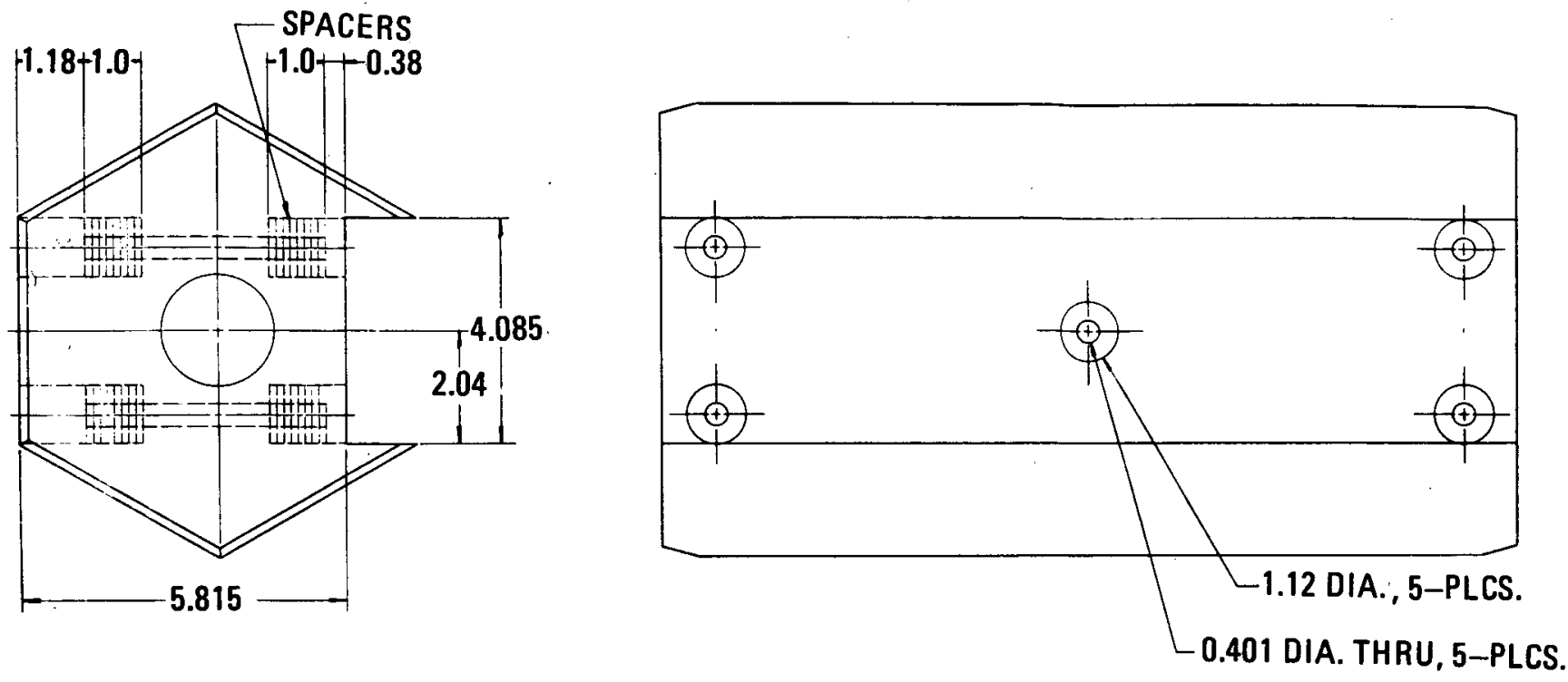

N

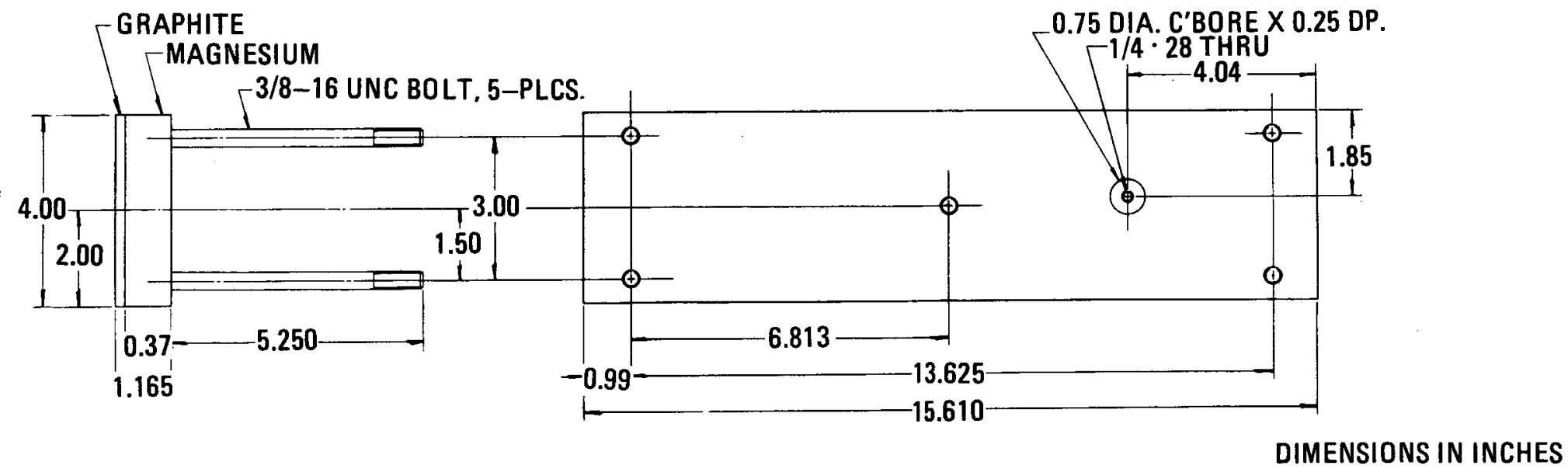

Fig. 4-12. In-core load measuring device (ILMD) 
channels of analog data. Both this system and the analog signal conditioning equipment associated with each boundary support and in-core transducer are discussed in the single-axis test report (Ref. 2).

Schematics for the new ILMDs are shown in Fig. 4-13. The outputs from the center and corner load washers were separately fed into charge amplifiers and summers, the final output producing (1) block center load, (2) the sum of four corner loads, and (3) the sum of all five load cells (total block load).

An oscillograph was used to record nine channels of information for the full test duration:

$\begin{array}{ll}\text { Fixture LVDT } & \text { FDX-1 } \\ \text { Fixture LVDT } & \text { FDY-1 } \\ \text { Boundary load cel1 } & \text { LC-67 } \\ \text { Boundary load cel1 } & \text { LC-72 } \\ \text { In-core force } & \text { IL-1 } \\ \text { load cel1 } & \\ \text { In-core force } & \text { IL-2 } \\ \text { load cel1 } & \\ \text { In-core force } & \text { IL-C1 } \\ \text { load cell } & \\ \text { In-core force } & \text { IL-C2 } \\ \text { load cel1 } & \end{array}$

These records were examined at the completion of each test in order to. check that the channels were operational and to verify the phase lag for sinusoidal and time history tests.

During the performance of the sinusoidal and time history vibration testing, the following data channels were permanently recorded on analog magnetic tape: 


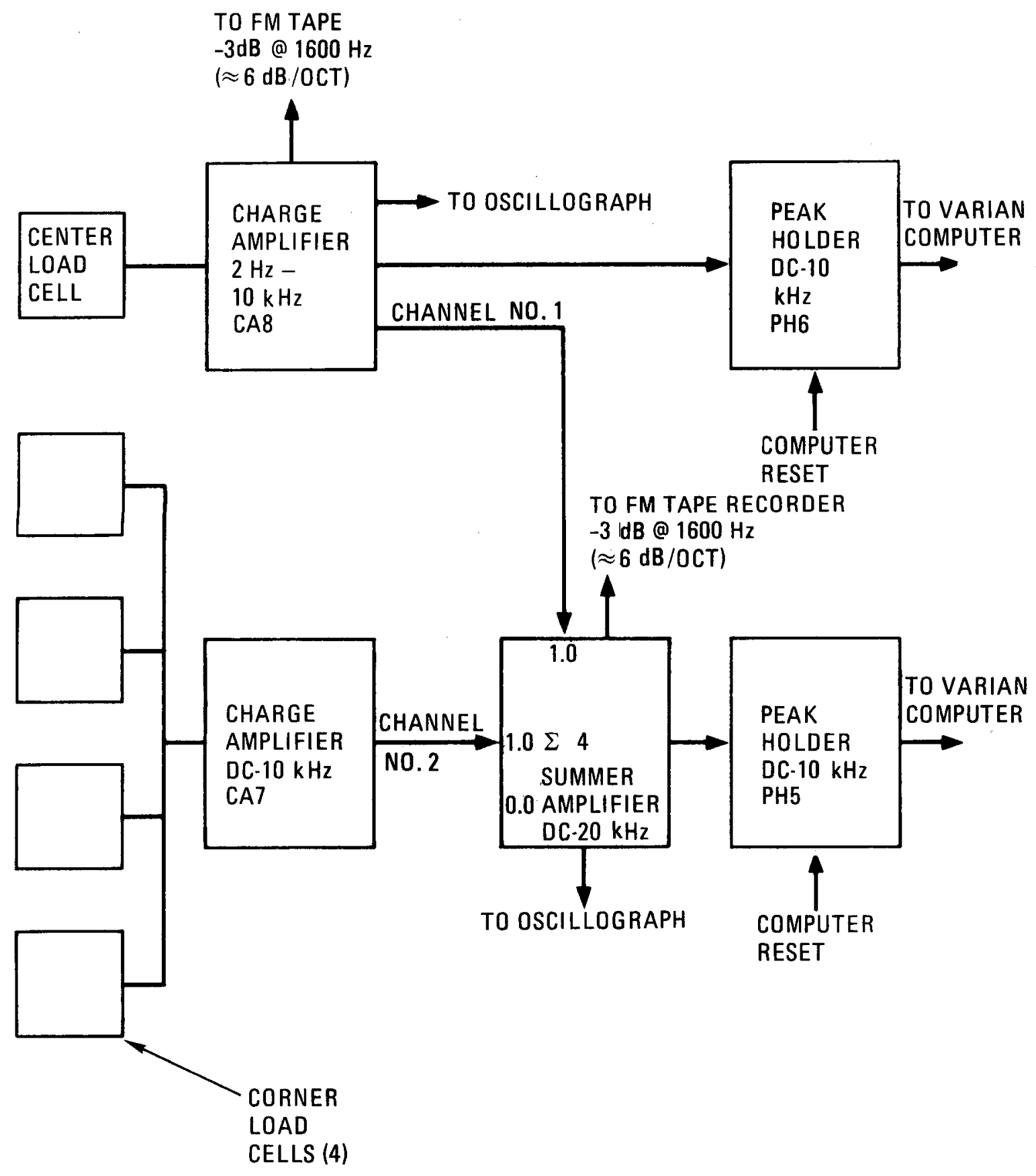

Fig. 4-13. ILMD load cell instrumentation 


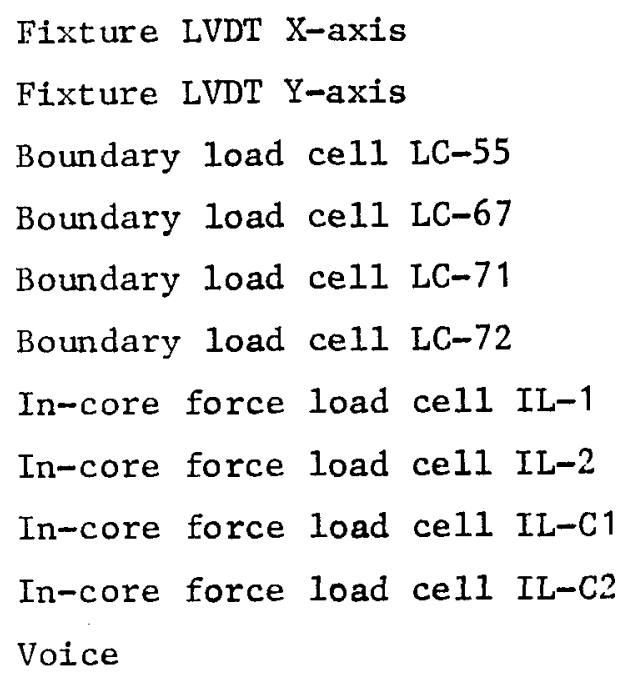

The procedures for data acquisition verification, also discussed in the single-axis test report, are outlined in detail in the AETL test procedure (Ref. 3.).

Periodically during the test program, the calibration voltages applied to the FM tape channels were measured and recorded. The FM magnetic tape is on file at AETL. The data obtained during the test performance are described in the FM magnetic tape log contained in Ref. 4.

4.4. INSTRUNENT AND SYSTEM CALIBRATIONS AND VERIFICATION

\subsubsection{Test Equipment}

Measuring and test equipment utilized in this test were calibrated by AETL at a commercial facility utilizing reference standards (whose calibration has been certified by being traceable to the National Bureau of Standards). A list of the test equipment used and calibration information concerning it are given in Ref. 4. 


\subsubsection{ILM Calibration}

Each ILMD was submitted to an extensive calibration procedure consisting of the following items. These are described in detail in Ref. 5.

Weight and Spin Balance. Each ILMD, as well as a standard half-scale graphite fuel element, was subjected to welght and spin balance tests about its vertical axis. The measurements were utilized for altering the test specimen so it would have the correct weight of $32.41 \mathrm{~b}$ within $\pm 2 \%$ and a minimum of unbalance in the test array. The actual data obtained, presented in Ref. 5, shows that the amount of ILMD unbalance was significantly less than the standard element at the completion of the ILMD modification.

Mass Moment of Inertia. The horizontal and vertical mass moments of inertia were measured for both ILMDs and several standard 1/2-scale core elements using a torsion pendulum (Fig. 4-14). A steel cylinder whose physical properties were easily measured was used for the calculation of the known moment of inertia. The time for 10 revolutions of the torsion pendulum to take place was measured 10 times for each test specimen.

Moment of Inertia (1b-in. ${ }^{2}$ )

\section{Horizontal Vertical}

$\begin{array}{lll}\text { Regular element } & 0.4300 & 0.2178 \\ \text { ILMD No. } 1 & 0.5780 & 0.2016 \\ \text { ILMD No. } 2 & 0.6167 & 0.1855\end{array}$

ILID Static Calibration and Stiffness. Each ILMD and two standard elements were tested in an Instron machine and were subjected to compression forces gradually increased from 0 to $5000 \mathrm{lb}$. At the force increments, the output voltage of the load assembly was measured on an oscilloscope while simultaneously measuring the deflection of the element. The 


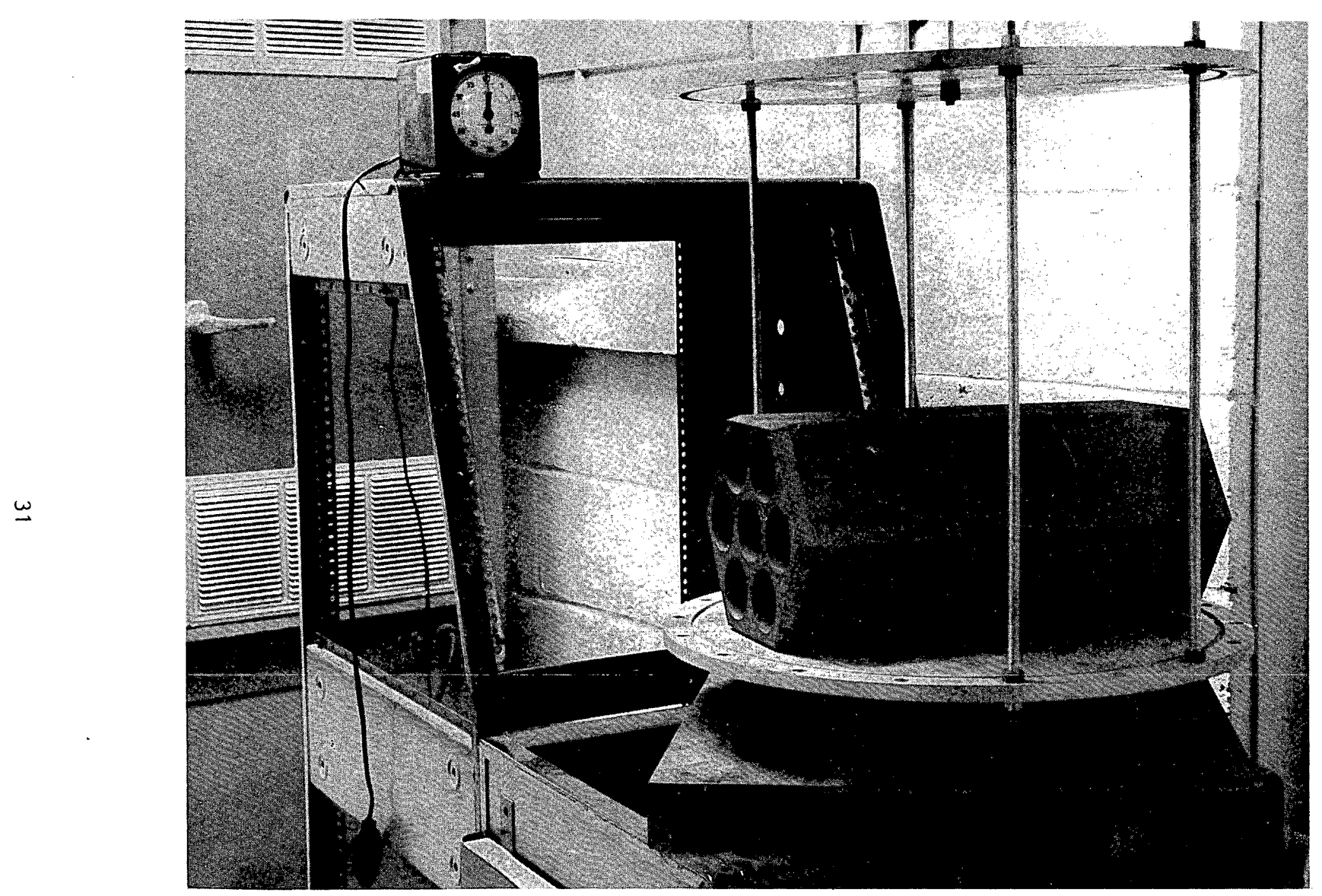

Fig. 4-14. ILMD mass moment of inertia test setup 
actual data obtained are presented in Ref. 5. The output of the ILMD load assembly was within $5 \%$ of the input load, which is inside the expected measurement accuracy of the load assembly and charge amplifier units. The stiffness of all elements was approximately $300,000 \mathrm{lb} / \mathrm{in}$. as determined by the tangent to the force deflection curve at approximately $3500 \mathrm{lb}$ force input.

ILMD Dynamic Calibration. Each ILMD was installed in a system as shown in Fig. 4-15. A 34.25 lb shock carriage was allowed to free fall and impact the measuring face of the ILMD. Several impact media were used during the performance of this dynamic calibration. During each calibration pulse, the input force measured by an accelerometer attached to the shock carriage was compared to the force output measured from the ILMD load cell configuration. A data sample, given in Table 8-2, shows that the output data is within $2.9 \%$ of the carriage drop load represented as one standard deviation.

ILMD Sinusoidal Dwell Calibration. A further check was made on these load assemblies by installing the two ILMDs face to face in the core test array and subjecting the core to constant frequency sinusoidal vibration. During the test, the outputs from both ILMDs were recorded simultaneously on an osc1llograph. The records demonstrated that the forces were within $\pm 5.0 \%$ of each other.

\subsubsection{End-to-End Calibrations}

A system calibration and channel allocation test was performed prior to test program initiation. This calibration was performed in order to verify that all cables and signal conditioning were routed correctly to the proper input channel of the digital computer as well as the FM magnetic tape recorder and oscillograph. In addition, the calibration verified that certain amplification was available at all of the recording devices based upon estimated maximum input values of test data. 


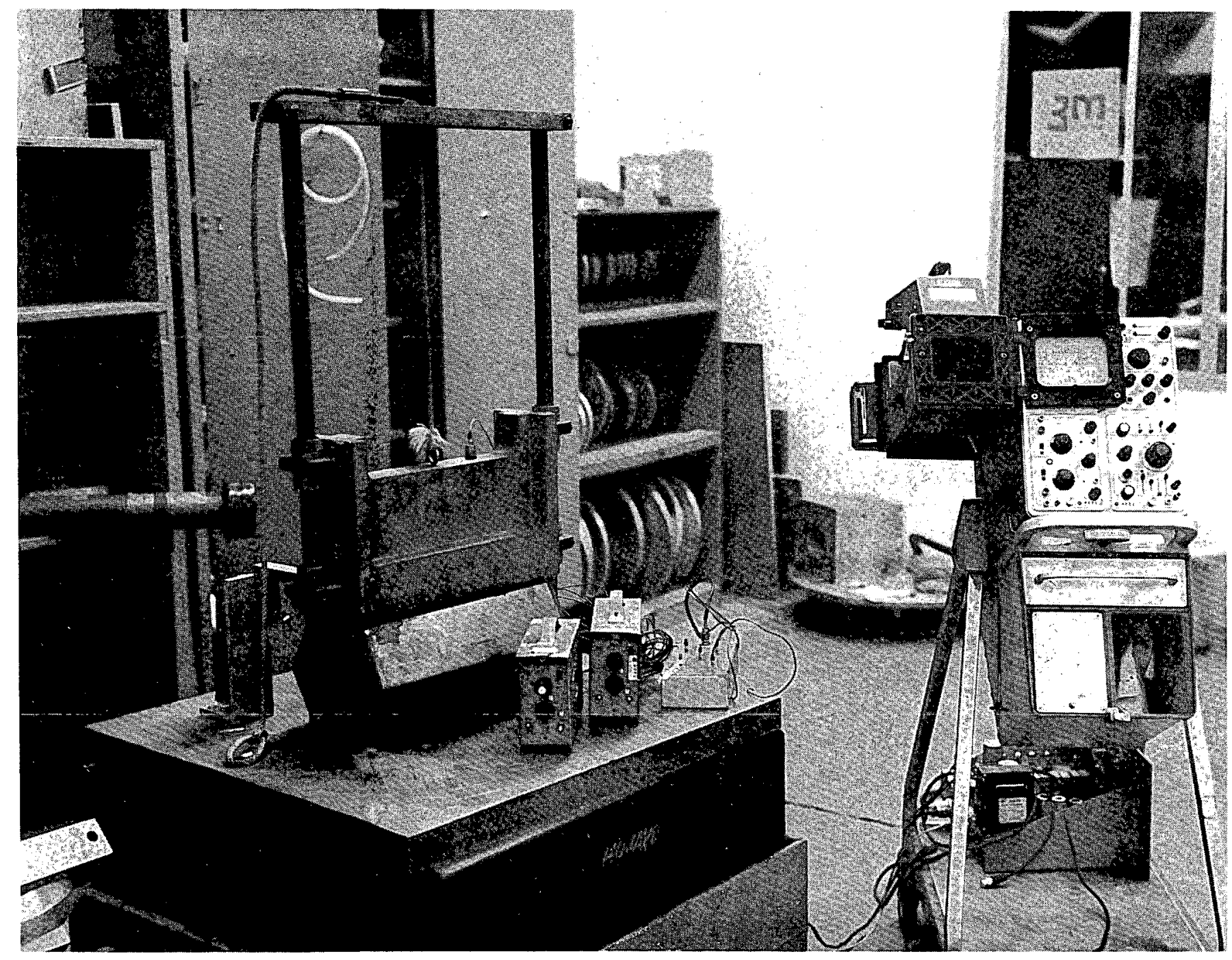

Fig. 4-15. ILMD dynamic calibration test setup 


\subsubsection{Insert Calibrations}

The insert calibration consisted of applying a known voltage to each signal conditioning module. The calibration was performed prior to any testing and in between a sequence of tests in the event there was more than three tests performed. It was provided at the beginning and end of each digital tape.

The data obtained were recorded and a computer sensitivity provided for each data channel. In addition, those channels that were recorded on an oscillograph and FM magnetic tape were also calibrated.

The insert calibration procedure was modifled for the following data channels:

$$
\begin{aligned}
& \text { In-core load cell IL-2 } \\
& \text { In-core load cell IL-C2 }
\end{aligned}
$$

These data channels incorporated Kistler charge amplifiers, which contained a different value calibration capacitor in the input circuit. The ac calibration voltage amplitude was too low a value to provide a stable output voltage to the computer and analog recorders. The actual sensitivity of the transducers was adjusted for each charge amplifier and the calculated computer sensitivity submitted as part of the digital tape data package.

\subsubsection{Other Calibrations}

Other calibrations were performed on the control system concerning the phase angle of input motion, LVDT calibration, and fixture accelerometer calibration. These are discussed in Section 4.1 . 
A series of tests was conducted to obtain values of coefficient of restitution for the ILMDs and to compare them with those obtained for the core elements containing no instrumentation. An average value of 0.4 was previously obtained for the 1/2-scale core elements for a range of impact velocities up to $60 \mathrm{in.} / \mathrm{sec}$.

The test apparatus employed is shown in Fig. 4-16, where two elements are impacted by sliding on "frictionless" bearings along two rails. One element represents the ILMD and the other a standard core element. The elements are given initial opposite velocities prior to impact. The initial velocities and the velocities after impact were recorded in order to calculate the coefficient of restitution. The tests are described in further detail in Ref. 5.

The coefficient of restitution as a function of impact velocity for ILMS No. 1 and No. 2 is shown in Fig. 4-17. Their average values are shown to be 0.48 and 0.37 , respectively. It is seen that these values compare quite well with the coefficient of restitution for the standard 1/2-scale element. 


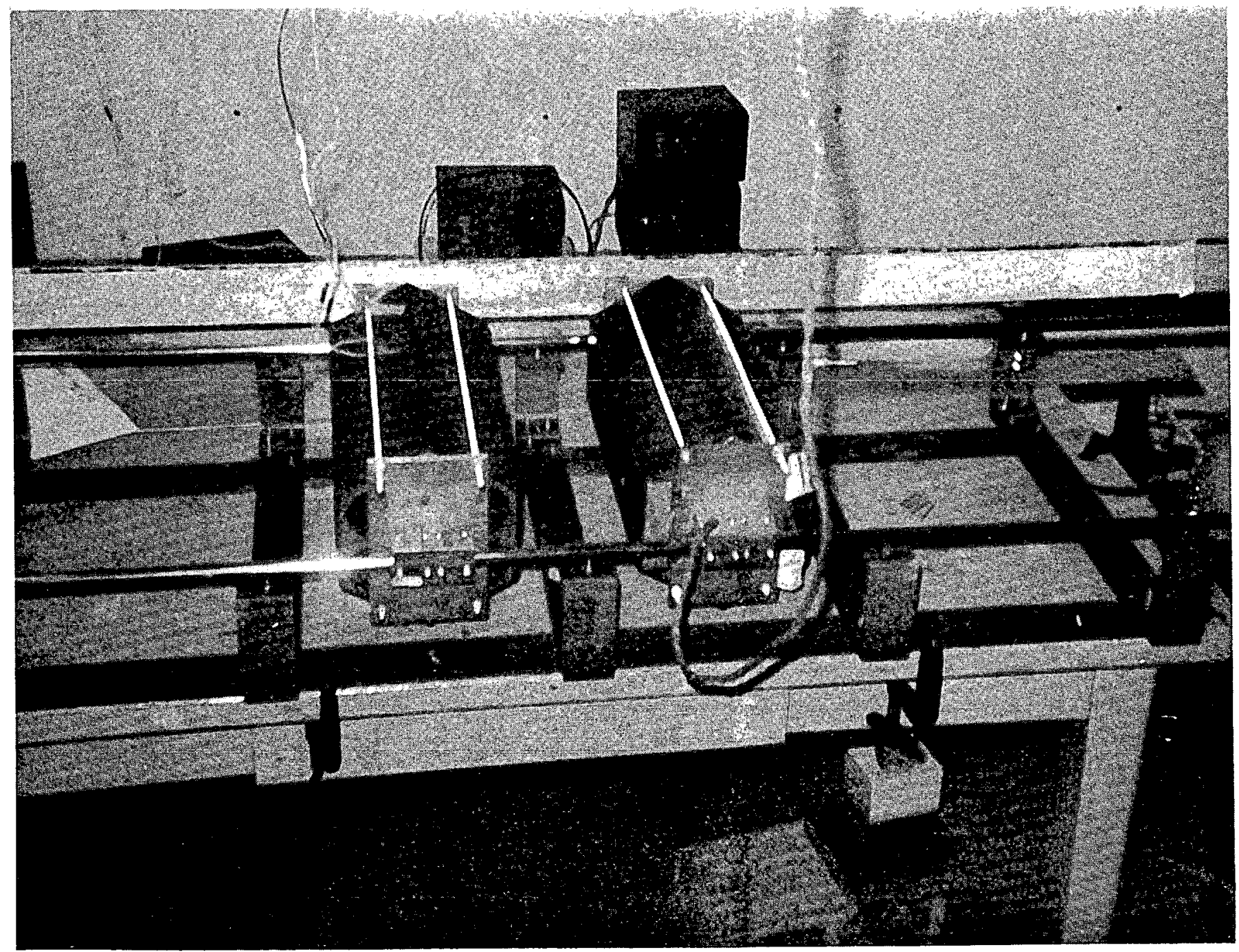

Fig. 4-16. ILMD coefficient of restitution test setup 


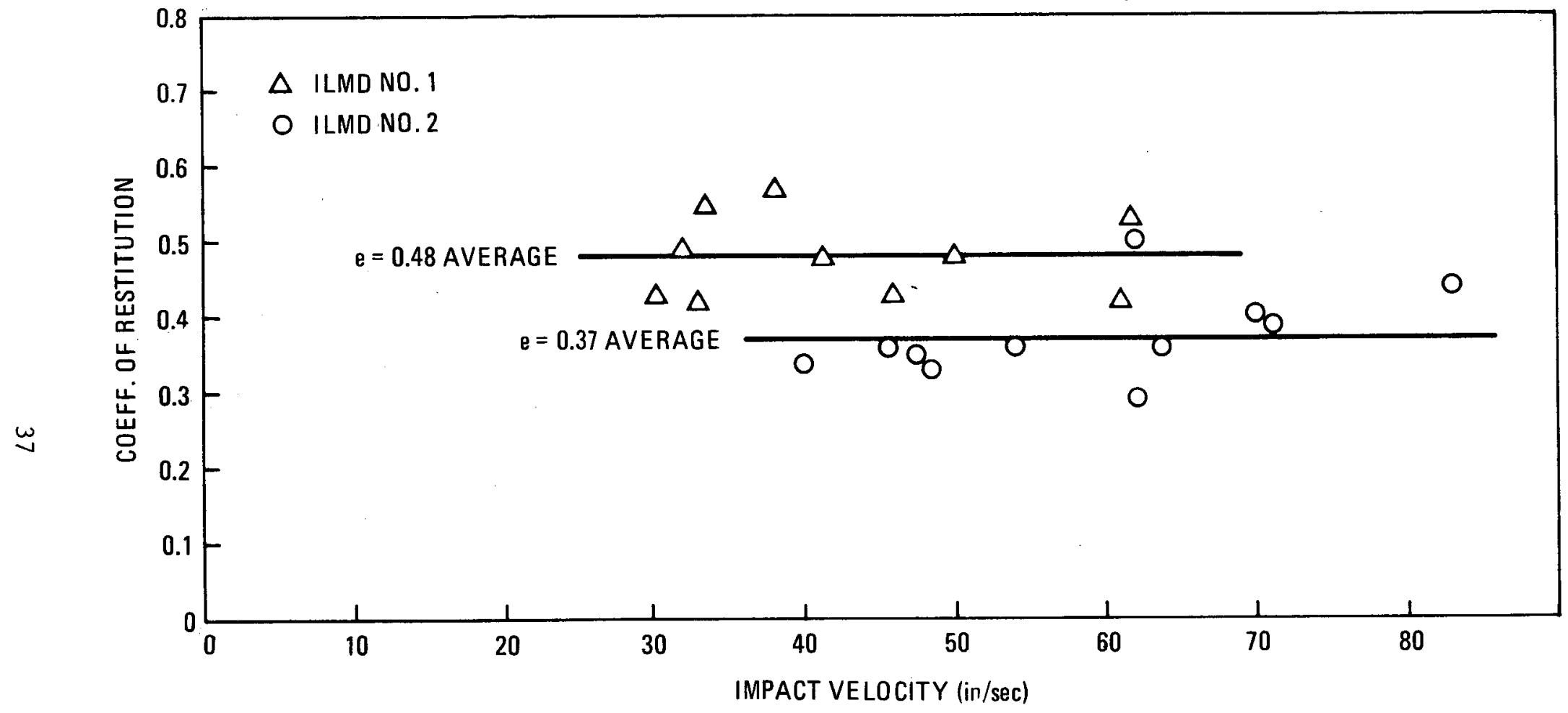

Fig. 4-17. ILMD coefficient of restitution 


\section{TEST PLAN}

Input to the rig consisted of exc1tation applied along two orthogonal horizontal axes simultaneously. Two different types of excitation were used: sinusoidal vibration and time history random motion. The orthogonal axes, termed the $X^{\prime}$ and $Y^{\prime}$ axes, were oriented $\pm 45^{\circ}$ from the across-theflats direction of the core elements as shown in Fig. 3-3. A complete summary of all tests performed is given in Table 5-1.

5.1. SINE SWEEP AND SINE DWELL INPUT

Sinusoidal vibration sweep tests (SS) were conducted at constant acceleration input of $0.53 \mathrm{~g}$ ranging in frequency from 1.5 to $15 \mathrm{~Hz}$. The rate of change of frequency was logarithmic at 0.5 decade per minute. This input was applied to both axes with a constant phase angle $\phi$ between the $X$ ' and $\mathrm{Y}^{\prime}$ axes :

$$
\begin{aligned}
& \ddot{X}^{\prime}=0.53 \sin (w t), \\
& \ddot{Y}^{\prime}=0.53 \sin (w t+\phi),
\end{aligned}
$$

The following phase angles and corresponding correlation coefficients were those specified for the test:

\begin{tabular}{cc}
$\begin{array}{c}\text { Correlation } \\
\text { Coefficient }\end{array}$ & $\begin{array}{c}\text { Phase Angle } \\
\left({ }^{\circ}\right)\end{array}$ \\
\cline { 2 - 2 } 1.00 & 0.0 \\
0.75 & 41.4 \\
0.50 & 60.0 \\
0.25 & 75.5 \\
0.00 & 90.0
\end{tabular}


TABLE 5-1

TEST PLAN

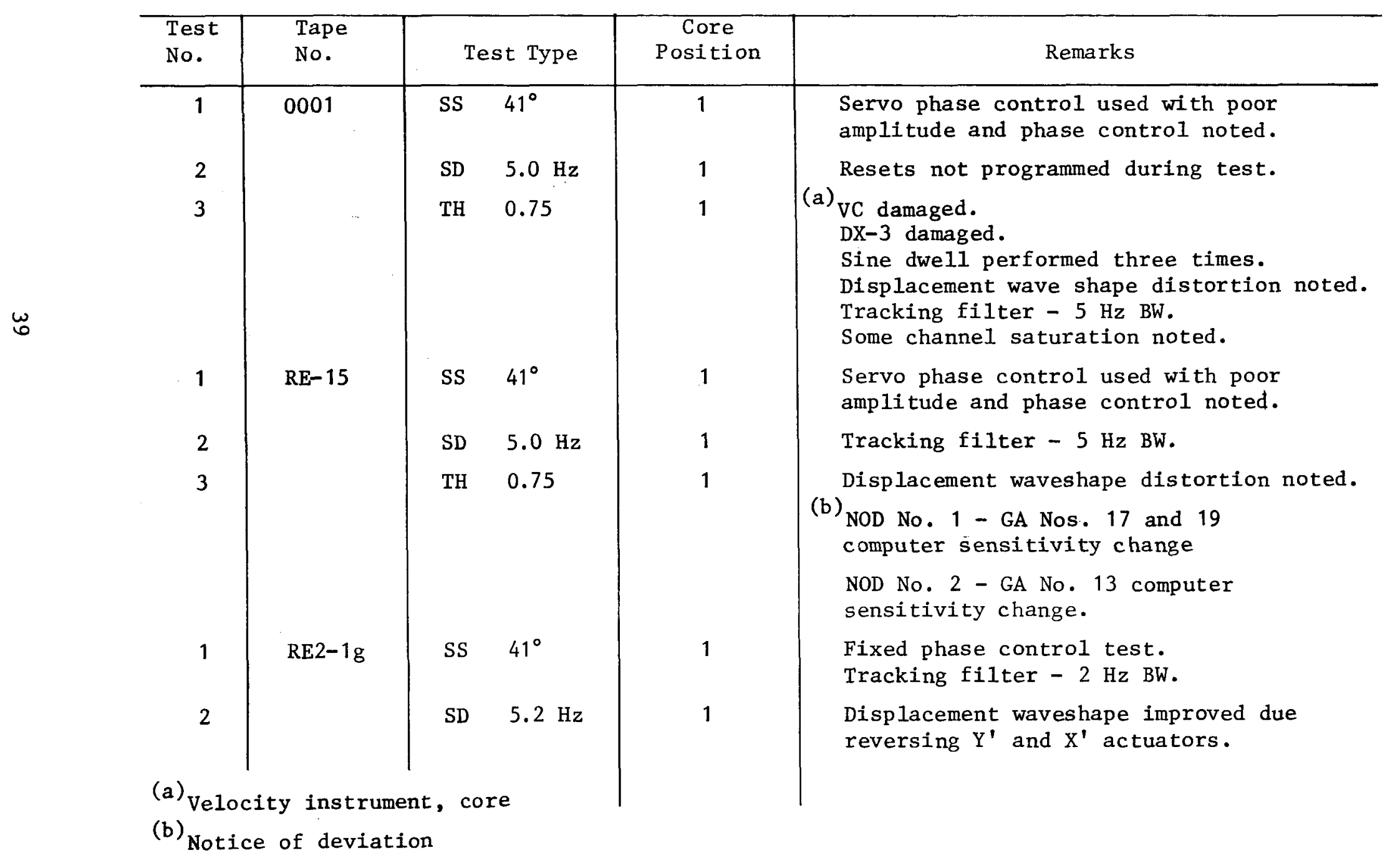


TABLE 5-1 (Continued)

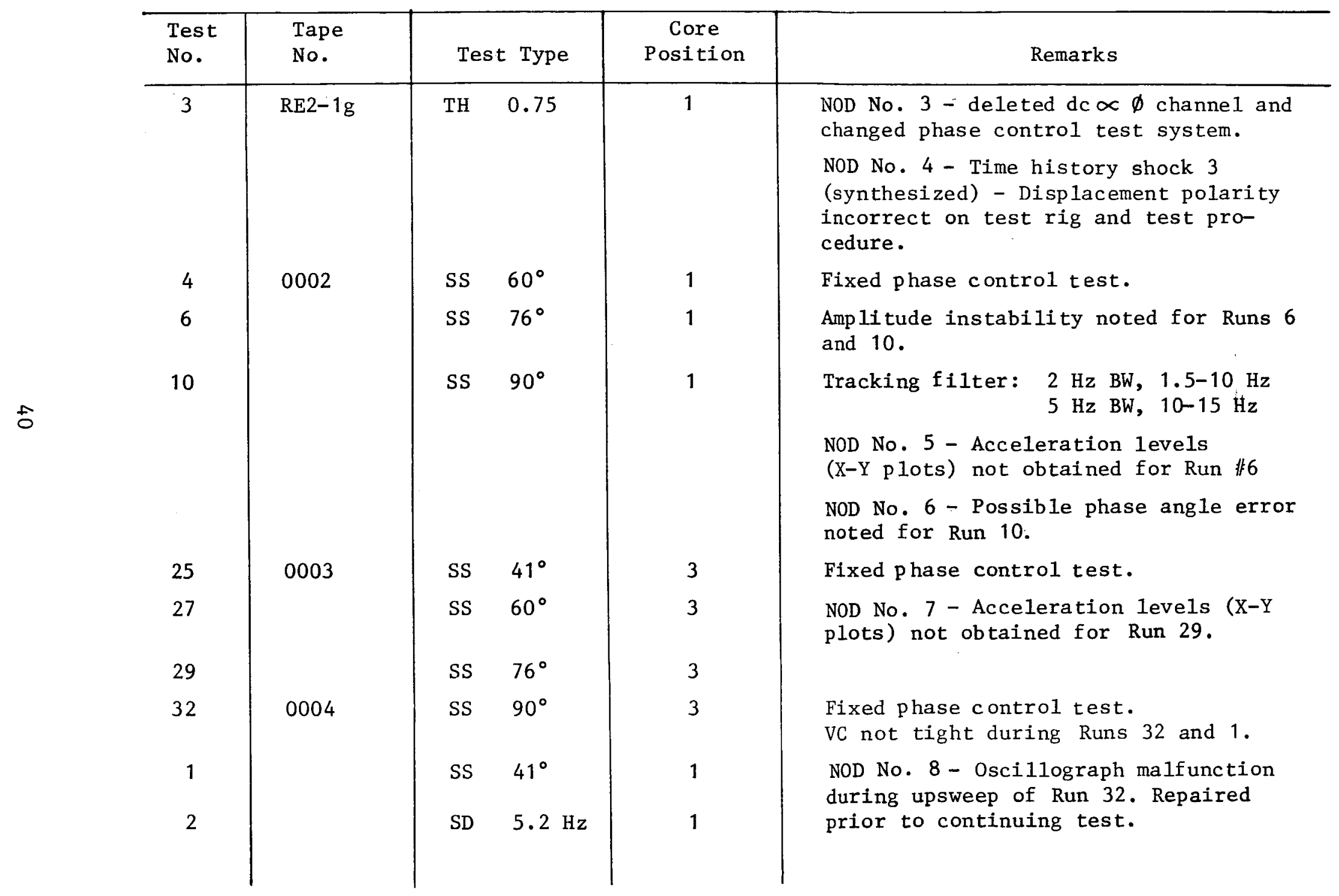


TABLE 5-1 (Continued)

\begin{tabular}{|c|c|c|c|c|c|}
\hline $\begin{array}{l}\text { Test } \\
\text { No. }\end{array}$ & $\begin{array}{l}\text { Tape } \\
\text { No. }\end{array}$ & \multicolumn{2}{|c|}{ Test Type } & $\begin{array}{l}\text { Core } \\
\text { Position }\end{array}$ & Remarks \\
\hline 35 & \multirow[t]{2}{*}{0005} & & $41^{\circ}$ & 4 & Fixed phase control test. \\
\hline 37 & & & $60^{\circ}$ & 4 & \\
\hline 39 & \multirow[t]{5}{*}{0006} & sS & $76^{\circ}$ & 4 & Fixed phase control test. \\
\hline 42 & & SS & $90^{\circ}$ & 4 & $\begin{array}{l}\text { Time history shocks phase, amplitude, } \\
\text { delays correct. }\end{array}$ \\
\hline 36 & & $\mathrm{TH}$ & 0.75 & 4 & $\begin{array}{l}\text { NoD No. } 9-\text { tracking filter }-2 \mathrm{~Hz} \mathrm{BW} \text {, } \\
1.5-15 \mathrm{~Hz} \text {. }\end{array}$ \\
\hline 38 & & $\mathrm{TH}$ & 0.50 & 4 & $\begin{array}{l}\text { NOD No. } 10-\text { TH shock } 9 \text { run } 10 \text {, last } \\
0.15 \text { second not recorded. }\end{array}$ \\
\hline 40 & & $\mathrm{TH}$ & 0.25 & 4 & $\begin{array}{l}\text { Servo amplifier master gain adjusted with } \\
\text { better amplitude stability observed. }\end{array}$ \\
\hline 43 & \multirow[t]{3}{*}{0007} & $\mathrm{TH}$ & 0.00 & 4 & $\begin{array}{l}\text { Repeated time history shocks until } \\
\text { oscillograph data indicated no instru- } \\
\text { ment output due to electrical transients. }\end{array}$ \\
\hline 44 & & $\mathrm{TH}$ & 0.00 & $4 a$ & $\begin{array}{l}\text { NOD No. } 11 \text { - Removed CAL signal from } \\
\text { GA. }\end{array}$ \\
\hline $\begin{array}{r}41 \\
9\end{array}$ & & $\begin{array}{l}\mathrm{TH} \\
\mathrm{TH}\end{array}$ & $\begin{array}{l}0.25 \\
0.25\end{array}$ & $\begin{array}{l}4 \mathrm{a} \\
1 \mathrm{a}\end{array}$ & $\begin{array}{l}\text { Numbers } 13,18,20 \text { (Kistler charge } \\
\text { amplifiers). System calibration data } \\
\text { and for insert calibration purposes. }\end{array}$ \\
\hline $\begin{array}{r}3 \\
5 \\
7 \\
8 \\
11 \\
12 \\
13\end{array}$ & 0008 & $\begin{array}{l}\text { TH } \\
\text { TH } \\
\text { TH } \\
\text { TH } \\
\text { TH } \\
\text { TH } \\
\text { TH }\end{array}$ & $\begin{array}{l}0.75 \\
0.50 \\
0.25 \\
0.25 \\
0.00 \\
0.00 \\
0.00\end{array}$ & $\begin{array}{l}1 \\
1 \\
1 \\
1 \\
1 \\
1 \\
1 \mathrm{a}\end{array}$ & $\begin{array}{l}\text { Repeated time history shocks until } \\
\text { oscillograph data indicated no } \\
\text { instrument output due to electrical } \\
\text { transients. } \\
\text {. }\end{array}$ \\
\hline
\end{tabular}


TABLE 5-1 (Continued)

\begin{tabular}{|c|c|c|c|c|c|}
\hline $\begin{array}{l}\text { Test } \\
\text { No. }\end{array}$ & $\begin{array}{l}\text { Tape } \\
\text { No. }\end{array}$ & & Type & $\begin{array}{c}\text { Core } \\
\text { Position }\end{array}$ & Remarks \\
\hline $\begin{array}{l}26 \\
28 \\
30 \\
33 \\
34 \\
31\end{array}$ & 0009 & $\begin{array}{l}\mathrm{TH} \\
\mathrm{TH} \\
\mathrm{TH} \\
\mathrm{TH} \\
\mathrm{TH} \\
\mathrm{TH}\end{array}$ & $\begin{array}{l}0.75 \\
0.50 \\
0.25 \\
0.00 \\
0.00 \\
0.25\end{array}$ & $\begin{array}{l}3 \\
3 \\
3 \\
3 \\
3 a \\
3 a\end{array}$ & $\begin{array}{l}\text { Repeated time history shock until } \\
\text { oscillograph data indicated no } \\
\text { instrument output due to electrical } \\
\text { transients. }\end{array}$ \\
\hline $\begin{array}{l}20 \\
21 \\
24 \\
23 \\
18 \\
16\end{array}$ & 0010 & $\begin{array}{l}\text { TH } \\
\text { TH } \\
\text { TH } \\
\text { TH } \\
\text { TH } \\
\text { TH }\end{array}$ & $\begin{array}{l}0.25 \\
0.25 \\
0.00 \\
0.00 \\
0.50 \\
0.75\end{array}$ & $\begin{array}{l}2 \\
2 \\
2 \\
2 \\
2 \\
2\end{array}$ & $\begin{array}{l}\text { Eddy current calibration performed at } \\
2400 \text { hours on } 7 / 25 / 75 \text {. } \\
\text { Tes ting started at } 0800 \text { hours } 7 / 26 / 75 \text {. } \\
\text { NOD No. } 12 \text { - Incorrect signal condition- } \\
\text { ing ranges recorded for G.A.C.'s } 17,18 \text {, } \\
19,20 . \\
\text { NOD No. } 15 \text { - Incorrect computer } \\
\text { sensitivity calculations noted. }\end{array}$ \\
\hline $\begin{array}{l}14 \\
15 \\
17\end{array}$ & 0011 & $\begin{array}{l}\text { SS } \\
\text { SD } \\
\text { SS }\end{array}$ & $\begin{array}{l}41^{\circ} \\
5.0 \mathrm{~Hz} \\
60^{\circ}\end{array}$ & $\begin{array}{l}2 \\
2 \\
2\end{array}$ & $\begin{array}{l}\text { NOD No. } 13 \text {, Added } 2 \text { channel to data } \\
\text { acquisition system. Added filtered } \\
\text { acceleration signals FAX and FAY, } 2 \mathrm{~Hz} \\
\text { BW. Slots formerly VC channel. } \\
\text { NOD No. } 14 \text { - Modified phase control } \\
\text { test method. Phase angle meter and an } \\
\text { oscilloscope used for adjusting a phase } \\
\text { calibration. The phase angle meter } \\
\text { was monitored during the sweep and the } \\
\text { ASM phase potentiometer adjusted as } \\
\text { required. } \pm 5^{\circ} \text { control apparent. } \\
\text { Evaluation of fixed phase angle test } \\
\text { control indicates a potential phase } \\
\text { angle drift of } 20^{\circ} \text { upwards from the } \\
\text { nominal phase angle adjusted prior to } \\
\text { initiating the frequency sweep. }\end{array}$ \\
\hline
\end{tabular}


TABLE 5-1 (Continued)

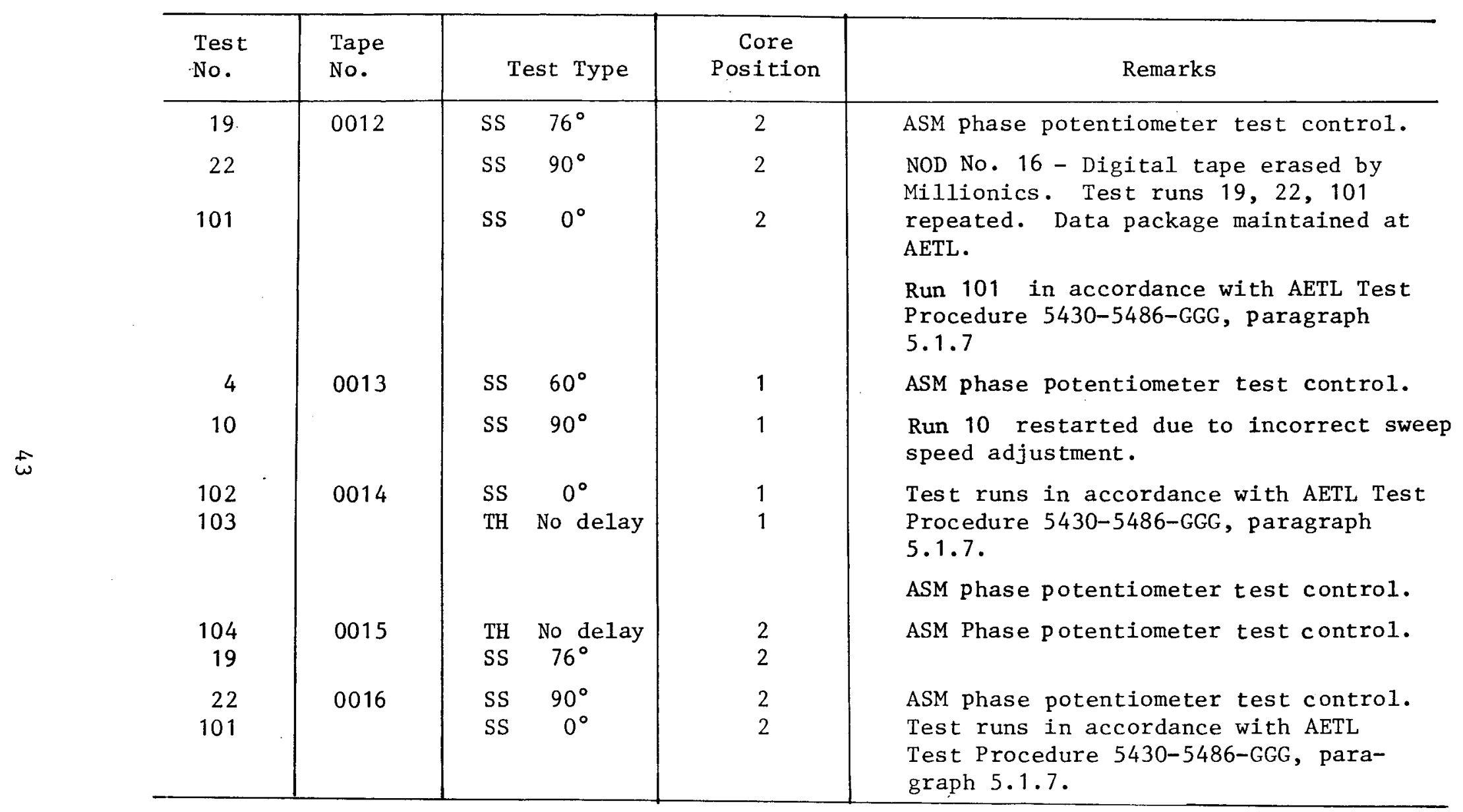


Portions of the test were conducted utilizing fixed phase control, which created a maximum phase angle error from the specified value of $\pm 15^{\circ}$. During sinusoidal testing, where the phase angle was manually monitored and adjusted, the phase angle accuracy was $\pm 5^{\circ}$. These methods of phase control are discussed in Section 4.1.

The sinusoidal dwells (SD) were also run at $0.53 \mathrm{~g}$ level at near resonant frequency (approximately $5 \mathrm{~Hz}$ ). In some cases, the phase angle was slowly varied from $0^{\circ}$ through $90^{\circ}$, taking approximately 60 seconds to go through the entire range. In all cases of a phase lag between the two input excitations, the $Y^{\prime}$-axis motion always leads the $\mathrm{X}^{\prime}$-axis motion as discussed in Section 4.1 .

\subsection{TIME HISTORY INPUT}

The time history (TH) input consisted of narrow band random motion represented by an actual earthquake (E1 Centro) and a GA synthesized design earthquake satisfying the NRC response spectra, Regulatory Guide 1.60, December 1973. These were generated from an analytical model of the HTGR prestressed concrete reactor vessel (PCRV) and reactor building, and are referred to as shock 9 and shock 3, respectively. The input waveforms are shown in Figs. 5-1 and 5-2. The input amplitudes were $0.355 \mathrm{~g}$ and $0.1775 \mathrm{~g}$ equivalent ground acceleration, which correspond to approximately $0.71 \mathrm{~g}$ and $0.35 \mathrm{~g}$ fixture acceleration, respectively.

Each time history was applied to the $X^{\prime}$ and $Y^{\prime}$ axes simultaneously. In most cases, a time lag between the inputs was adjugted such that the $X^{\prime}$ motion led the $Y^{\prime}$ motion. This is discussed in Section 4.1. Several time lags were utilized for shock 9 and shock 3 corresponding to the following correlation coefficients : 


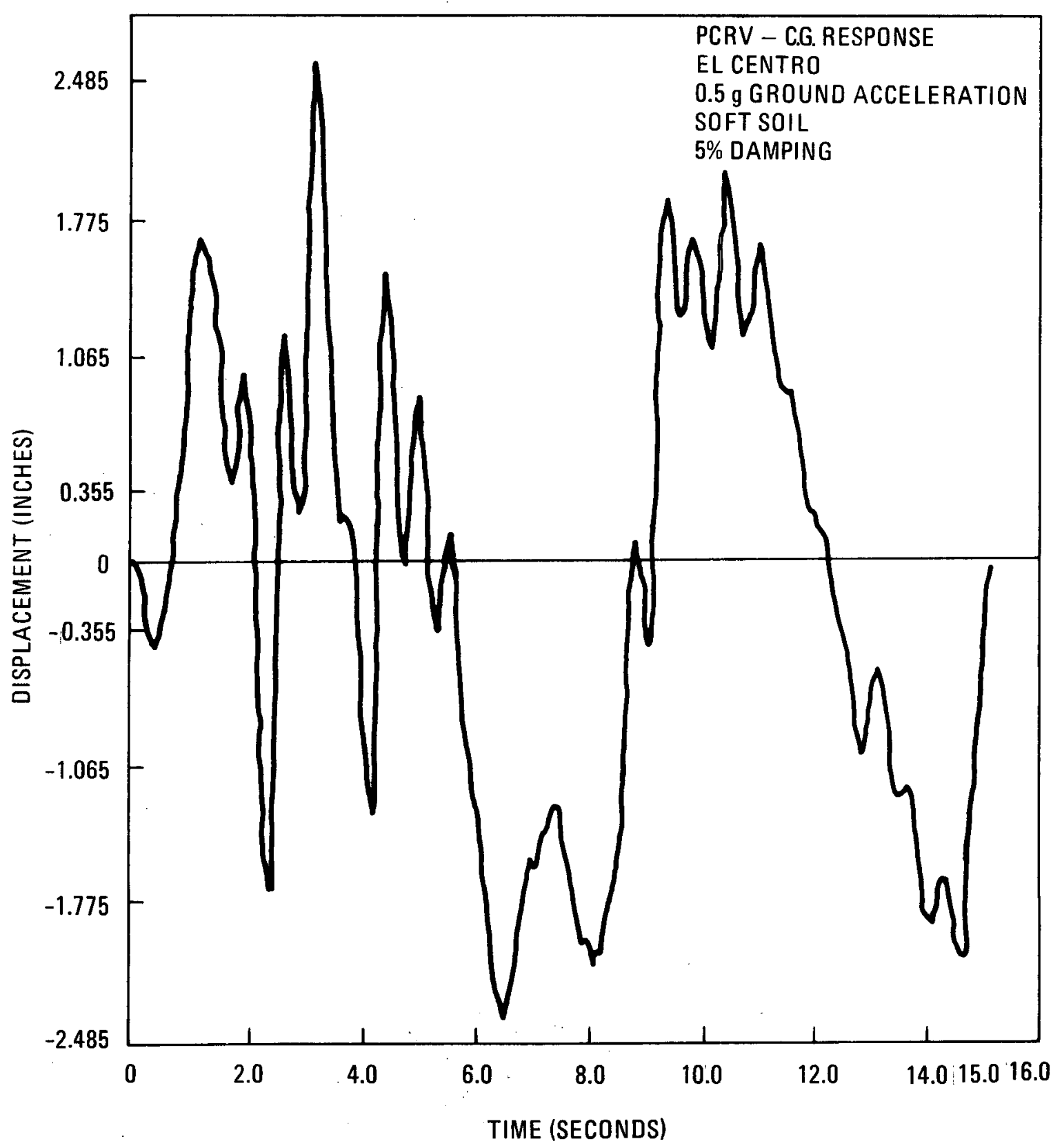

Fig. 5-1. Time history of shock 9 (1/2 scale) 


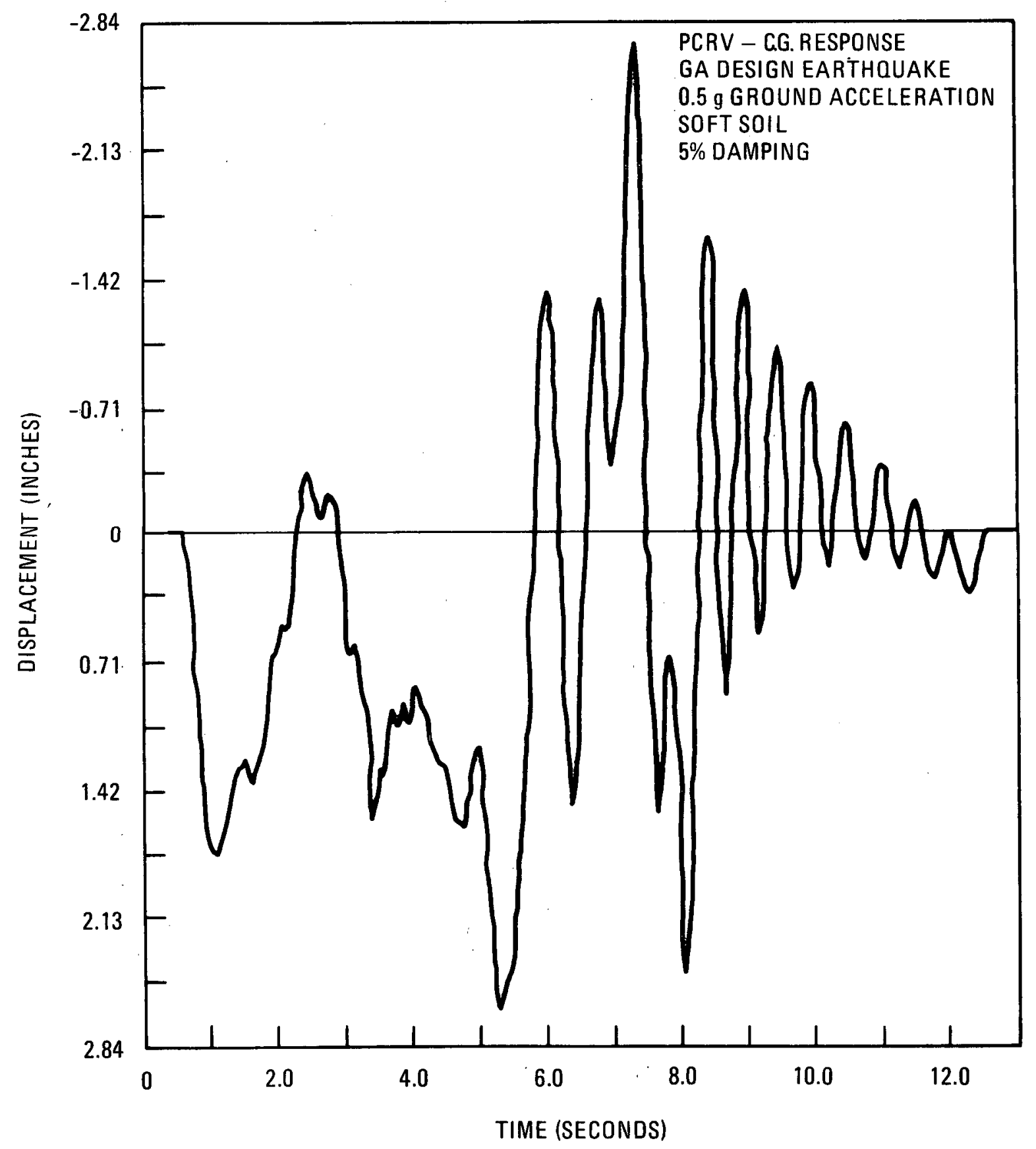

Fig. 5-2. Time history of shock 3 (1/2 scale) 


\begin{tabular}{|c|c|c|}
\hline $\begin{array}{l}\text { Correlation } \\
\text { Coefficient }\end{array}$ & $\begin{array}{c}\text { Time Lag } \\
\text { Shock } 9 \\
\text { (sec) } \\
\end{array}$ & $\begin{array}{c}\text { Time Lag } \\
\text { Shock } 3 \\
\text { (sec) }\end{array}$ \\
\hline 1.00 & 0.0 & 0.0 \\
\hline 0.75 & 0.288 & 0.131 \\
\hline 0.50 & 0.721 & 0.206 \\
\hline 0.25 & 1.334 & 0.601 \\
\hline 0.0 & 1.986 & 0.754 \\
\hline
\end{tabular}

These time lags were applied with a tolerance value of 0.030 second.

5.3. INSTRUNENT LOCATIONS

During testing, instrumented core elements were located at one of seven core positions. The positions were chosen on the basis of an analysis with a computer code modeling the core test array. The analysis demonstrated that element loads occurred symmetrically in all four quadrants of the core, so that only a single quadrant need be fully instrumented. These locations, as well as the locations of the permanently mounted boundary support instruments, are shown in Fig. 5-3.

The configurations of the instrumentation in the trio of blocks for al1 core positions are shown in Figs. 4-10 and 4-11. 


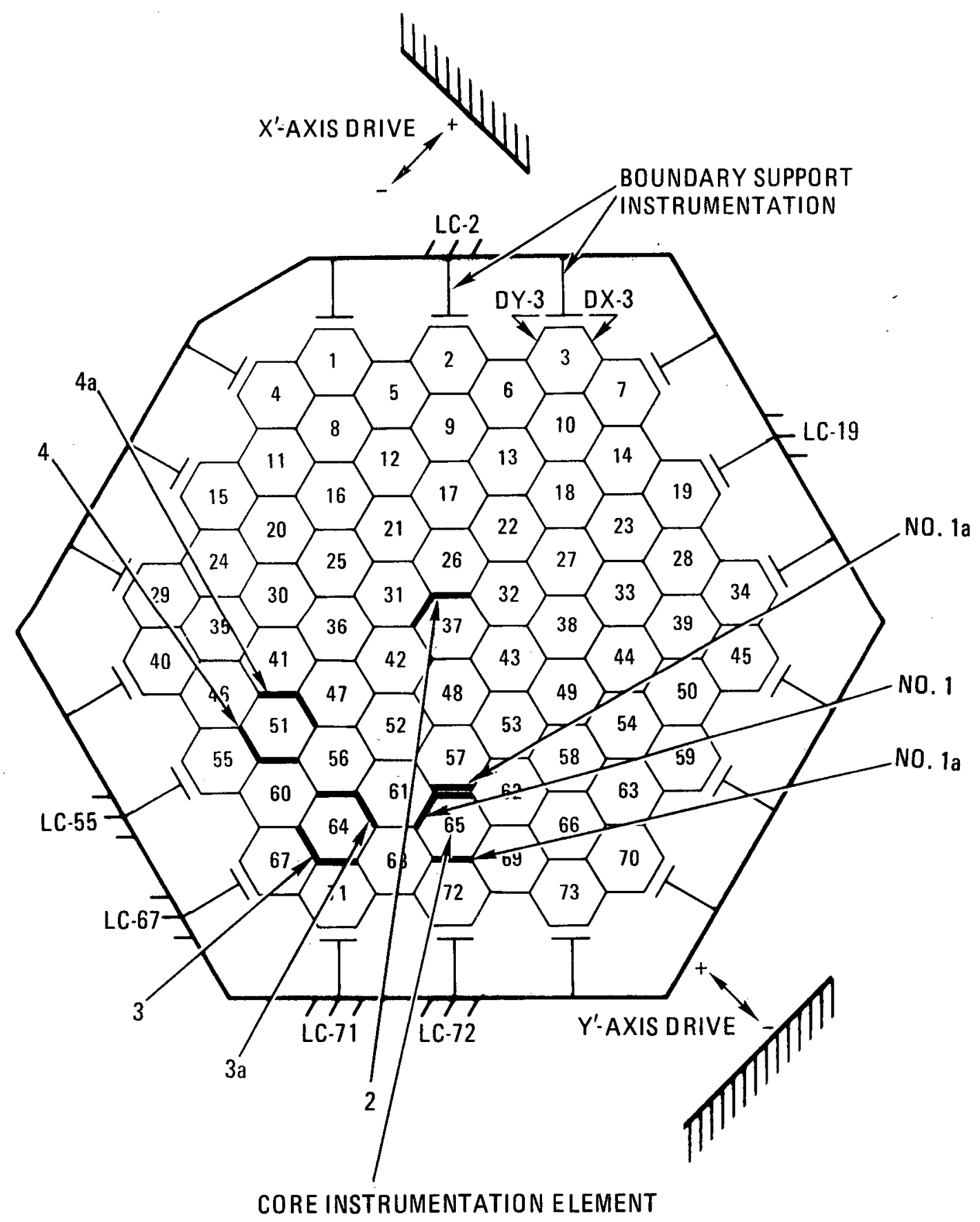

Fig. 5-3. Core instrumentation positions 
6. DATA REDUCTION METHODS

The first step in data reduction was conversion of digital information on the Varian tape to Univac data tape format. A dump was used to check the Varian to the Univac conversion system whenever it was deemed necessary.

The next operation was the use of program DATAT, which translated the raw data into engineering units, using instrument calibration factors. The data were then stored in the Univac 1108.

After these preliminary steps, specialized programs were used to further process the data, the specific operations depending on whether the run was sine sweep, sine dwe11, or a time history.

For sine sweeps, the following programs were employed.

PEKAVG. Extracts peak average force displacement and values in fixed frequency intervals of a given frequency range.

VELOS. Calculates peak average velocities in fixed frequency intervals of a given frequency range. The program also calculates the correlation coefficient for two-axis motion using the shaker LVDTs.

DATAP. Plots instrument response as a function of time.

PGPLOT. Plots instrument response as a function of frequency for sine sweep tests. 
For sine dwells, the THPEAK routine (for time history data reduction) was modified to give peak values of the loads at intervals of 1 second throughout the dwell. Also, a DATAP routine was modified for the dwell so that phase versus time plots could be obtained. Using the above two procedures, plots of loads as a function of phase could be generated.

For time histories, the following routines were used:

THPEAK. Finds maximum peak values for a given time history.

THPEKV. Obtains maximum peak velocities for a given time history. 


\section{TEST RESULTS}

The results presented in this section are typical responses selected from the bulk of the test data. A more complete set of reduced test data is collected in Ref. 1. A summary list describing this data is given in Table 7-1.

The test results exist in three basic forms: (1) all data are contained on digital data tapes stored in the GA computer archives and data packages, including analog data on oscillograph paper, in Record Storage (Sorrento Valley), (2) initial data reduction listing; i.e., computer printouts utilizing the software described in Section 6 , also kept in Record Storage, and (3) hand and computer plots contained in Ref. 1.

\subsection{PPETEST AND SYSTEM VERIFICATION}

The pretest served as a final verification of the entire test system. It consisted of a sine sweep, sine dwel1, and two time histories, corresponding to test runs 1,2 , and 3 as listed in Table 5-1. Tests 1, 2, and 3 were repeated three times, the third time successfully. The AETL pretest report (Ref. 5) discusses in detail the difficulties encountered and the results obtained from these tests.

\subsection{CORE DYNAMIC CHARACTERISTICS}

Sinusoidal sweep and dwell excitation input as described in Section 5.1 were used to study core dynamic characteristic behavior. The study this time was limited to comparing the resonance phenomena for two-axis input with single axis input motion and determining the motion characteristics and distribution of forces in the core as a function of phase shift 
TABLE 7-1

SUMMARY OF 1/2-SCALE TWO-AXIS TEST DATA (0.5-IN. CORE GAP)

\begin{tabular}{|c|c|c|c|c|c|c|}
\hline Data Type & Response & $\begin{array}{l}\text { Excitation } \\
\text { Input }\end{array}$ & $\begin{array}{l}\text { Test } \\
\text { Number }\end{array}$ & Section & $\begin{array}{l}\text { Core } \\
\text { Position }\end{array}$ & $\begin{array}{c}\text { Corr. } \\
\text { Coefficient }\end{array}$ \\
\hline $\begin{array}{l}\text { Frequency response curves } \\
\text { (peak average) }\end{array}$ & $\begin{array}{l}\text { Displ. } \\
\text { Velocity } \\
\text { Force }\end{array}$ & SINS $(0.53 \mathrm{~g})$ & $\begin{array}{r}10 \\
22 \\
101 \\
102\end{array}$ & A1 & $\begin{array}{l}\text { CP } 1 \\
\text { CP } 2 \\
\text { CP } 2 \\
\text { CP1 }\end{array}$ & $\begin{array}{l}0.0 \\
1.0\end{array}$ \\
\hline $\begin{array}{l}\text { Force distribution at } \\
\text { resonance (MNR) }\end{array}$ & $\begin{array}{l}\text { Velocity } \\
\text { Force }\end{array}$ & SINS $(0.53 \mathrm{~g})$ & $\begin{array}{r}101 \\
10\end{array}$ & $\mathrm{~A} 2$ & $\begin{array}{l}\mathrm{CP} 2 \\
\mathrm{CP} 1\end{array}$ & $\begin{array}{l}1.0 \\
0.0\end{array}$ \\
\hline $\begin{array}{l}\text { Phase response curves } \\
\text { (peak average) }\end{array}$ & Force & $\begin{aligned} \text { SIND } & (5.2 \mathrm{~Hz}) \\
& (5.0 \mathrm{~Hz})\end{aligned}$ & $\begin{array}{r}2 \\
15\end{array}$ & A3 & $\begin{array}{l}\mathrm{CP} 1 \\
\mathrm{CP} 2\end{array}$ & -- \\
\hline $\begin{array}{l}\text { Time history force distribution } \\
\text { (maximum) shocks } 3 \& 9\end{array}$ & $\begin{array}{l}\text { Velocity } \\
\text { Force }\end{array}$ & $\mathrm{TH}(0.71 \mathrm{~g})$ & $\begin{array}{r}11 \\
13 \\
23 \\
33 \\
34 \\
43 \\
44 \\
7 \\
9 \\
20 \\
30 \\
31 \\
40 \\
41 \\
5 \\
18 \\
28 \\
38 \\
3 \\
16\end{array}$ & A4 & $\begin{array}{l}\text { CP1 } \\
\text { CP1a } \\
\text { CP2 } \\
\text { CP3 } \\
\text { CP 3a } \\
\text { CP4 } \\
\text { CP4a } \\
\text { CP1 } \\
\text { CP1a } \\
\text { CP2 } \\
\text { CP3 } \\
\text { CP 3a } \\
\text { CP4 } \\
\text { CP4a } \\
\text { CP1 } \\
\text { CP2 } \\
\text { CP3 } \\
\text { CP4 } \\
\text { CP1 } \\
\text { CP2 }\end{array}$ & 0.75 \\
\hline
\end{tabular}


TABLE 7-1 (Continued)

\begin{tabular}{l|c|c|c|c|c|c}
\hline Data Type & Response & $\begin{array}{c}\text { Excitation } \\
\text { Input }\end{array}$ & $\begin{array}{c}\text { Test } \\
\text { Number }\end{array}$ & Section & $\begin{array}{c}\text { Core } \\
\text { Position }\end{array}$ & $\begin{array}{c}\text { Corr. } \\
\text { Coefficient }\end{array}$ \\
\hline & & & 26 & & CP3 & \\
& & & 36 & & CP4 & \\
& & & 103 & & CP1 & 1.0 \\
\hline
\end{tabular}


between the two inputs. Further description and discussion of the basic resonance phenomena and frequency response, mode shapes, and damping of the 1/2-scale, 73-element test core are contained in Ref. 2 .

The frequency and phase response data are shown as PEAKAVG amplitude values in the plots presented representing the mean of all peaks in frequency intervals of $0.2 \mathrm{~Hz}$. This process tends to reduce the effects of system randomess in the data and provides for smoother and more legible plots.

\subsubsection{Frequency Response}

Typical resonance curves corresponding to a sweep-up for two-axis input at $0.53 \mathrm{~g}$ fixture acceleration and $0.5 \mathrm{in}$. core gap, the $\mathrm{Y}^{\prime}$-axis motion leading the $\mathrm{X}^{\prime}$-axis motion by $90^{\circ}$, are shown in Figs. 7-1 through 7-5. In these plots, the jump frequency or resonant frequency appear close to $6.2 \mathrm{~Hz}$ as shown by instruments recording displacement and force.

In comparison, the resonant frequency for single axis motion, simulated by in-phase, two-axis input at $0.53 \mathrm{~g}$, is slightly higher. From Figs. 7-6 and 7-7, the jump is seen to occur at approximately $6.5 \mathrm{~Hz}$. The reason for this could be that in-phase excitation has a larger maximum Amplitude along the rectilinear $X^{\prime} Y^{\prime}$-axis as demonstrated in Fig. 7-8. Since the core constitutes a spring hardening system that was demonstrated in a 1/5-scale, full-array test (Ref. 6), the resonant frequency will increase with increasing amplitude. Figure 7-9 shows the resonant frequencies plotted for two-axis input having different phase angle. Although some scatter in the data exists, the trend shows clearly a decrease in resonant frequency with phase angle both for sweep-up and sweep-down. 


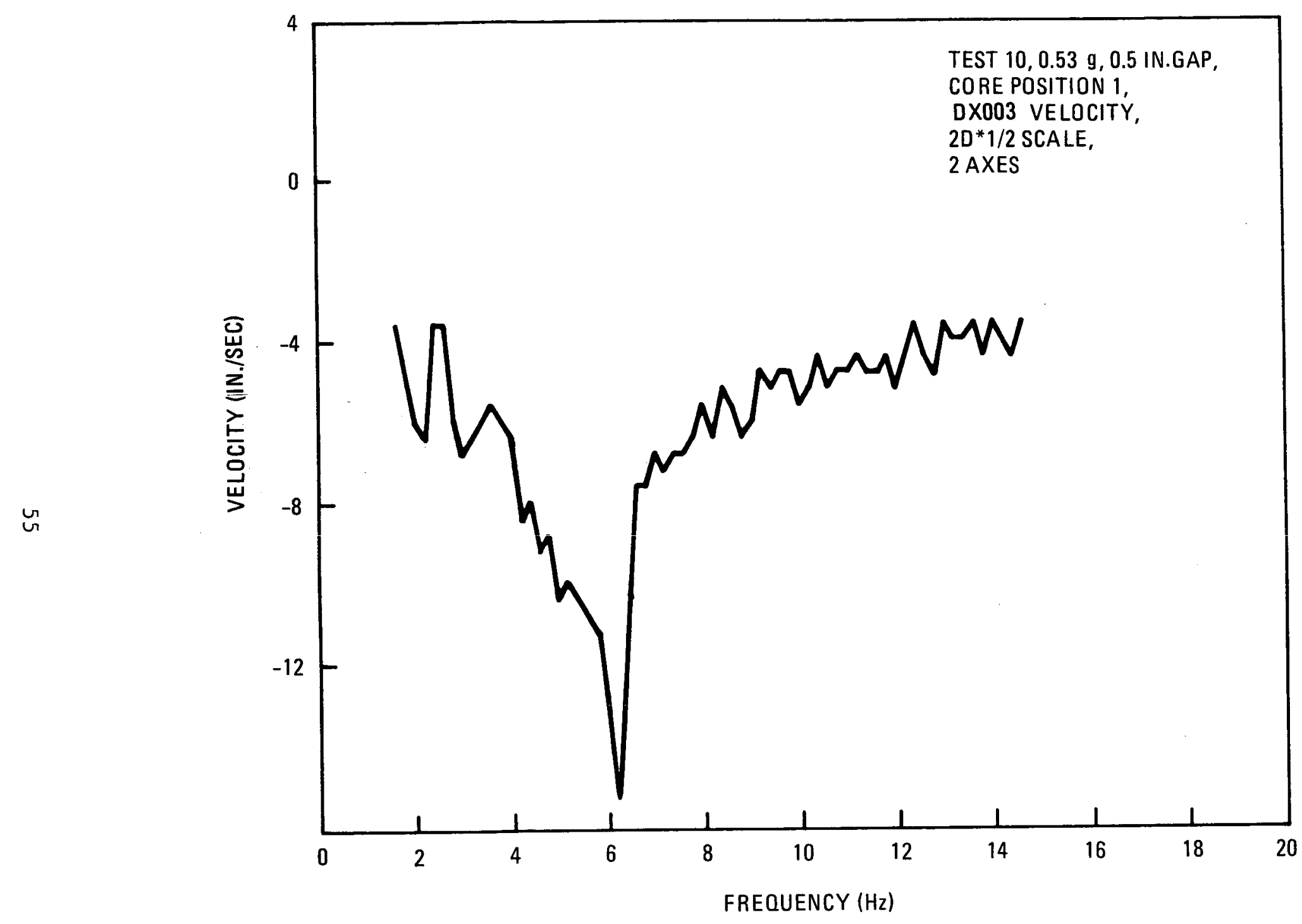

Fig. 7-1. Frequency response curve, (peak average core velocity, DX003), $\phi=90^{\circ}$ 


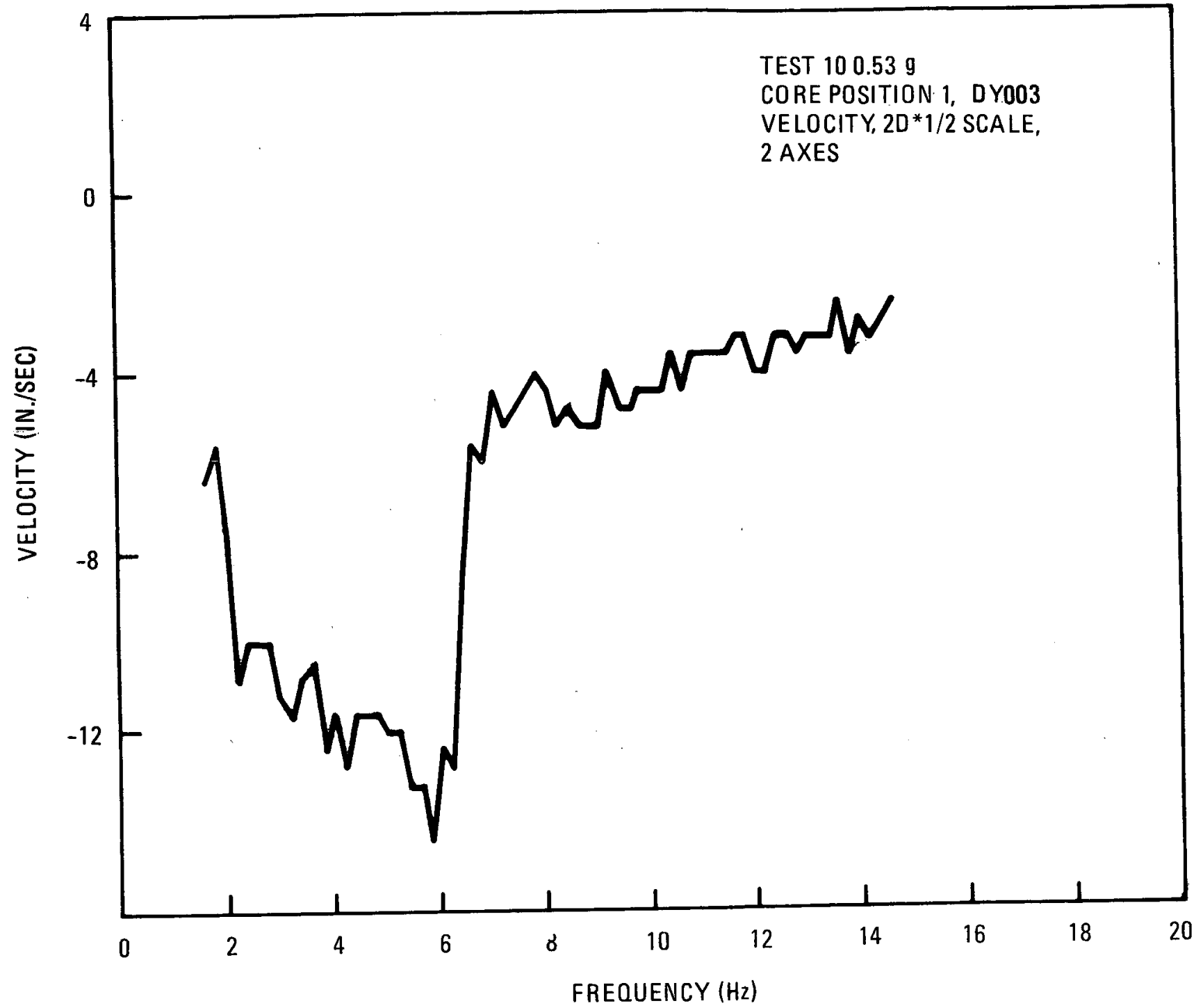

Fig. 7-2. Frequency response curve (peak average core velocity, DY003), $\phi=90^{\circ}$ 
$\underline{v}$

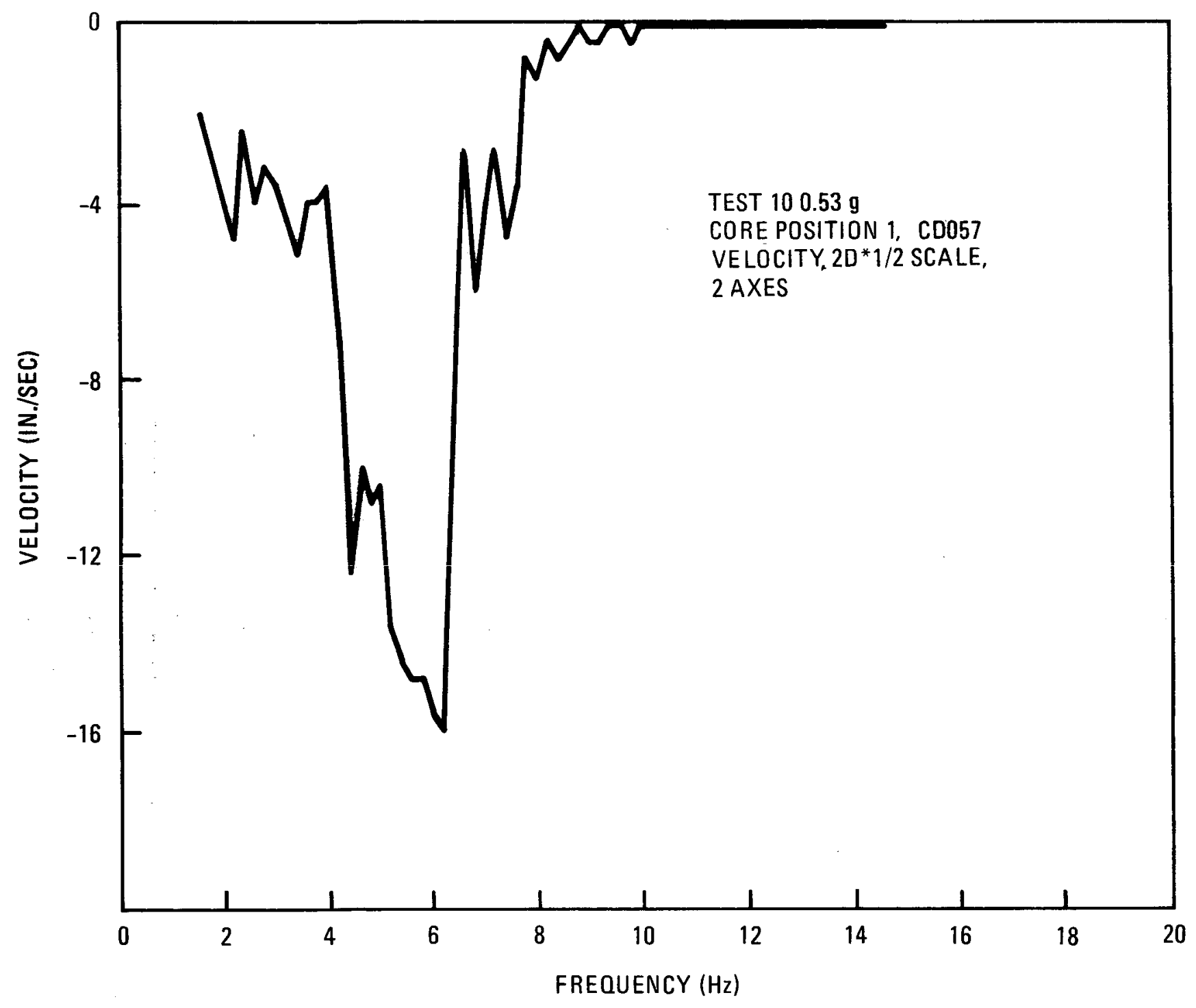

Fig. 7-3. Frequency response curve (peak average element velocity, CD057), $\phi=90^{\circ}$ 


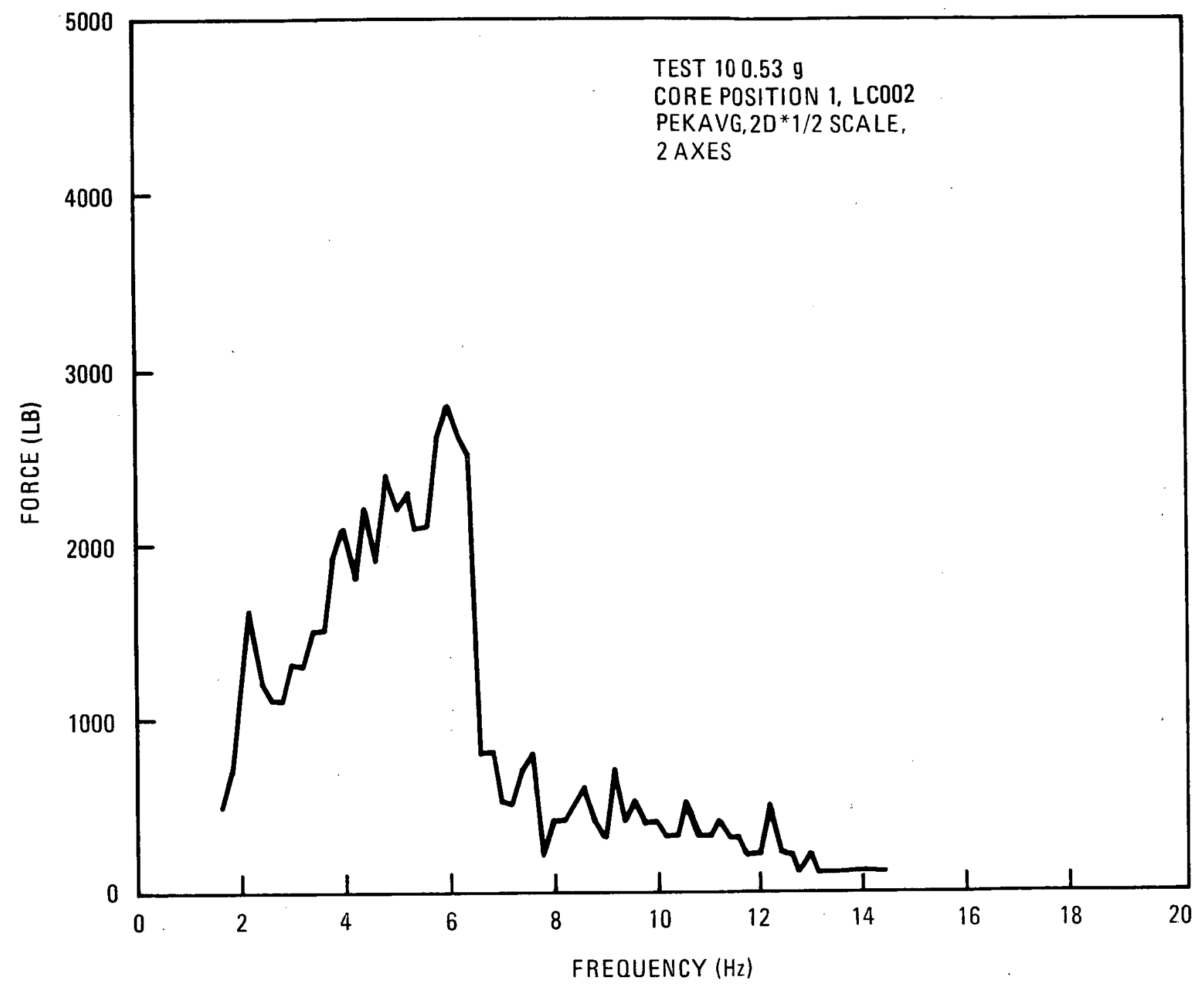

Fig. 7-4. Frequency response curve (peak average force, LC002), $\phi=90^{\circ}$ 


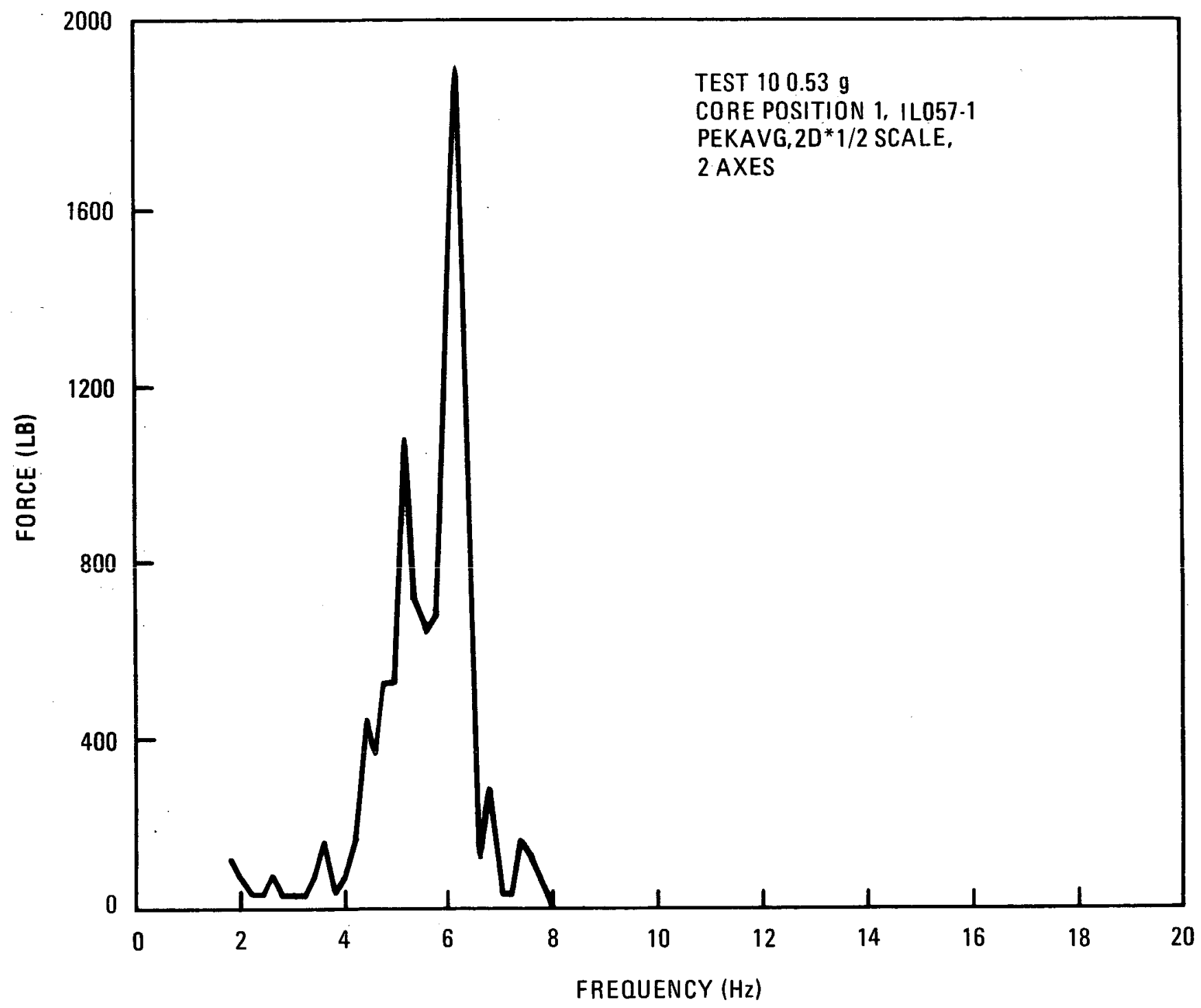

Fig. 7-5. Frequency response curve (peak average force, IL057-1), $\phi=90^{\circ}$ 


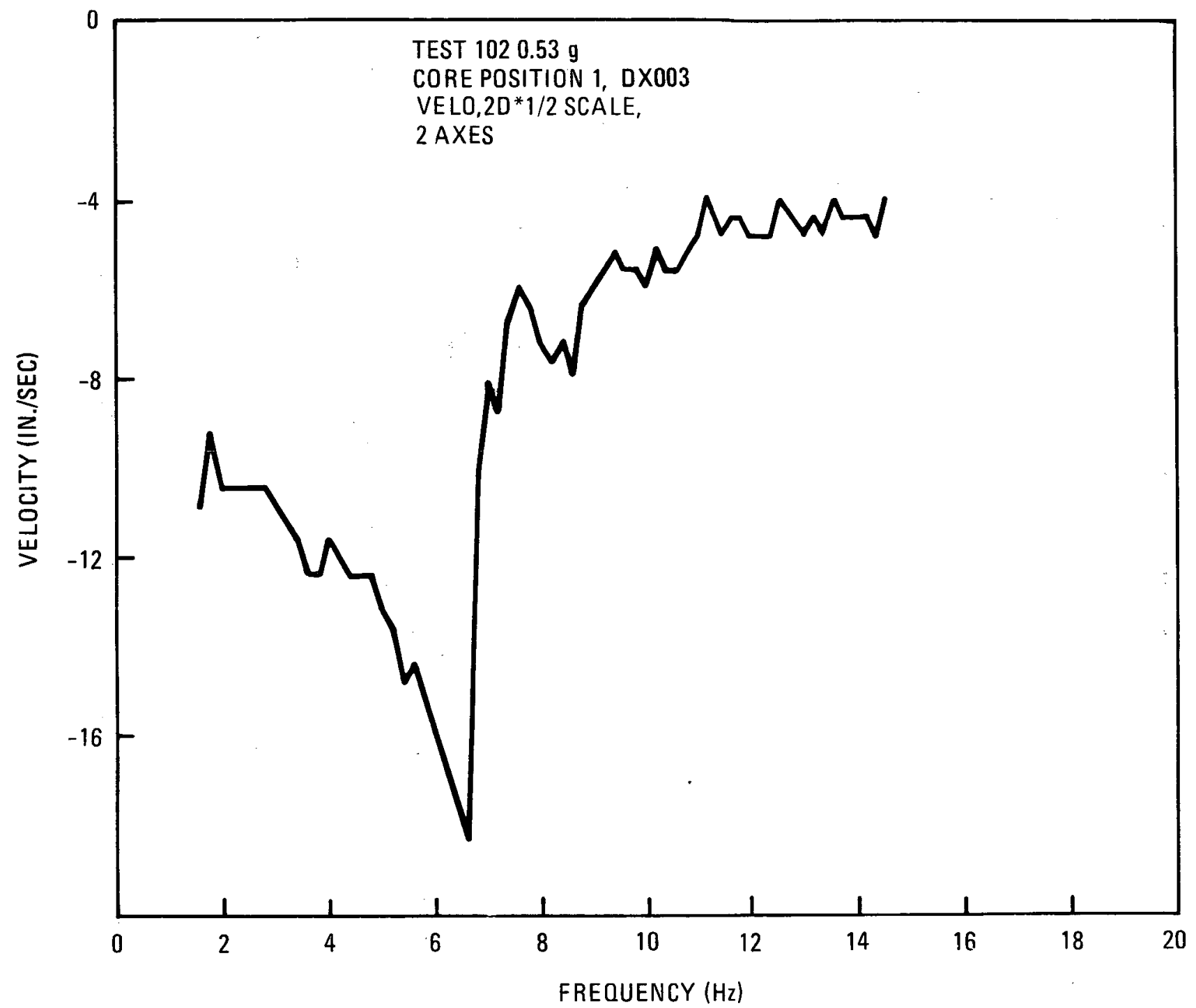

Fig. 7-6. Frequency response curve (peak average core velocity, DX003), $\phi=0^{\circ}$ 


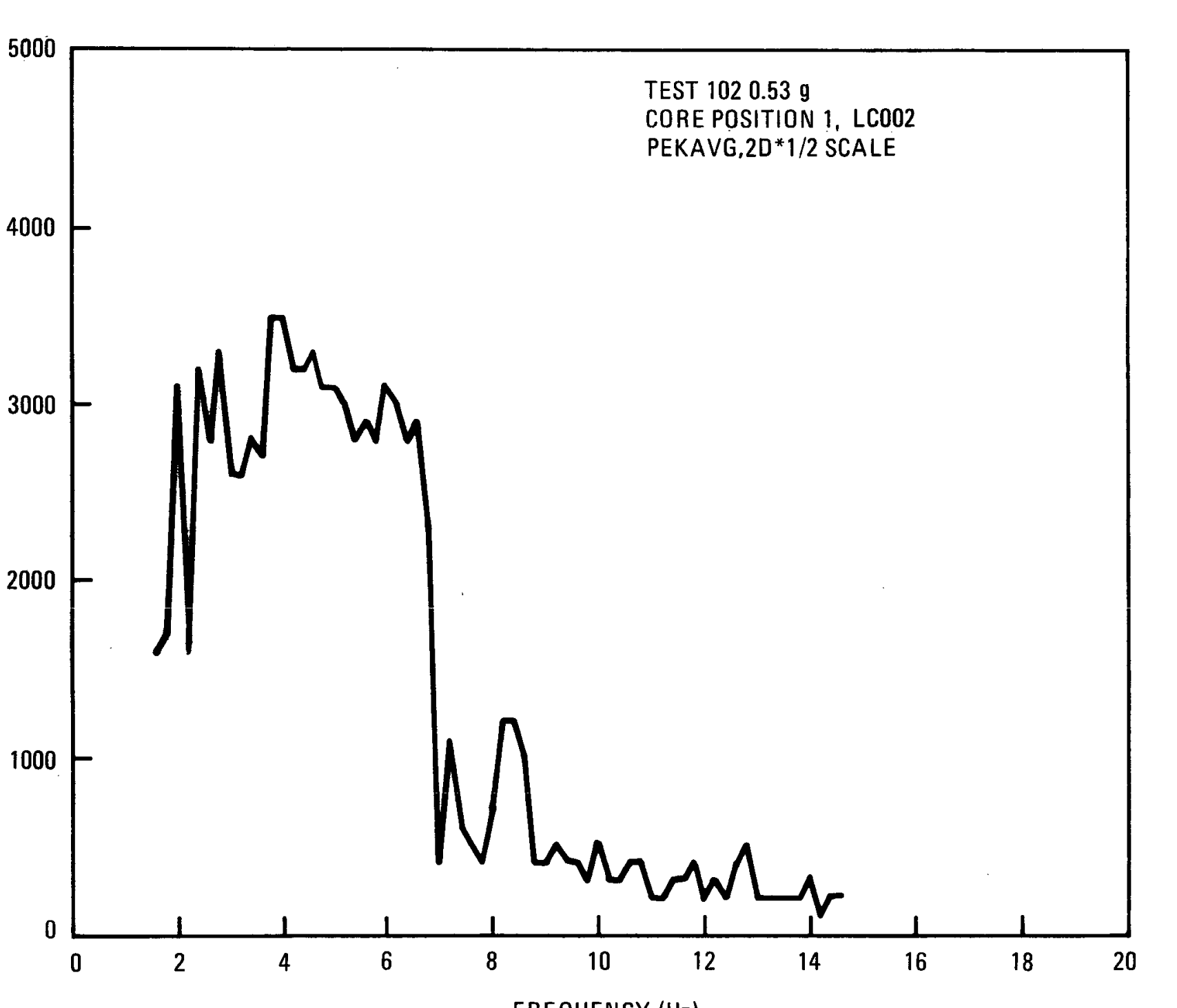




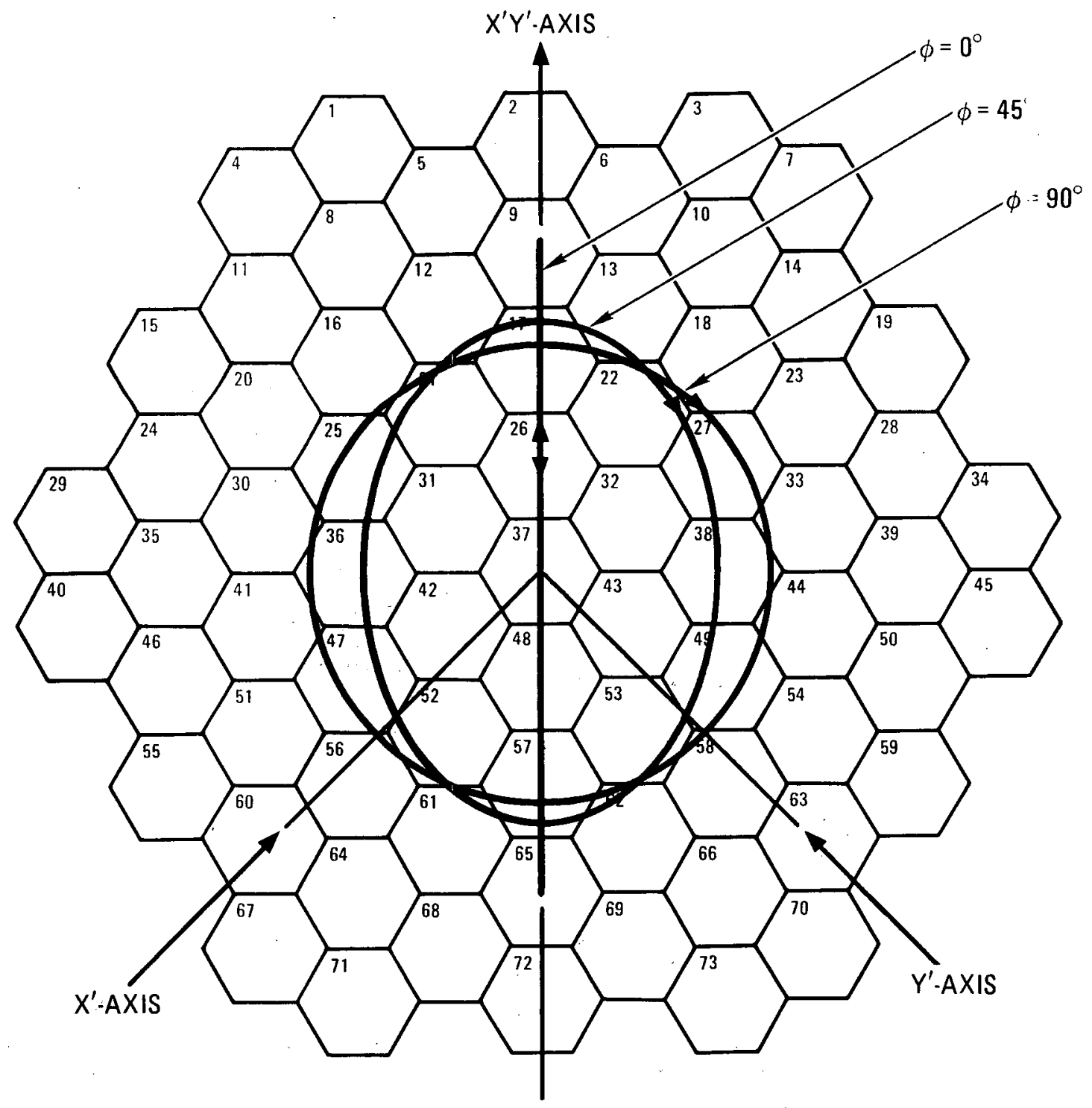

Fig. 7-8. Two-axis excitation modes for different phase angles 


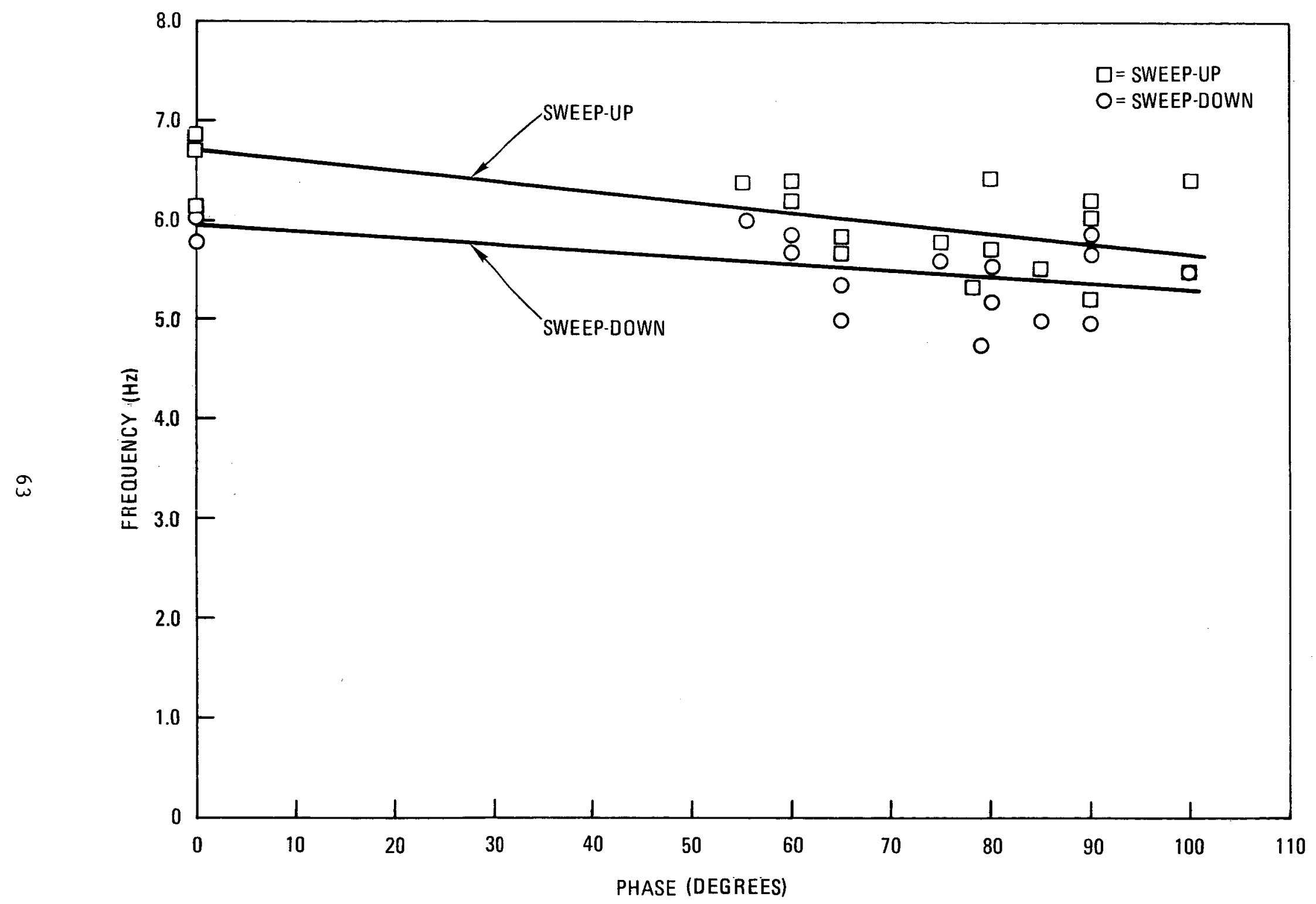

Fig. 7-9. Resonant frequency as a function of phase angle 


\subsubsection{Phase Dependence of Forces and Relative Velocities}

The boundary support and in-core forces as well as relative velocities are, as expected, strongly dependent on the phase relationship between the $\mathrm{X}^{\prime}$-axis and $\mathrm{Y}^{\prime}$-axis inputs. This is demonstrated by comparing Figs. 7-10 and 7-11, representing zero phase angle, with Figs. 7-12 and 7-13, representing a $90^{\circ}$ phase angle. These values represent maximum near resonance, (MNR), which is an average of the three largest peaks within $1.0 \mathrm{~Hz}$ of resonance. It is seen that both the forces and relative velocities are maximum for $0^{\circ}$ phase angle and represent locations along the $X^{\prime} Y^{\prime}$-axis. The $90^{\circ}$ phase angle motion results in forces and velocities of near equal magnitude at symmetrical positions about the $X^{\prime}-Y^{\prime}$-axis. This makes sense since a $90^{\circ}$ phase between $Y^{\prime}$-axis and $X^{\prime}$-axis motion produces, in essence, a circular core motion.

Further information on how the core response changes with two-axis phase shifts is given in Figs. 7-14 through 7-17. These figures represent sine dwells at constant frequency $(5.0 \mathrm{~Hz})$ where the phase angle between the $Y^{\prime}$-axis and $X^{\prime}$-axis input is slowly varied from $0^{\circ}$ to $180^{\circ}$. The load response from the dwells represents maximum peak values over intervals of 1 second during the entire dwell period as discussed in Section 6 . It is seen how the boundary support force (LCO02) and in-core force (IL057-1), shown in Figs. 7-14 and 7-15, decrease with an increase in phase since these sensors are lined up along the $X^{\prime} Y^{\prime}$-direction. The in-core force (IL061-2), shown in Fig. 7-17, is seen to increase with phase up to about $70^{\circ}$, where a maximum occurs. It is interesting to note that this maximum occurs when the phase angle approximately corresponds to the angle that the $\mathrm{X}^{\prime}$-axis makes with the impacting face $\left(75^{\circ}\right)$.

A comparison of Figs. 7-15 and 7-16 also shows that the load on the center load washer in the ILMD is about one-half the sum of the loads on the four load washers situated at the element corners. Also, since very similar load curves result, this means that all collisions occurring are essentially flat-on. 
1/2-SCALE 2D TEST RESULTS

*MNR FORCE DISTRIBUTION

(LB)

DURING SINE SWEEP-UP

$0.53 \mathrm{~g}$

0 PHASE ANG LE

TEST $101 / 102$

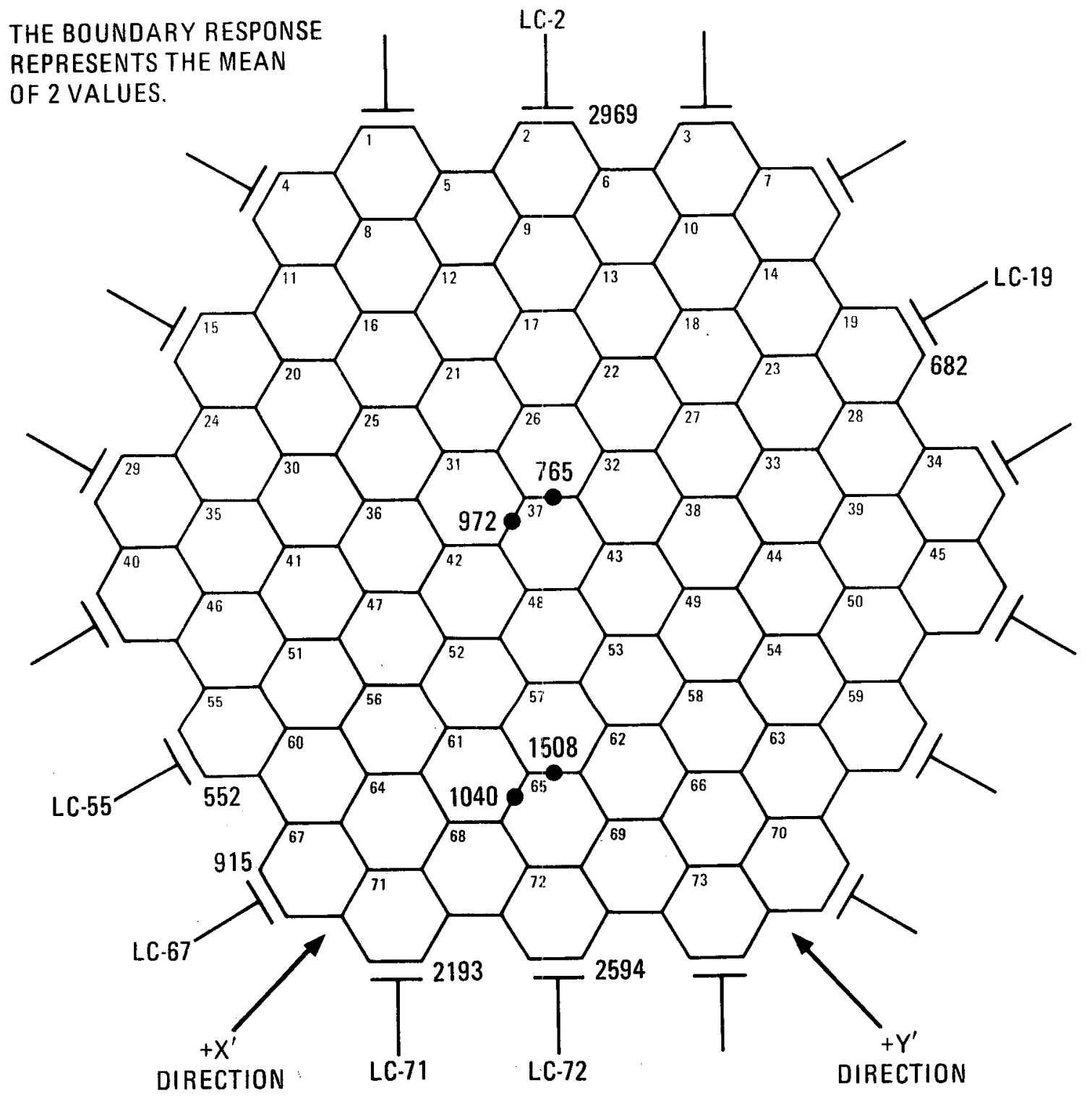

*AVERAGE OF 3 LARGEST VALUES WITHIN 1 Hz OF RESONANCE

Fig. 7-10. Distribution of force (peak average) at resonance, $\phi=0^{\circ}$ 
1/2-SCALE 2D TEST RESULTS

*MNR VELOCITY DISTRIBUTION

(IPS)

\section{DURING SINE SWEEP-UP}

\section{$0.53 \mathrm{~g}$}

$0^{\circ}$ PHASE ANGLE

TEST $101 / 102$

\section{LC-2}

THE BOUNDARY RESPONSE
REPRESENTS THE MEAN

OF 2 VALUES.

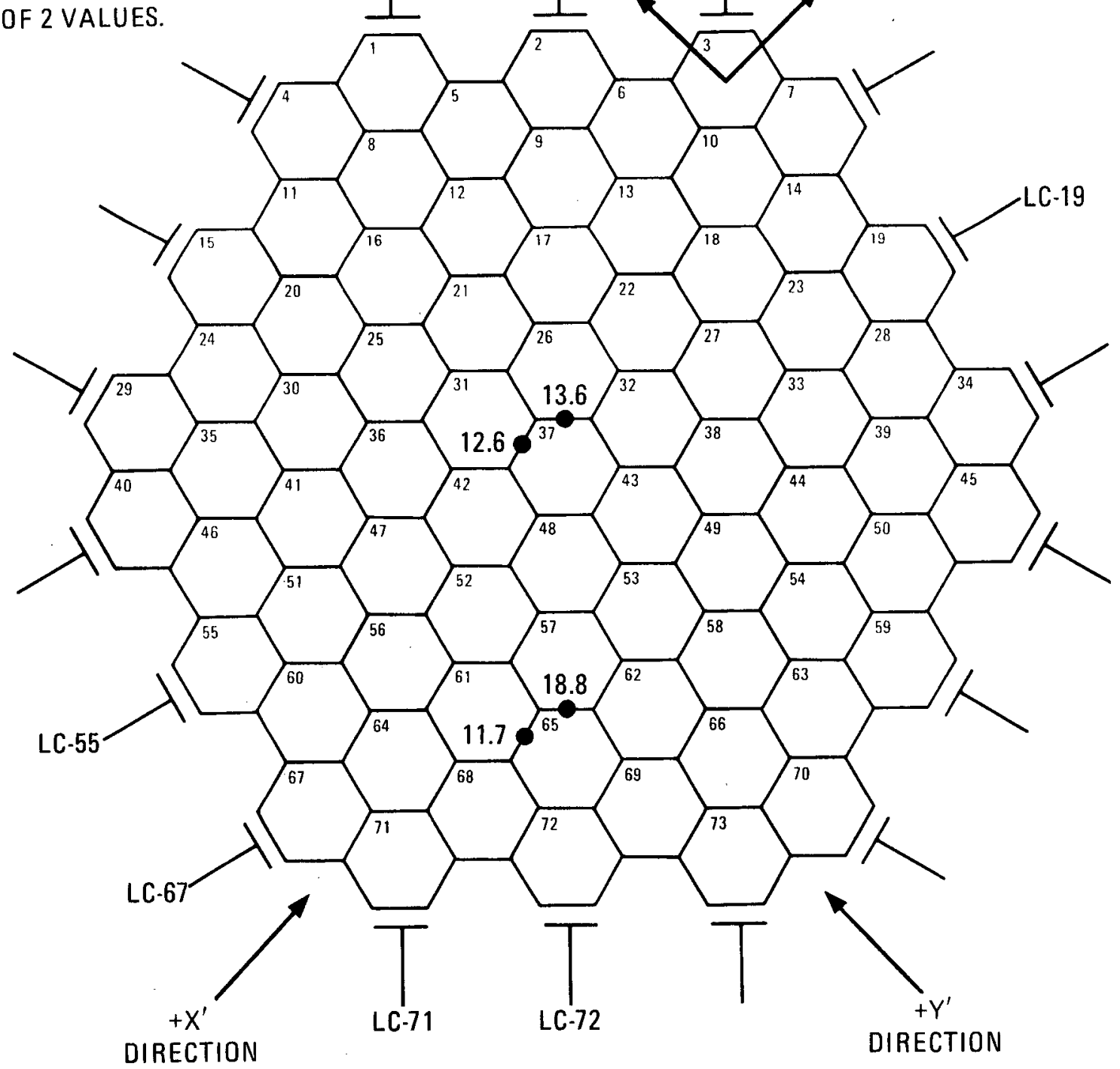

${ }^{*}$ AVERAGE OF 3 LARGEST VALUES WITHIN $1 \mathrm{~Hz}$ OF RESONANCE

Fig. 7-11. Distribution of velocity (peak average) at resonance, $\phi=0^{\circ}$ 
DURING SINE SWEEP-UP

$0.53 \mathrm{~g}$

$90^{\circ}$ PHASE ANGLE

TESTS $10,22,32 \& 42$

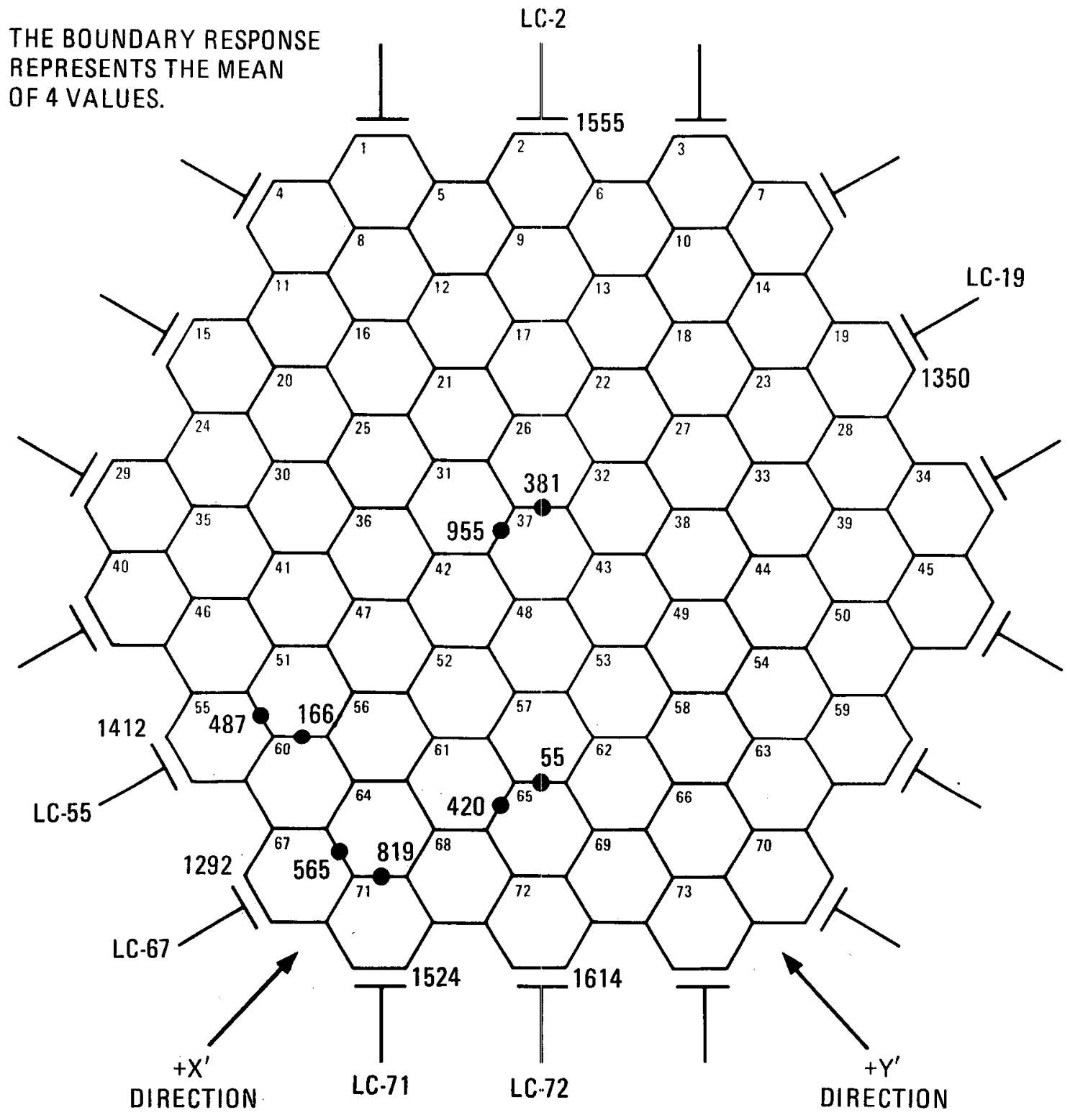

*AVERAGE OF 3 LARGEST VALUES WITHIN $1 \mathrm{~Hz}$ OF RESONANCE

Fig. 7-12. Distribution of force (peak average) at resonance, $\phi=90^{\circ}$ 
1/2 SCALE 2D TEST RESULTS

*MNR VELOCITY DISTRIBUTION

(IPS)

\section{DURING SINE SWEEP-UP \\ $0.53 \mathrm{~g}$ \\ $90^{\circ}$ PHASE ANGLE}

TEST $10,22,32,42$

LC-2

THE BOUNDARY RESPONSE
REPRESENTS THE MEAN

OF 4 VALUES.

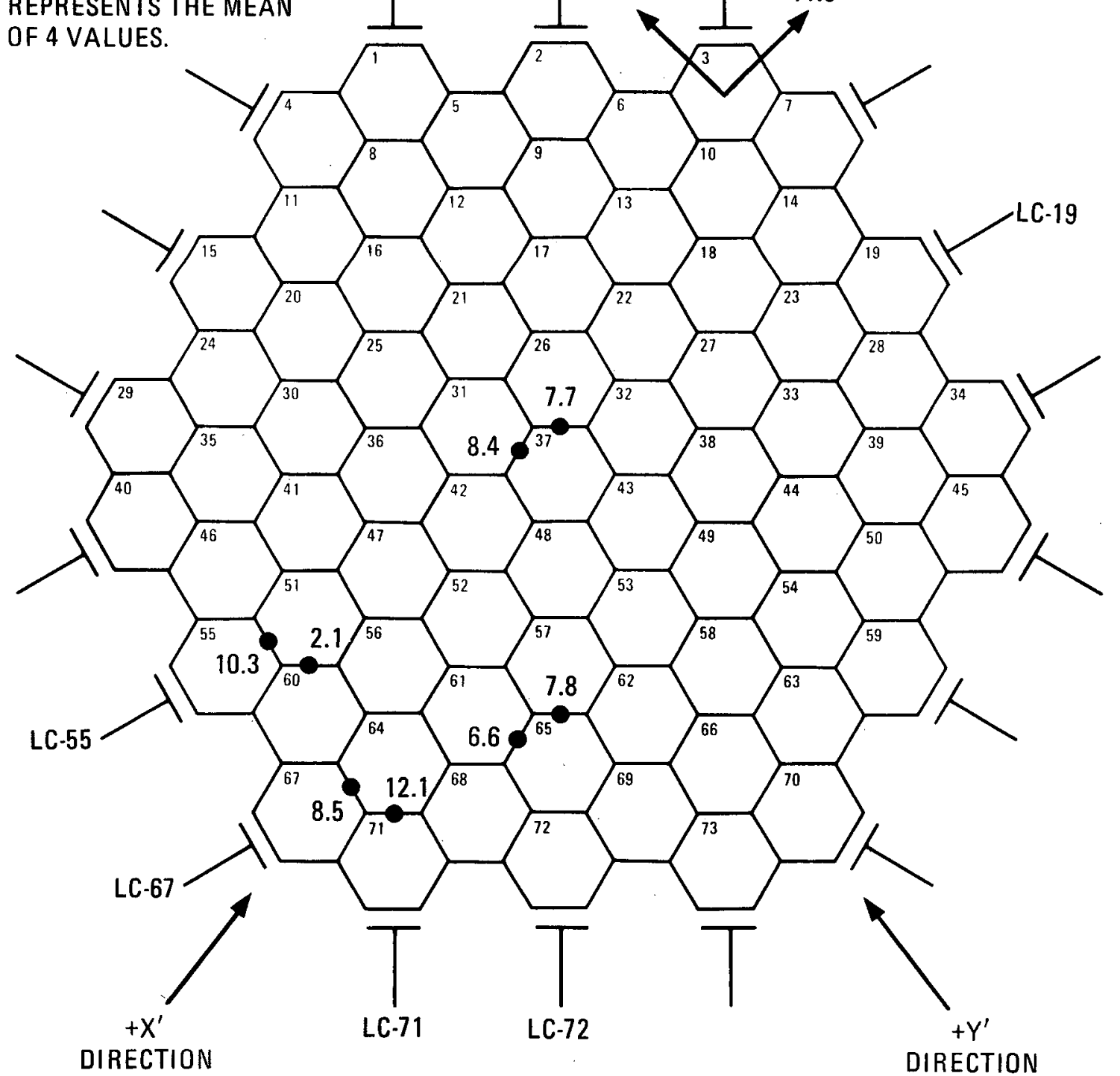

*AVERAGE OF 3 LARGEST VALUES WITHIN 1 Hz OF RESONANCE

Fig. 7-13. Distribution of velocity (peak average) at resonance, $\phi=90^{\circ}$ 


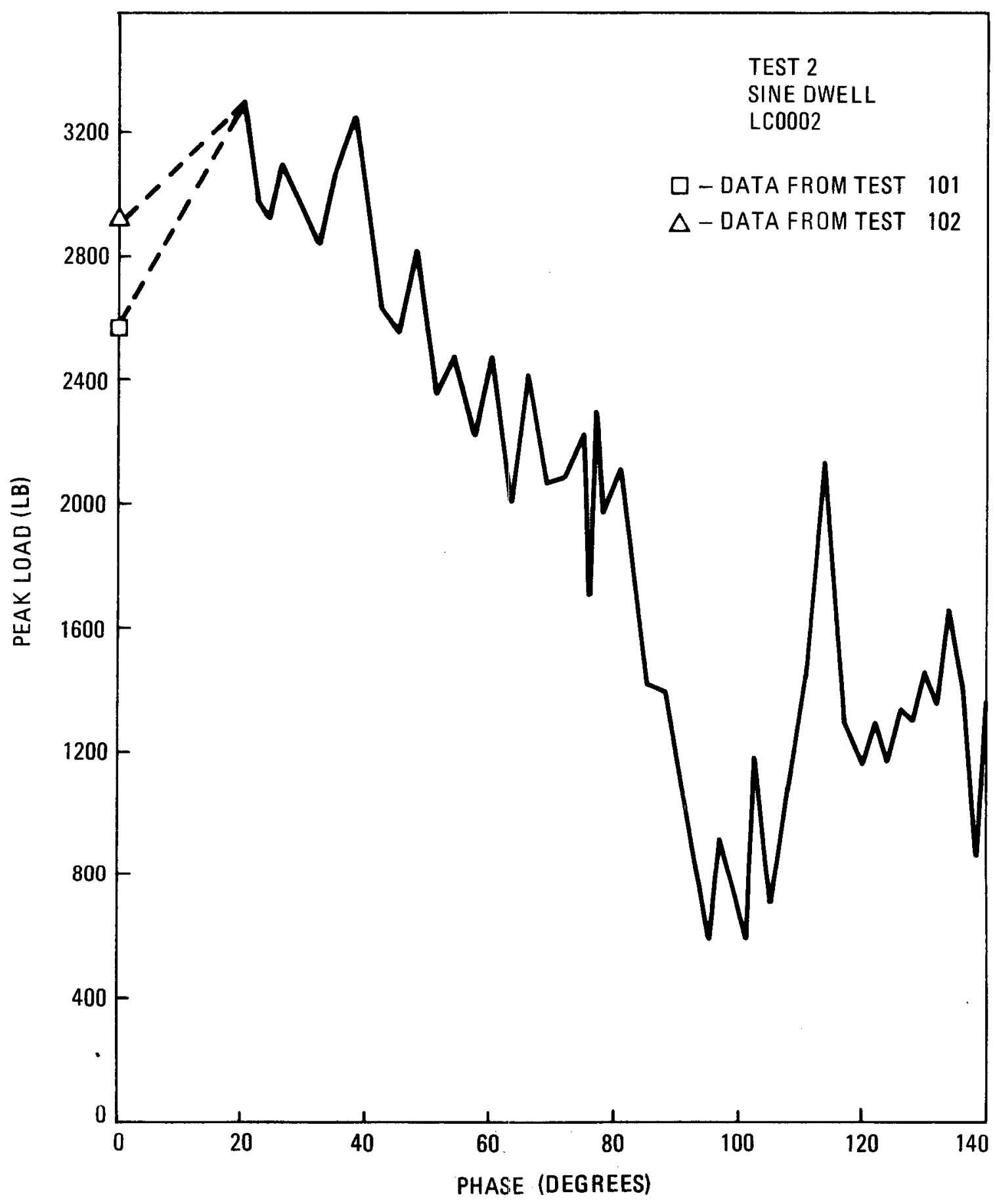

Fig. 7-14. Boundary support force, LC002 (peak average) versus phase angle 


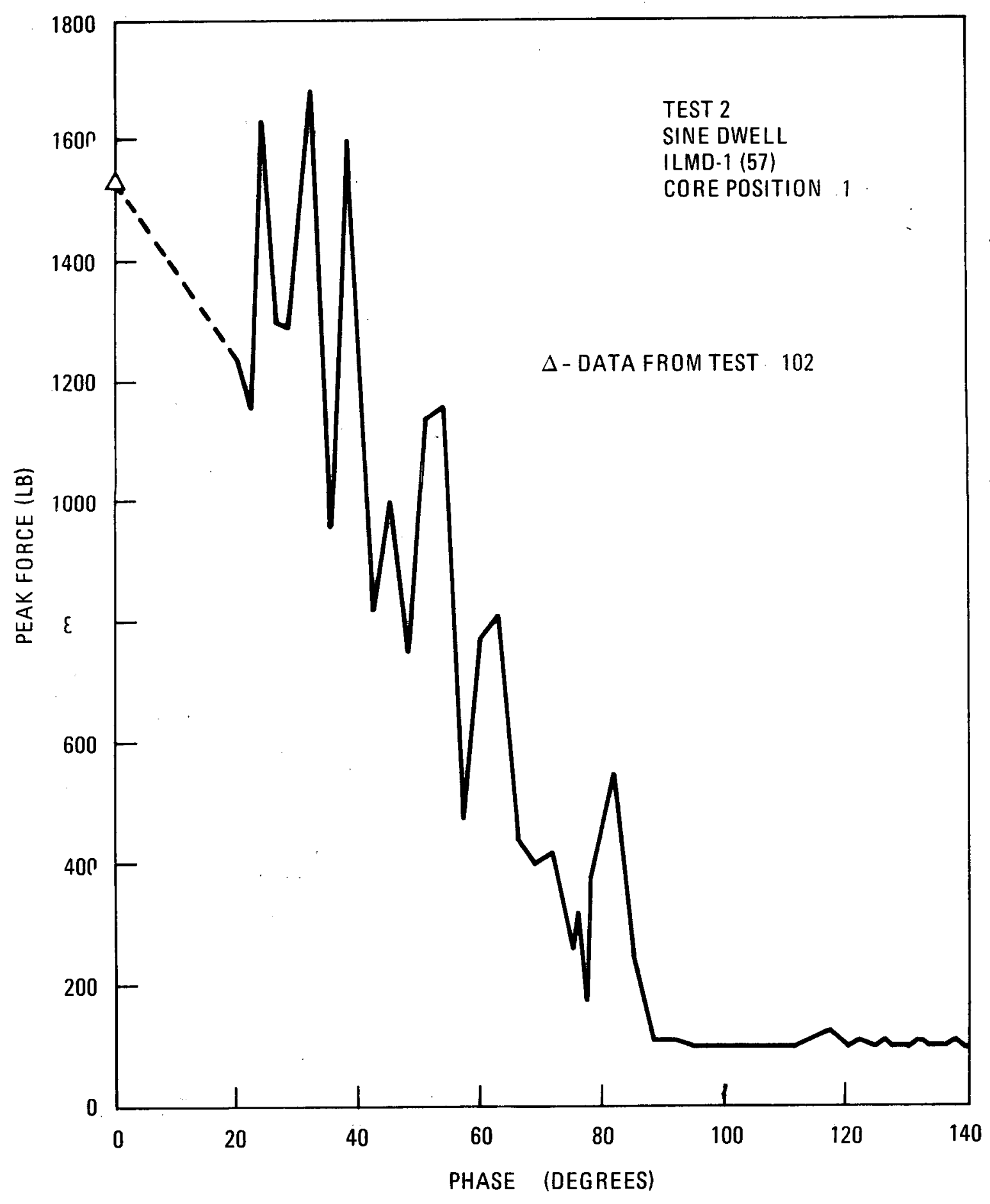

Fig. 7-15. In-core force, ILMD-1 (peak average), versus phase angle 


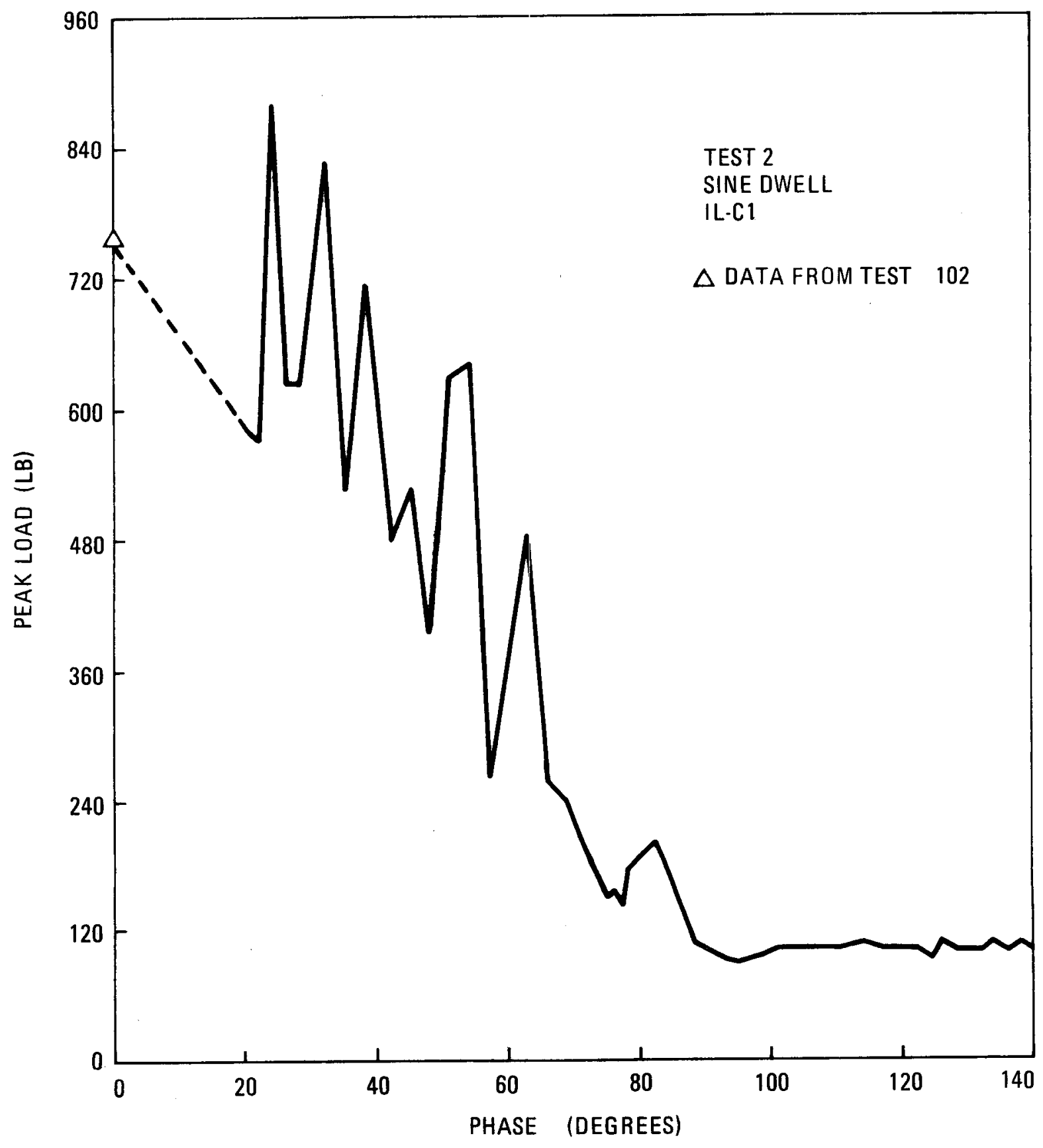

Fig. 7-16. In-core force, IL-C1 (peak average), versus phase angle 


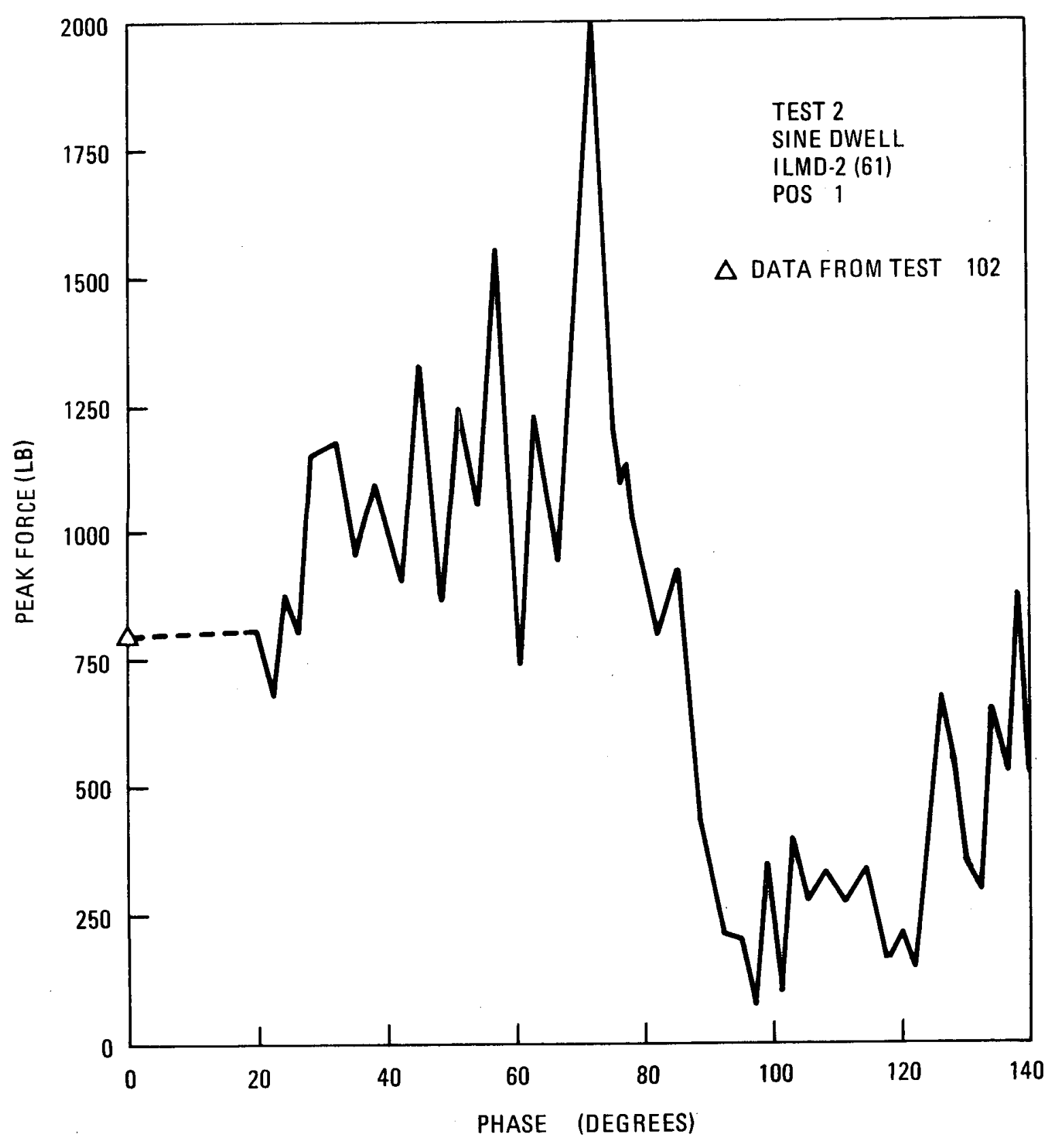

Fig. 7-17. In-core force, ILMD-2 (peak average), versus phase angle 


\subsection{TIME HISTORY RESPONSE}

The core response to time history excitation is represented by the GA synthesized design earthquake (shock 3) and E1 Centro shock 9 at $0.355 \mathrm{~g}$ equivalent ground acceleration as described in Section 5.2. The data reduction was performed with program THPEAK, which prints out the overall maximum peak response value during the earthquake.

Maximum relative velocities and forces at the core supports and incore for shocks 3 and 9 representing in-phase motion (correlation coefficlent equal to 1.0 ) between the $X^{\prime}$ and $Y^{\prime}$ axes are shown in Figs. 7-18 through 7-21. It is seen that the GA design earthquake generally produces a higher response.

The response from out-of-phase excitation, shown in Figs. 7-22 through 7-29, represents correlation coefficients of $0.0,0.25,0.50$, and 0.75 . Their corresponding time lags are given in Section 5.2. As for sinusoidal excitation input, it is shown that maximum response generally occurs for in-phase excitation.

Also included in this data selection are the velocity and face response at $0.1775 \mathrm{~g}$ ground acceleration (Figs. 7-30 and 7-31). As expected, the response was roughly cut in half.

\subsection{COMPARISON BETWEEN SINGLE-AXIS AND TWO-AXIS TESTS}

Comparisons between single-axis test results (Ref. 2) and two-axis results were made possible by arranging in-phase two-axis input to correspond to equivalent single-axis input. Thus, for sine sweep:

$$
\overrightarrow{0.53} \ddot{X^{\prime}}+\overrightarrow{0.53} \ddot{Y}^{\prime}=\overrightarrow{0.75} \ddot{X^{\prime}} \ddot{Y^{\prime}} \text { (fixture acceleration), }
$$

and time history:

$$
\overrightarrow{0.355} \ddot{X}^{\prime}+\overrightarrow{0.355} \ddot{Y}^{\prime}=\overrightarrow{0.5} \ddot{X}^{\prime} \ddot{Y}^{\prime} \text { (ground acceleration). }
$$


1/2-SCALE 2D TEST RESULTS

${ }^{*}$ MAX FORCE DISTRIBUTION

(LB)

TIME HISTORY

SHOCK $3, g=0.71$

CORRELATION $=1.0$

TEST $103 / 104$

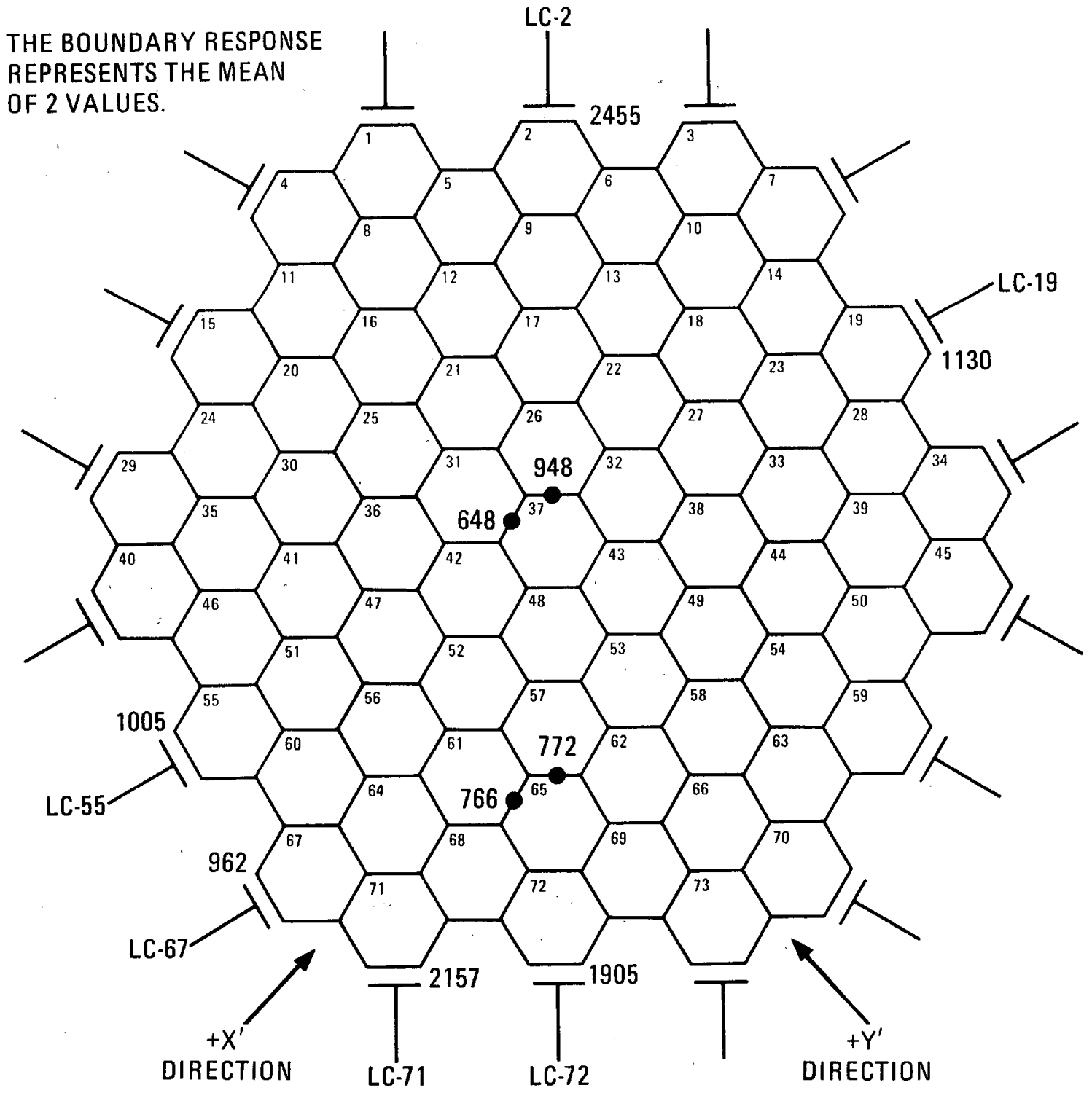

*AVERAGE OF 3 LARGEST VALUES WITHIN $1 \mathrm{~Hz}$ OF RESONANCE

Fig. 7-18. Distribution of maximum force, shock 3, correlation $=1.0$ 
1/2.SCALE 2D TEST RESULTS

*MAX VELOCITY DISTRIBUTION

(IPS)

TIME HISTORY

SHOCK $3, g=0.71$

CORRELATION $=1.0$

TEST $103 / 104$

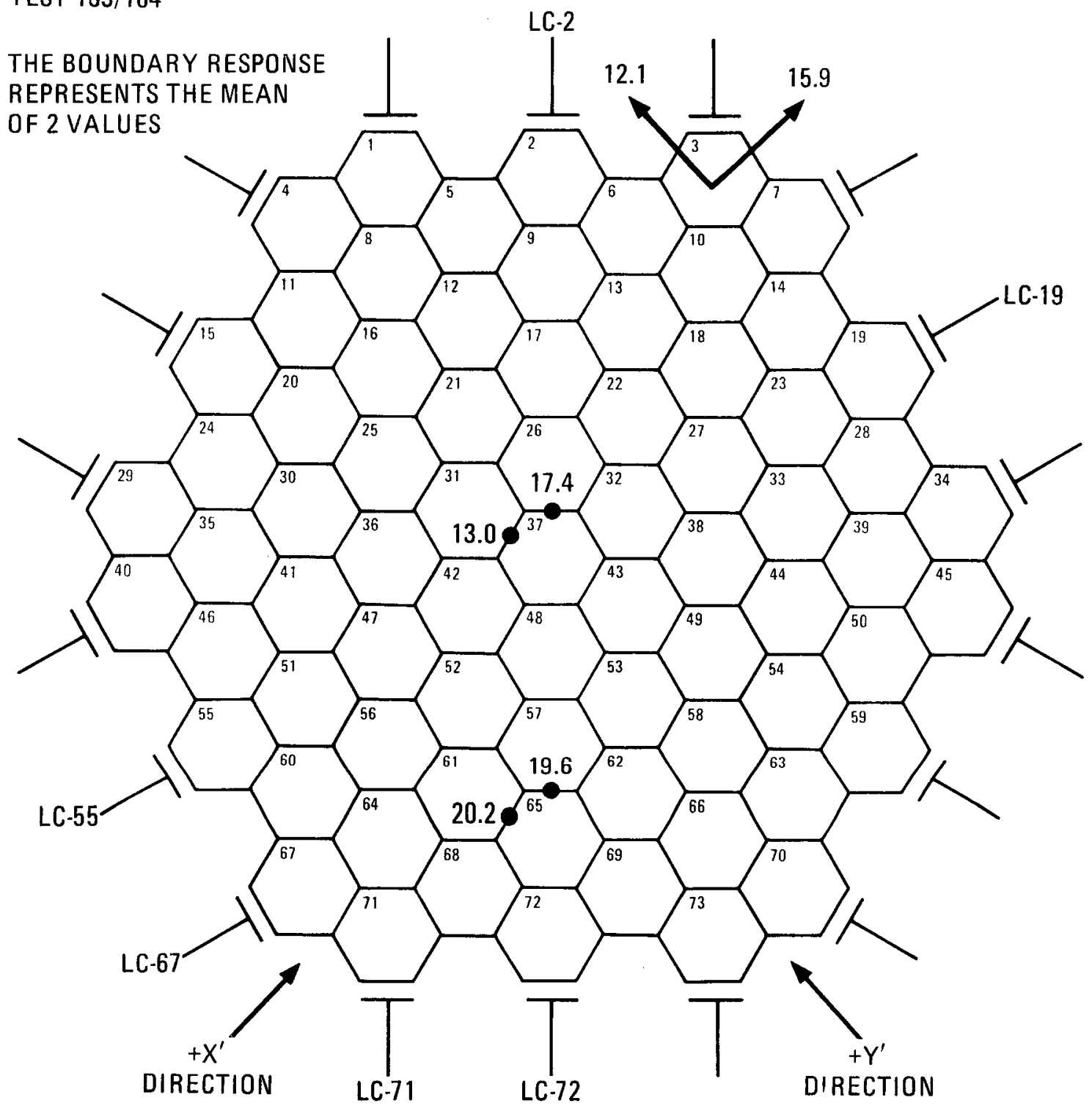

*AVERAGE OF 3 LARGEST VALUES WITHIN 1 Hz OF RESONANCE

Fig. 7-19. Distribution of maximum velocity, shock 3, correlation $=1.0$ 
1/2-SCALE 2D TEST RESULTS

* MAX FORCE DISTRIBUTION

(LB)

TIME HISTORY

SHOCK $9, g=0.71$

CORRELATION $=1.0$

TEST $103 / 104$

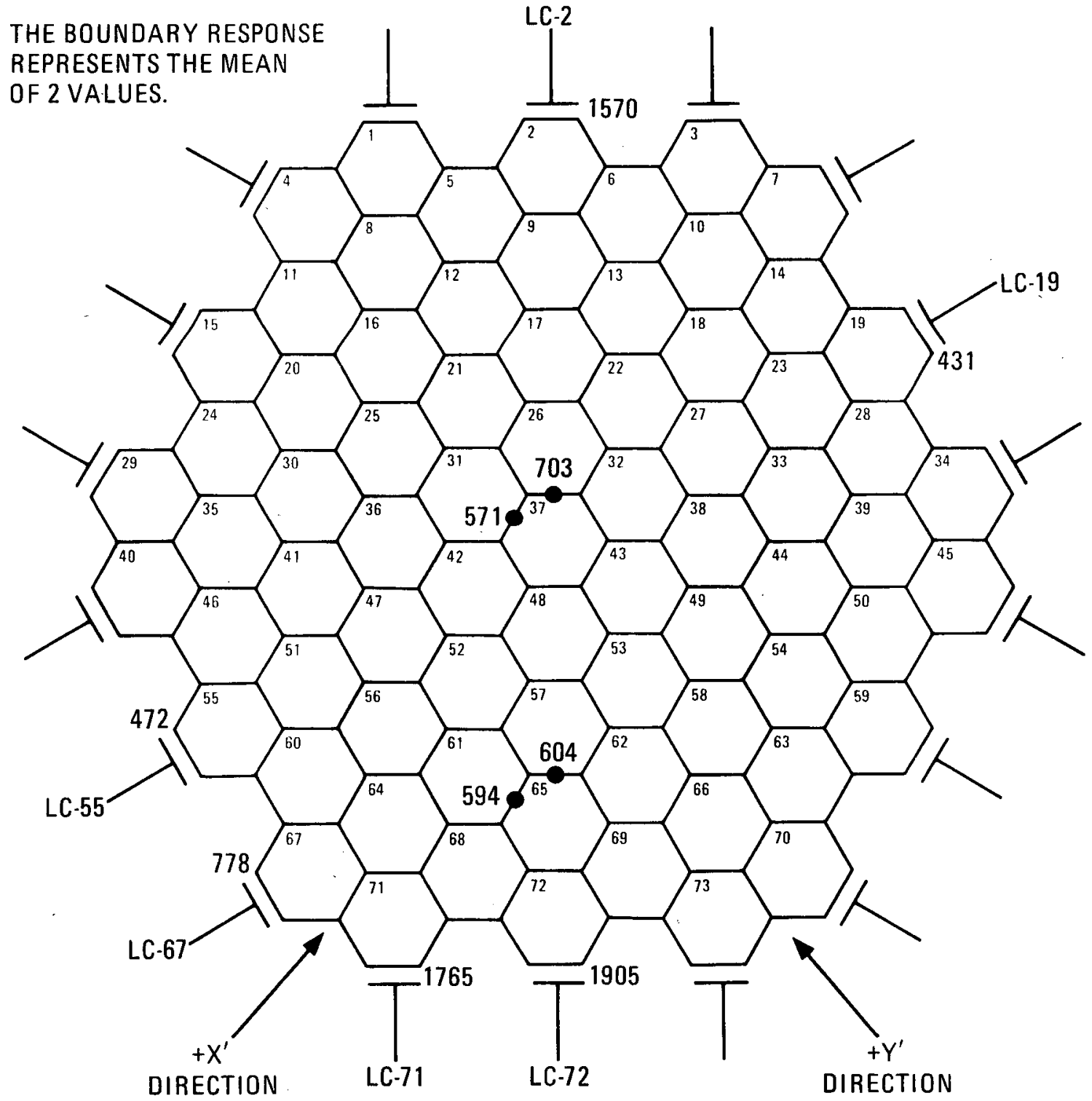

*AVERAGE OF 3 LARGEST VALUES WITHIN 1 . Hz OF RESONANCE

Fig. 7-20. Distribution of maximum force, shock 9, correlation $=1.0$ 
1/2-SCALE 2D TEST RESULTS

*MAX VELOCITY DISTRIBUTION

(IPS)

TIME HISTORY

\section{SHOCK $9, g=0.71$}

CORRELATION $=1.0$

\section{TEST $103 / 104$}

THE BOUNDARY RESPONSE REPRESENTS THE MEAN OF 2 VALUES.

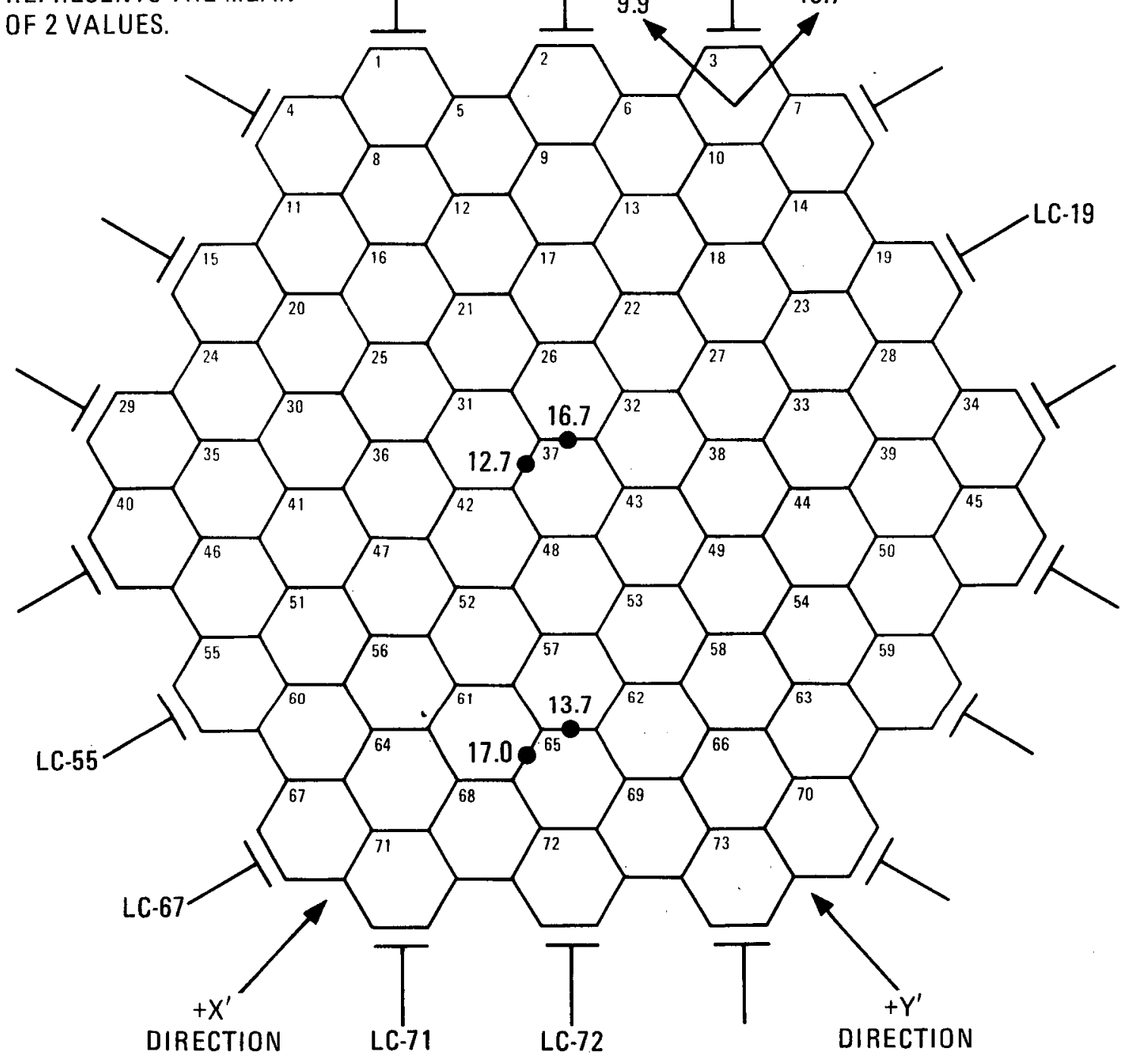

*AVERAgE OF 3 LARgeSt VAlUES WITHIN 1 Hz OF RESONANCE

Fig. 7-21. Distribution of maximum velocity, shock 9 , correlation $=1.0$ 
1/2-SCALE $2 D$ TEST RESULTS

*MAX FORCE DISTRIBUTION

(LB)

TIME HISTORY

\section{SHOCK $3, g=0.71$}

CORRELATION $=0.0$

TESTS $11,13,23,33,34,43 \& 44$

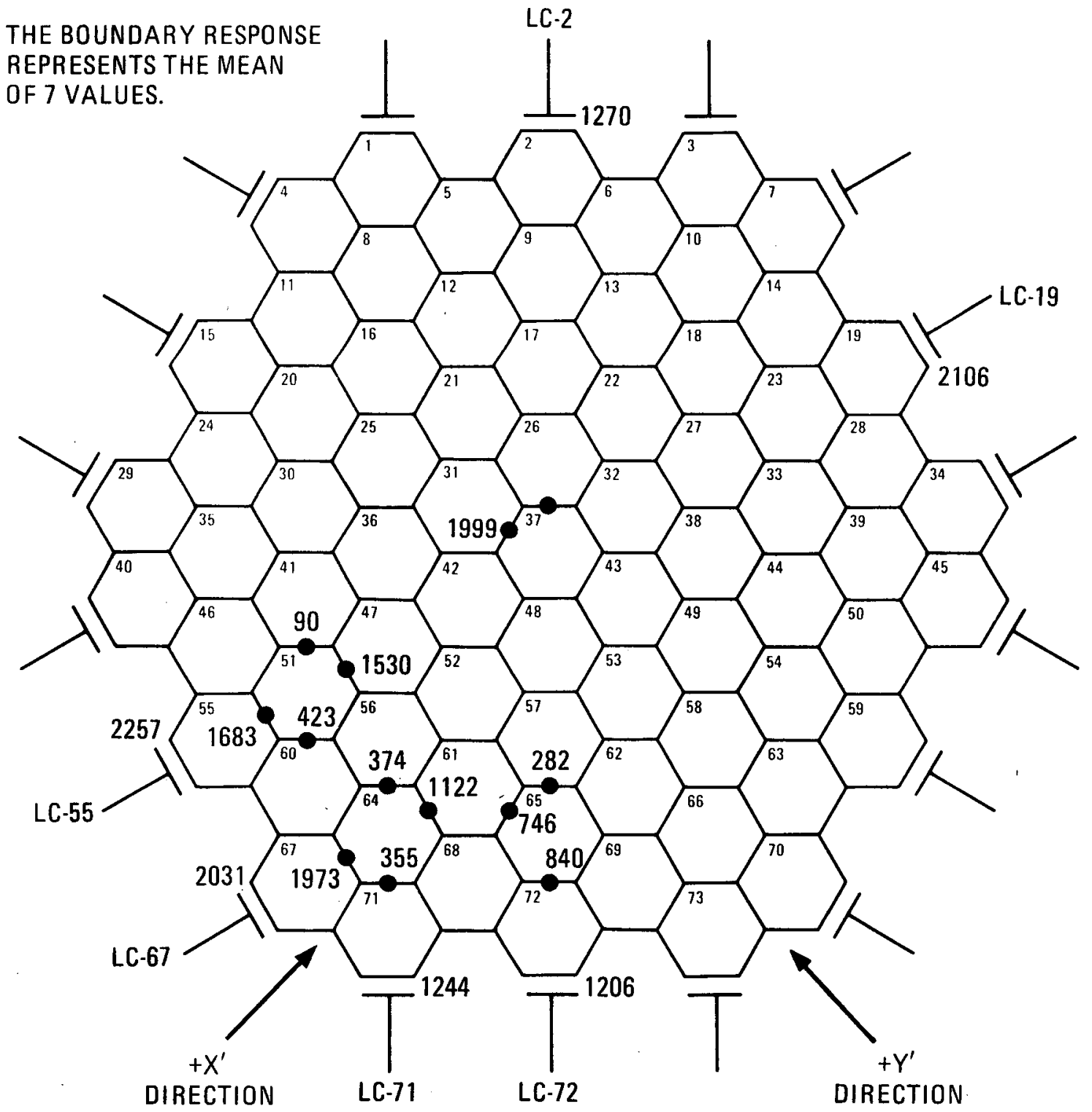

*AVERAGE OF 3 LARGEST VALUES WITHIN $1 \mathrm{~Hz}$ OF RESONANCE

Fig. 7-22. Distribution of maximum force, shock 3, correlation $=0.0$ 
1/2-SCALE 2D TEST RESULTS

*MAX VELOCITY DISTRIBUTION

(IPS)

TIME HISTORY

SHOCK $3, \mathrm{~g}=0.71$

CORRELATION $=0.0$

TESTS $11,13,22,33,34,43 \& 44$

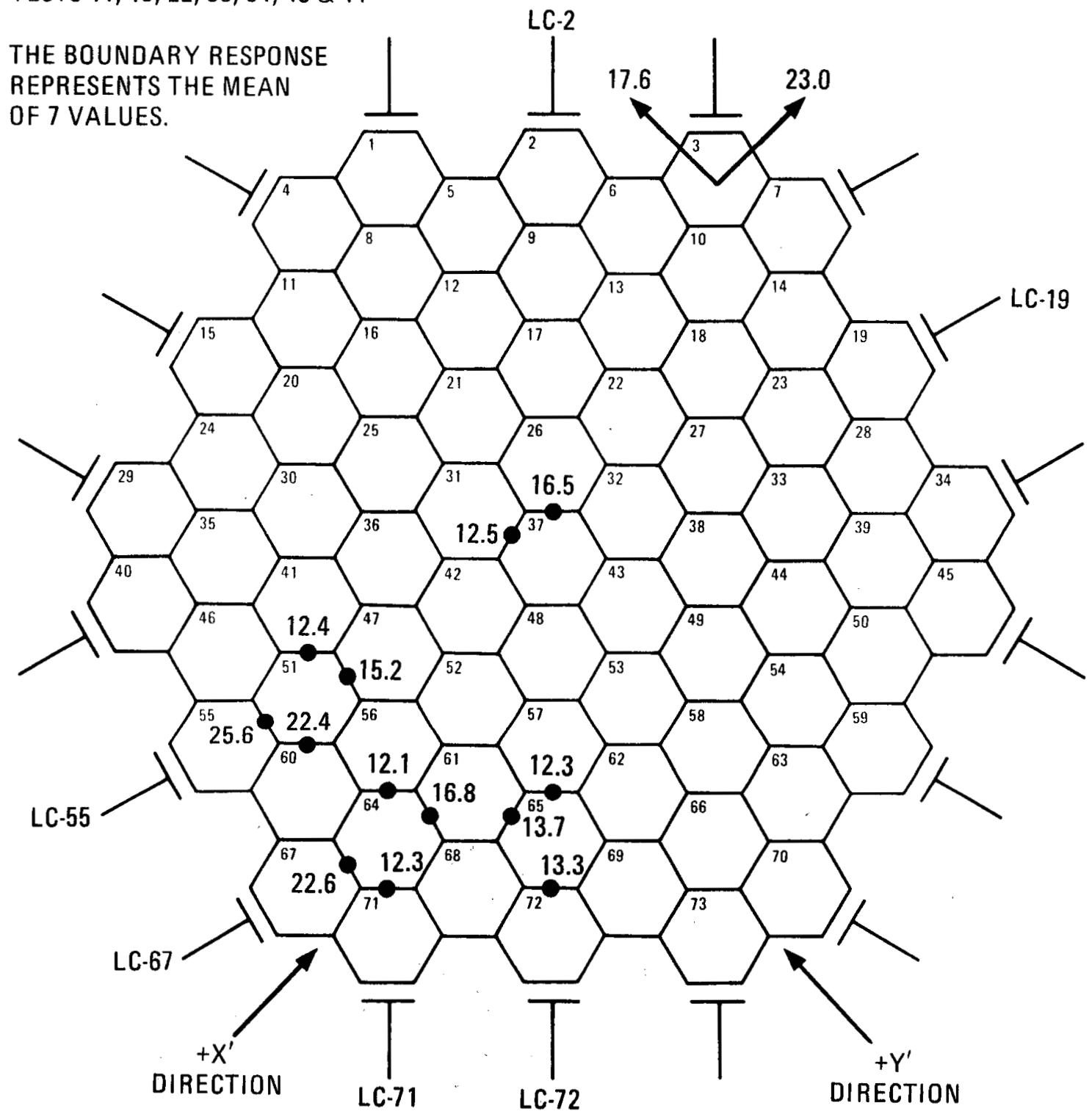

*AVERAGE OF 3 LARGEST VALUES WITHIN $1 \mathrm{~Hz}$ OF RESONANCE

Fig. 7-23. Distribution of maximum velocity, shock 3 , correlation $=0.0$ 
1/2-SCALE 2D TEST RESULTS

*MAX FORCE DISTRIBUTION

(LB)

TIME HISTORY

SHOCK $3, g=0.71$

CORRELATION $=0.25$

TESTS 7, 9, 20, 30, 31, $40 \& 41$

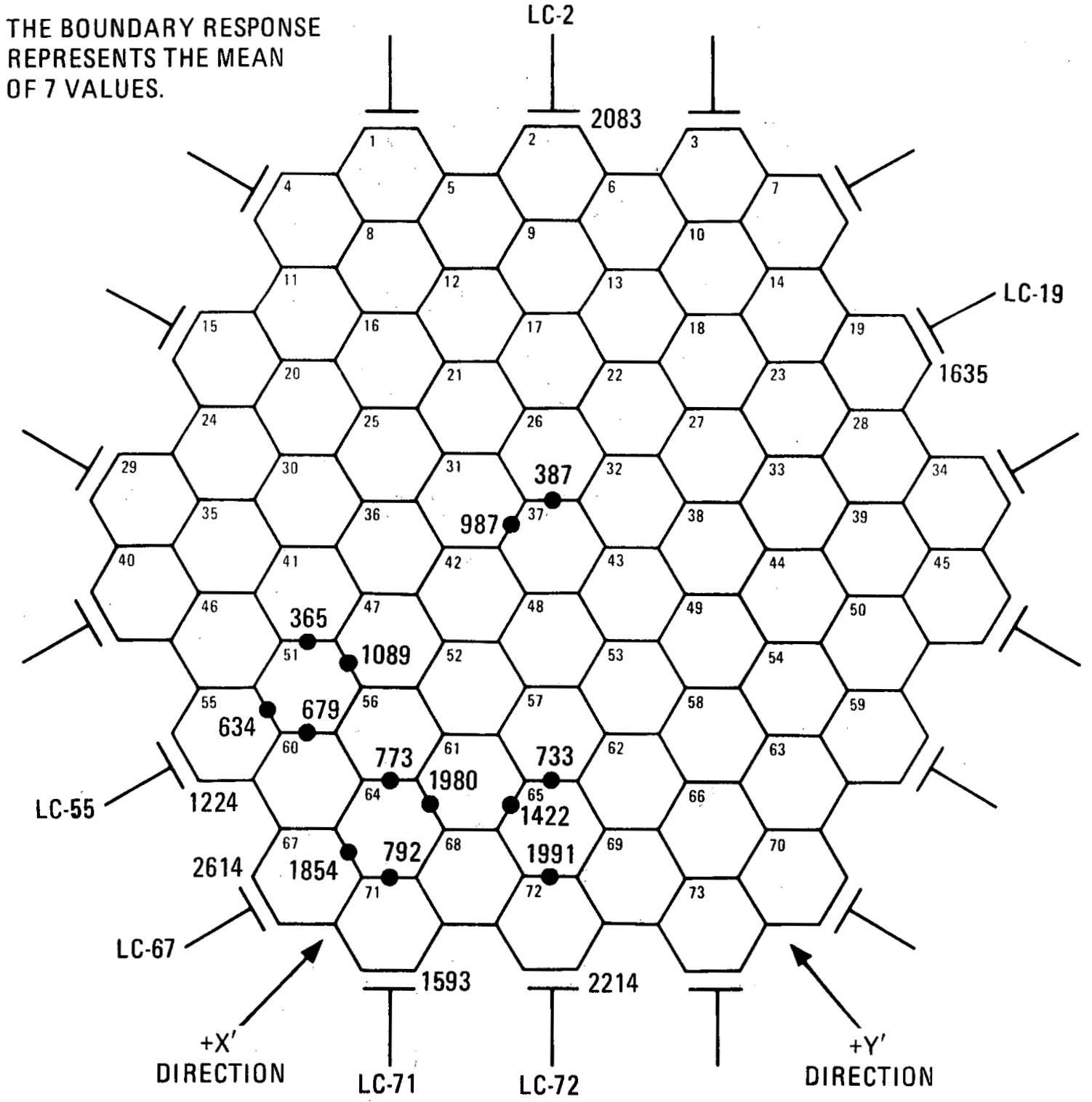

*AVERAGE OF 3 LARGEST VALUES WITHIN $1 \mathrm{~Hz}$ OF RESONANCE

Fig. 7-24. Distribution of maximum force, shock 3, correlation $=0.25$ 


\section{1/2-SCALE 2D TEST RESULTS}

*MAX VELOCITY DISTRIBUTION

(IPS)

TIME HISTORY

SHOCK $3, g=0.71$

CORRELATION $=0.25$

TESTS $7,9,20,30,31,40 \& 41$

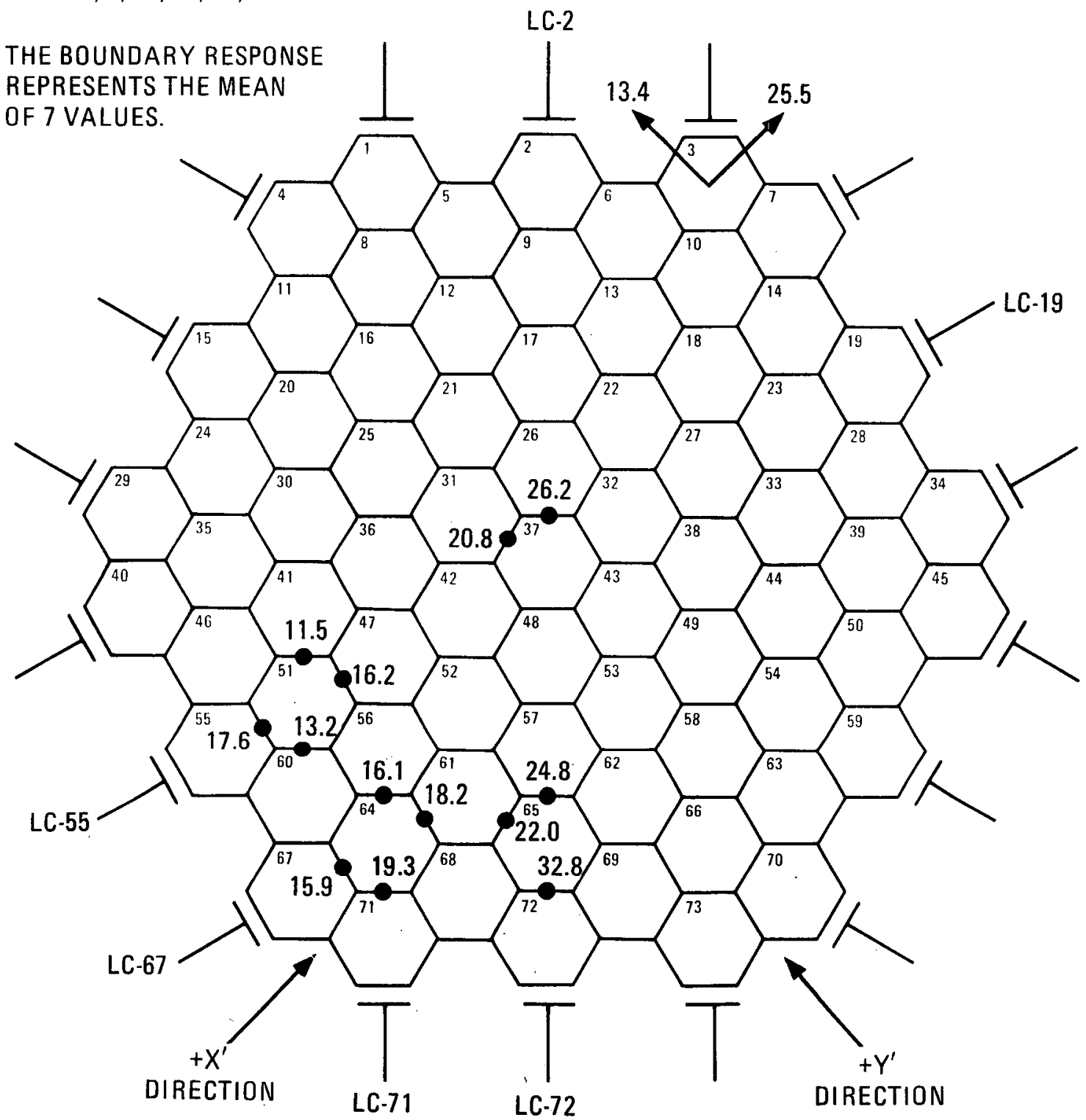

*AVERAGE OF 3 LARGEST VALUES WITHIN 1 IHz OF RESONANCE

7-25. Distribution of maximum velocity, shock 3 , correlation $=0.25$ 


\section{1/2-SCALE 2D TEST RESULTS}

*MAX FORCE DISTRIBUTION

(LB)

\section{TIME HISTORY}

SHOCK $3, g=0.71$

CORRELATION $=0.50$

TESTS $5,18,28 \& 38$

THE BOUNDARY RESPONSE

REPRESENTS THE MEAN.

OF 4 VALUES.

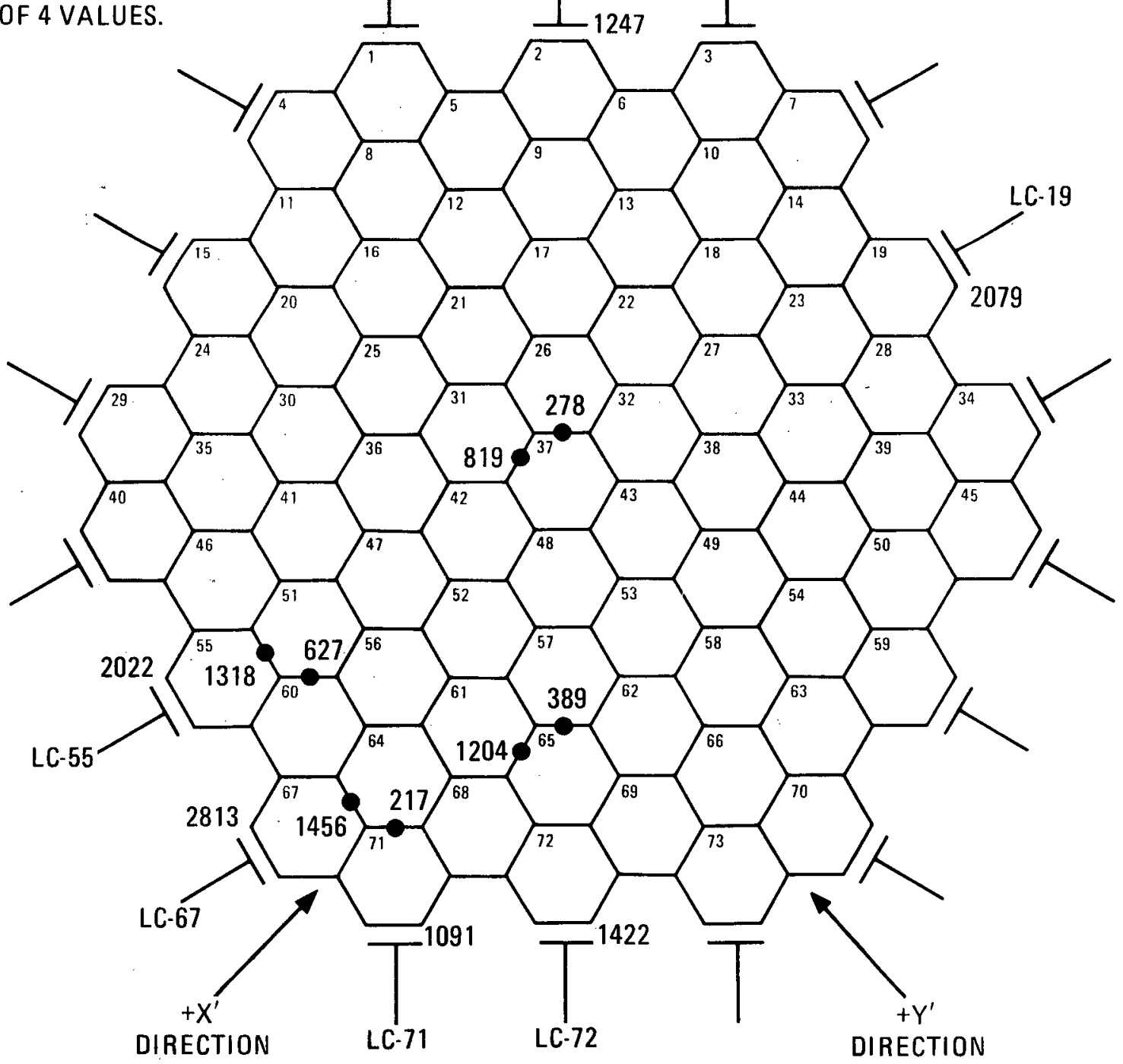

*AVERAGE OF 3 LARGEST VALUES WITHIN $1 \mathrm{~Hz}$.F RESONANCE

Fig. 7-26. Distribution of maximum force, shock 3, correlation $=0.50$ 
TIME HISTORY

SHOCK, $g=0.71$

CORRELATION $=0.50$

TESTS $5,18,28 \& 38$

THE BOUNDARY RESPONSE REPRESENTS THE MEAN OF 4 VALUES.

\section{LC-2}

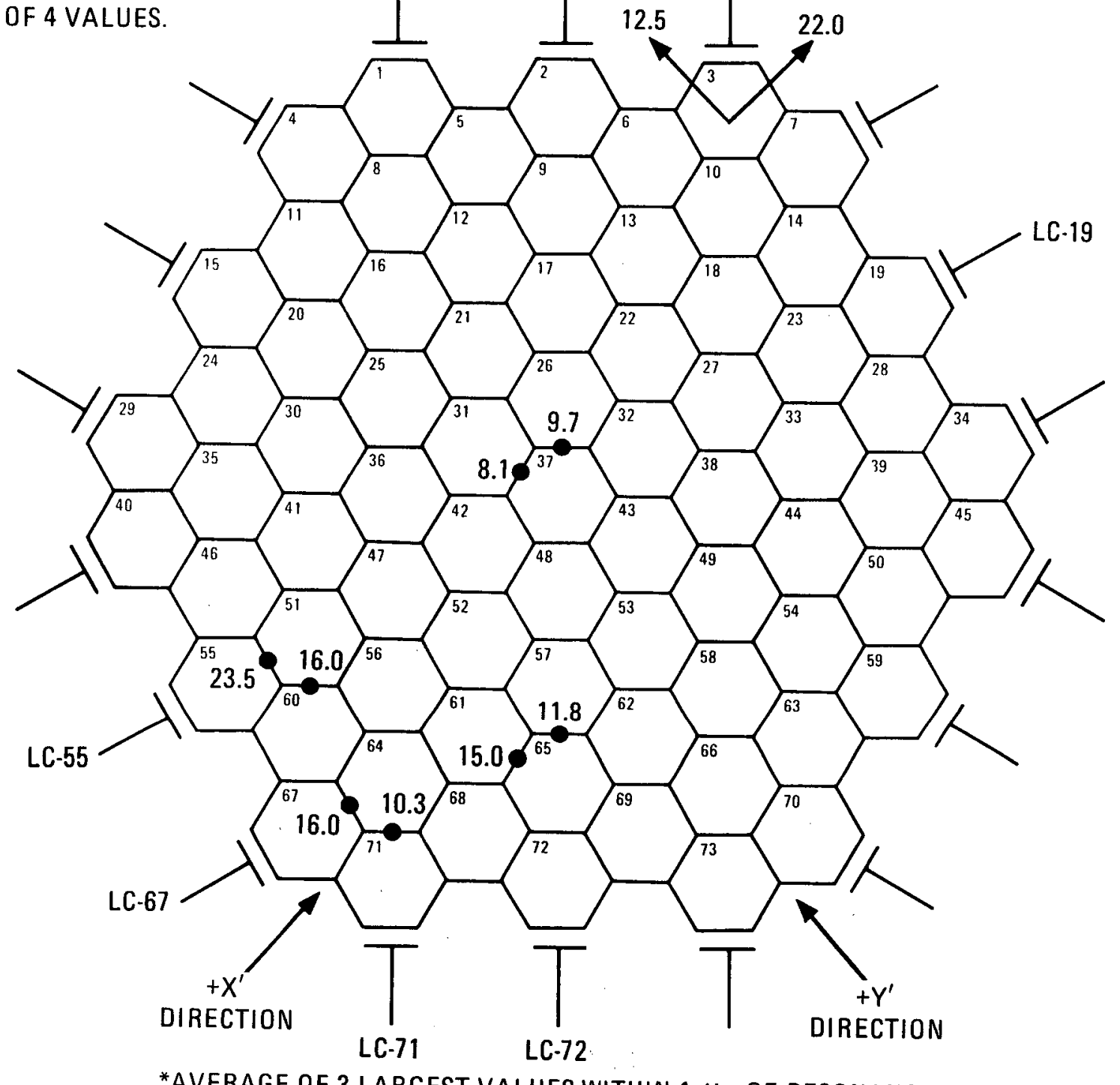

*AVERAGE OF 3 LARgEST VALUES WITHIN $1 \mathrm{~Hz}$.F RESONANCE

Fig. 7-27. Distribution of maximum velocity, shock 3 , correlation $=0.50$ 
1/2-SCALE 2D TEST RESULTS

*MAX FORCE DISTRIBUTION

(LB)

TIME HISTORY

SHOCK $3, g=0.71$

CORRELATION $=0.75$

TESTS $3,16,26 \& 36$

THE BOUNDARY RESPONSE

REPRESENTS THE MEAN

OF 4 VALUES.

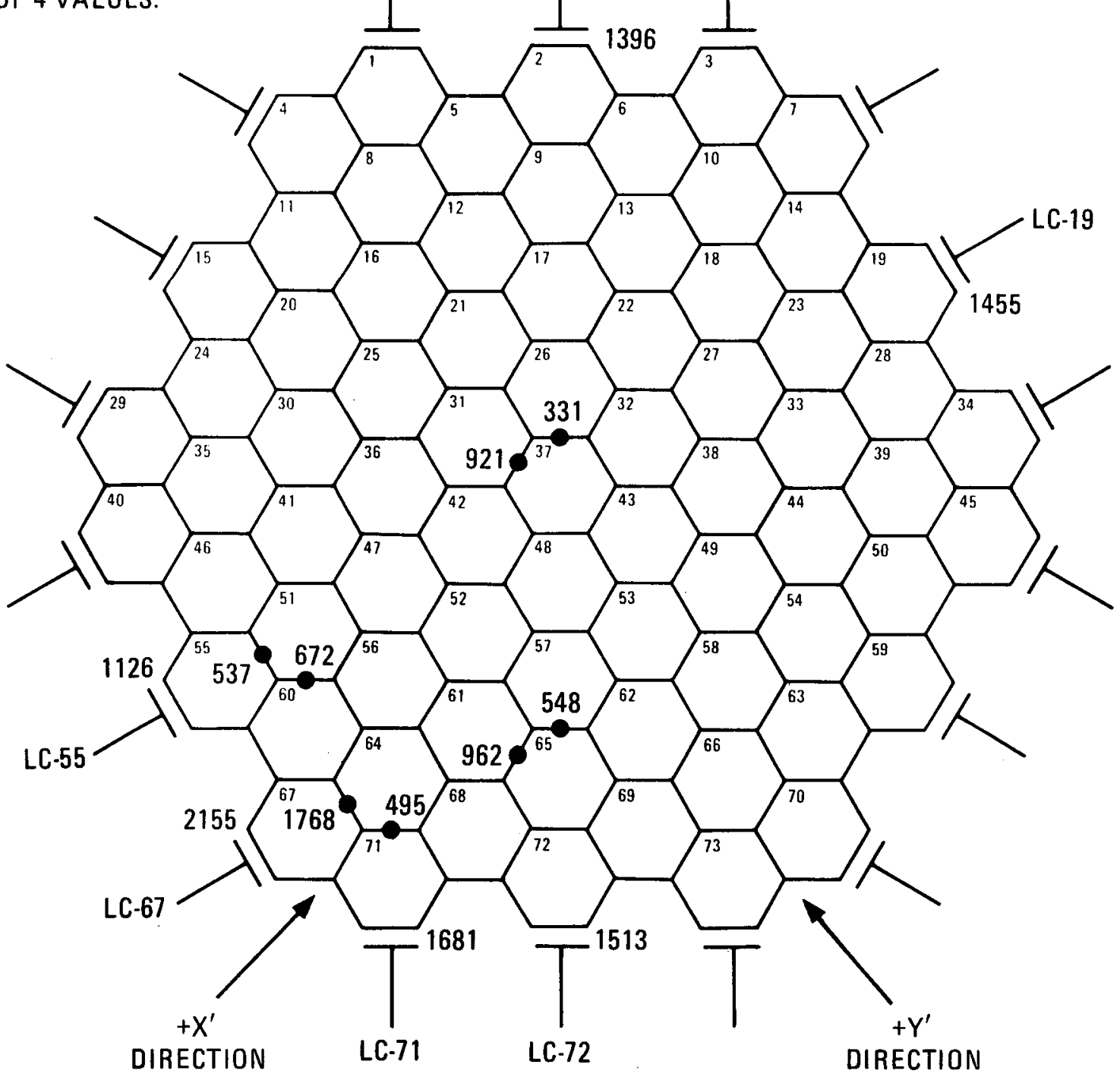

*AVERAGE OF 3 LARGEST VALUES WITHIN $1 \mathrm{~Hz}$ OF RESONANCE

Fig. 7-28. Distribution of maximum force, shock 3, correlation $=0.75$ 


\section{1/2 SCALE 2D TEST RESULTS}

*MAX VELOCITY DISTRIBUTION

(IPS)

TIME HISTORY

SHOCK $3, g=0.71$

CORRELATION $=0.75$

TESTS $3,16,26 \& 36$

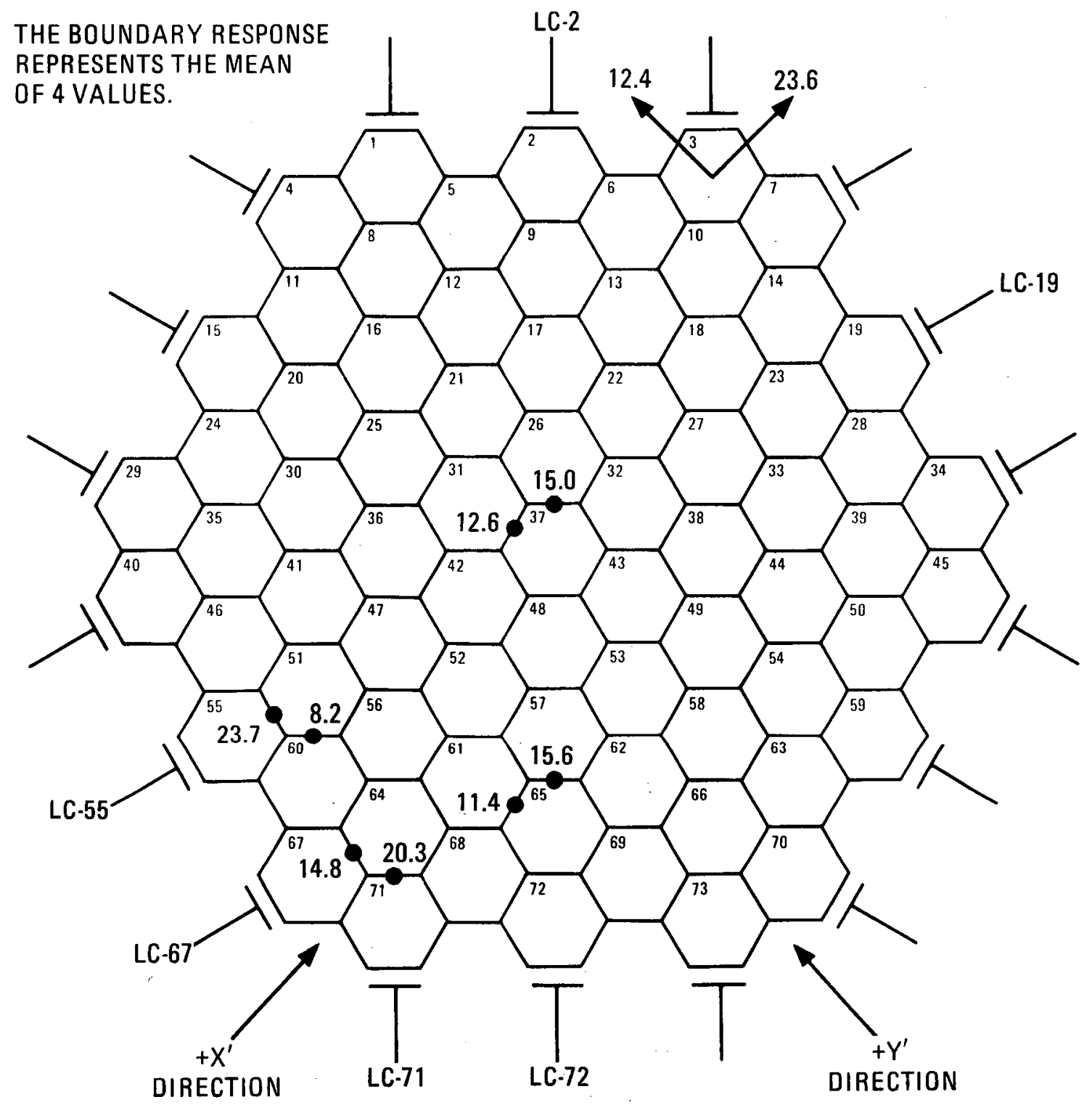

*AVERAGE OF 3 LARGEST VALUES WITHIN $1 \mathrm{~Hz}$ OF RESONANCE

Fig. 7-29. Distribution of maximum velocity, shock 3, correlation $=0.75$ 
1/2-SCALE 2D TEST RESULTS

*MAX FORCE DISTRIBUTION

(LB).

TIME HISTORY

SHOCK $3, g=0.35$

CORRELATION $=0.0$

TESTS $12 \& 24$

THE BOUNDARY RESPONSE REPRESENTS THE MEAN OF 2 VALUES.

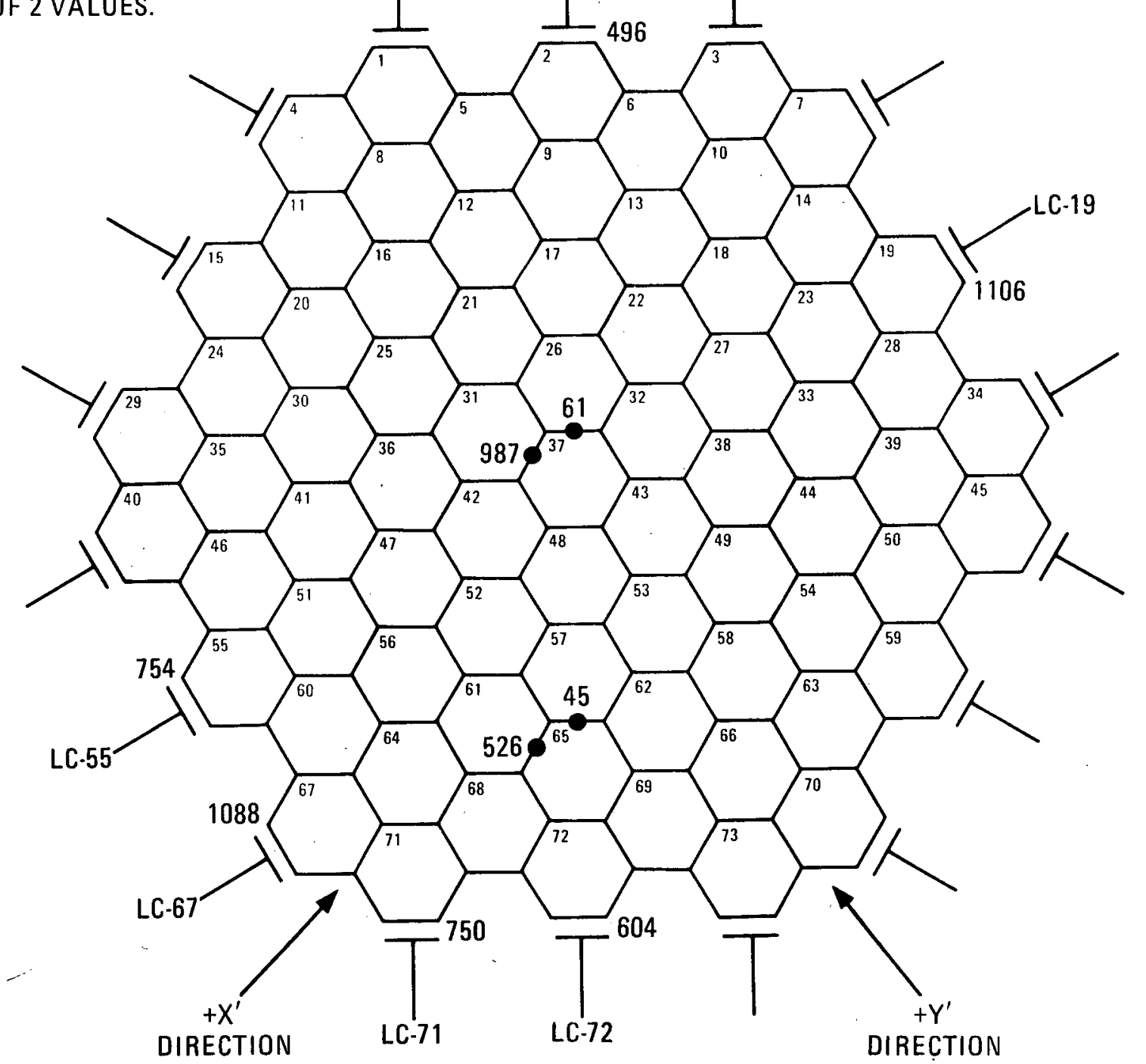

*AVERAGE OF 3 LARGEST VALUES WITHIN 1 ! Hz OF RESONANCE

Fig. 7-30. Distribution of maximum force $0.1775 \mathrm{~g}$, shock 3, correlation $=0.0$ 
TIME HISTORY

SHOCK 3, $\mathrm{a}=0.35$

CORRELATION $=0.0$

TESTS $12 \& 24$

THE BOUNDARY RESPONSE REPRESENTS THE MEAN

OF 2 VALUES.

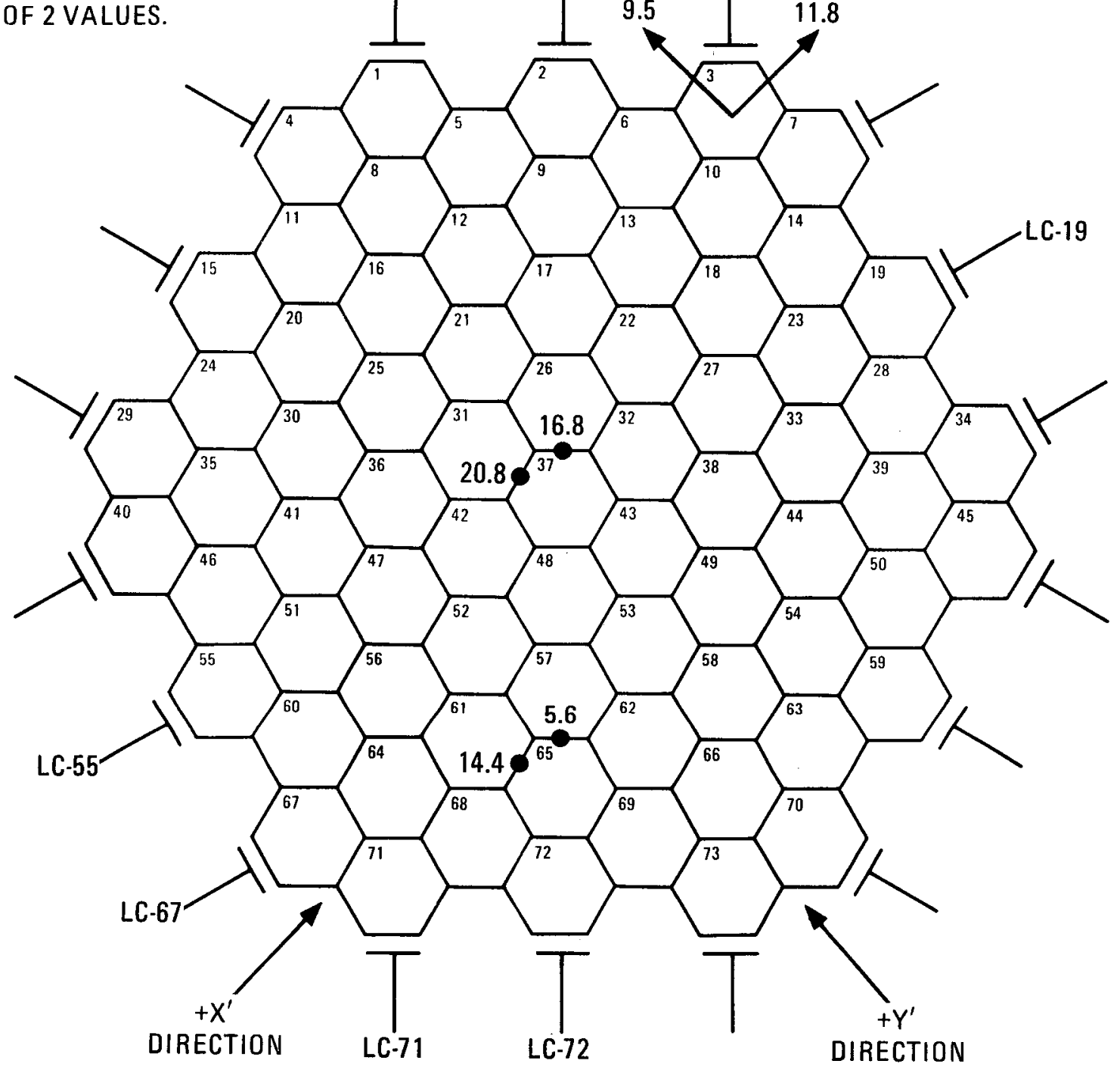

*AVERAGE OF 3 LARgEST VALUES WITHIN 1 Hz OF RESONANCE

Fig. 7-31. Distribution of maximum velocity, $0.1775 \mathrm{~g}$, shock 3 , correlation $=0.0$ 
From Ref. 2, the resonant frequency from single-axis sine sweep excitation was $7.4 \mathrm{~Hz}$ for a $0.5 \mathrm{in}$. gap compared with $6.6 \mathrm{~Hz}$ for two-axis excitation. A comparison of maximum boundary support forces and in-core element forces and velocities near resonance is shown in Fig. 7-32. Fairly good agreement is shown between the tests. Figures 7-33 and 7-34 show comparisons between time history tests (shocks 3 and 9). The results from shock 9 agree closely, but boundary support forces for shock 3 deviate somewhat.

It can be concluded, however, that the inaccuracies in these comparisons are of magnitudes comparable with the deviations in test data from repeated tests. On that basis, the agreement between the single-axis and the two-axis tests is acceptable. 
INPUT, FIXTURE ACCELERATION

SINGLE AXIS: $\quad X^{\prime} Y^{\prime}=0.75 \mathrm{~g}$

TWO AXES: $\quad X^{\prime}=Y^{\prime}=0.53 \mathrm{~g}$

SINE SWEEP

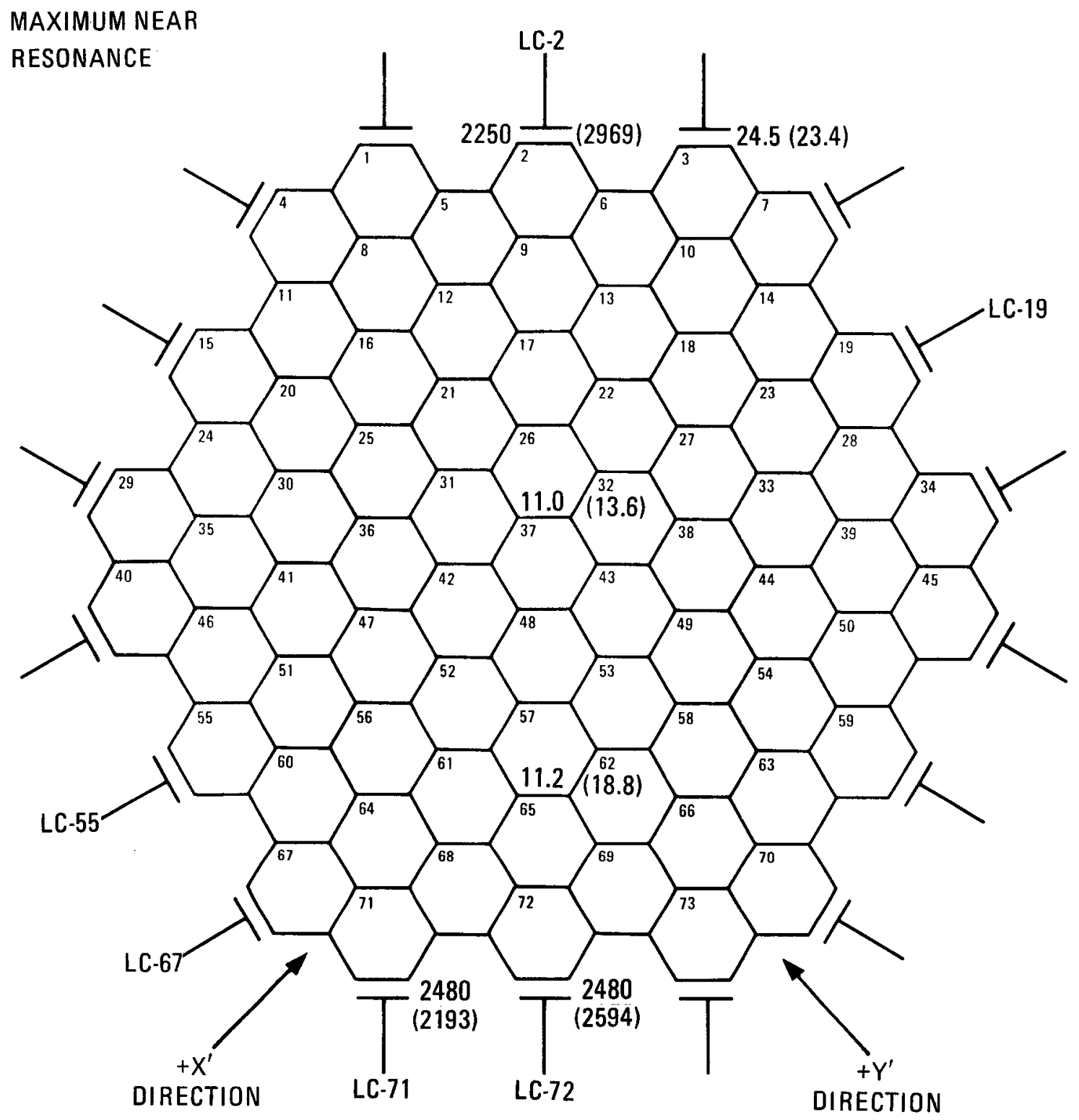

FORCES (LB) AND VELOCITIES (IPS)

SINGLE-AXIS TEST RESULTS ARE SHOWN IN PARENTHESES

Fig. 7-32. Comparison between 1/2-scale single-axis and two-axis tests, sine sweep 
INPUT, GROUND ACCELERATION

SING LE AXIS: $\quad X^{\prime} Y^{\prime}=0.5 \mathrm{~g}$

TWO AXES: $\quad X^{\prime}=Y^{\prime}=0.355 \mathrm{~g}$

EL CENTRO NO. 9

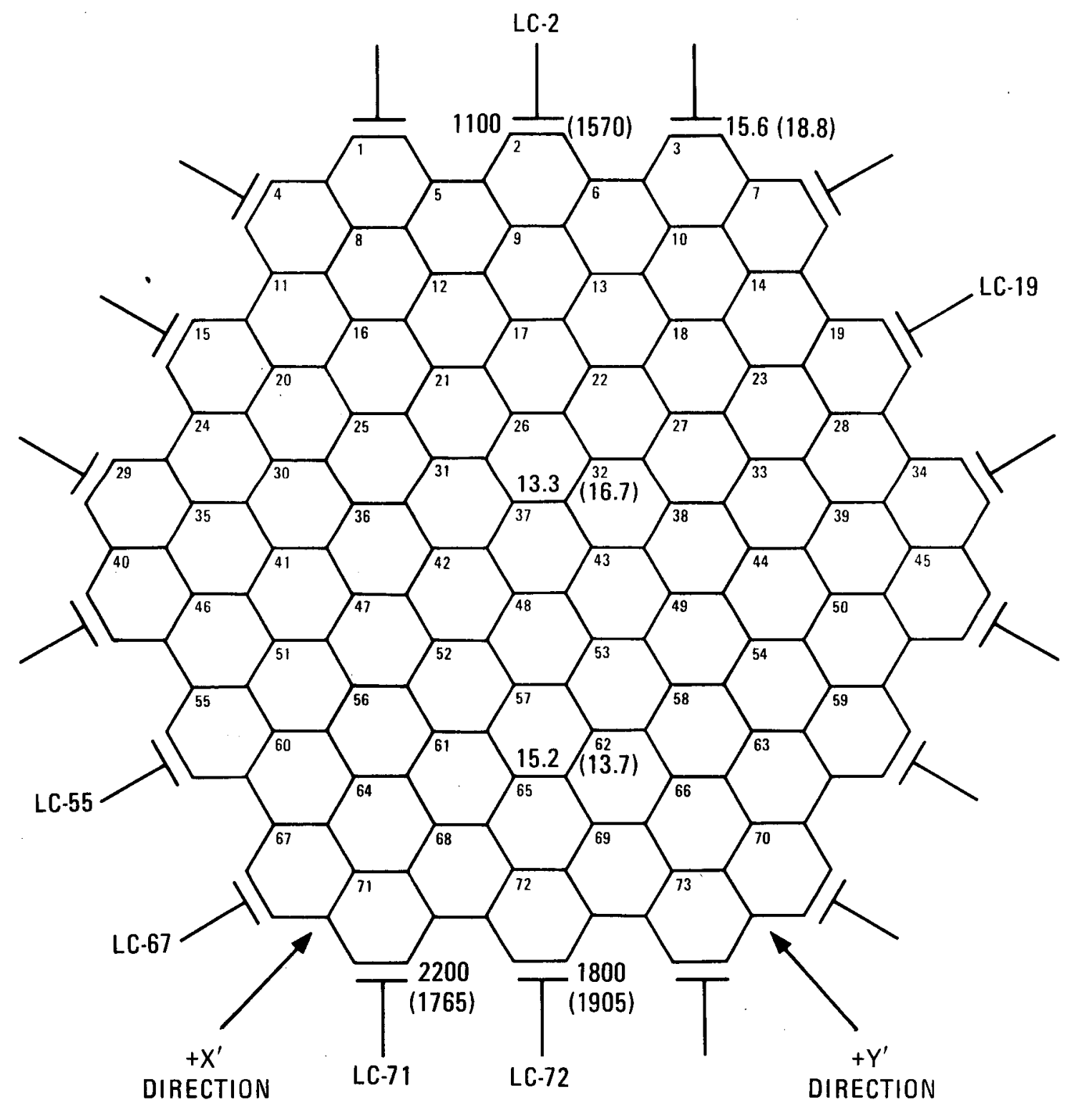

FORCES (LB) AND VELOCITIES (IPS)

SINGLE-AXIS TEST RESULTS ARE SHOWN IN PARENTHESES

Fig. 7-33. Comparison between 1/2-scale stngle-axis and two-axis tests, E1 Centro earthquake No. 9 
INPUT, GROUND ACCELERATION

SINGLE AXIS: $\quad X^{i} Y^{\prime}=0.5 \mathrm{~g}$

TWO AXES: $\quad X^{\prime}=Y^{\prime}=0.355 \mathrm{~g}$

GA NO. 3

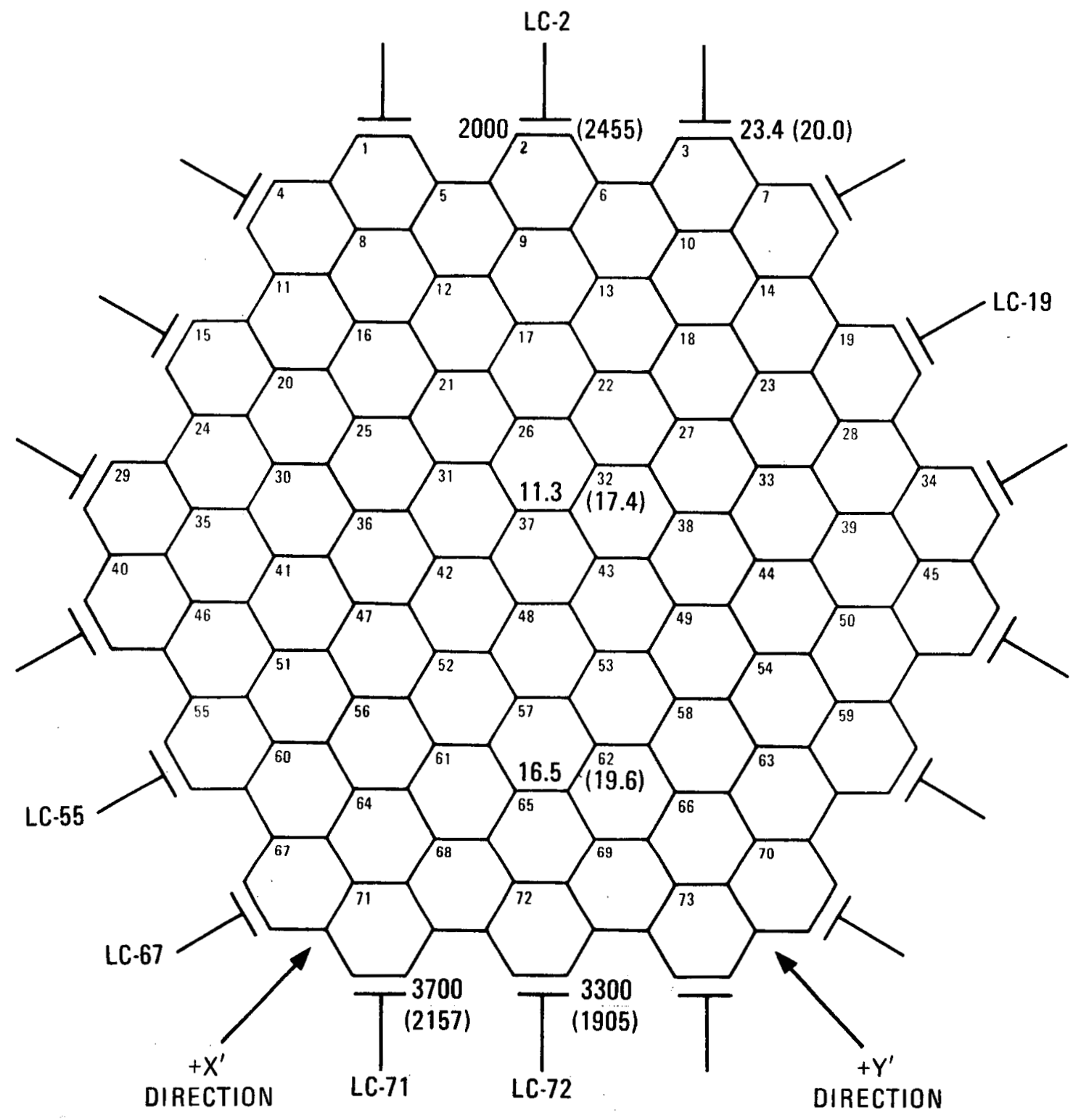

FORCES (LB) AND VELOCITIES (IPS)

SINGLE-AXIS TEST RESULTS ARE SHOWN IN PARENTHESES

Fig. 7-34. Comparison between 1/2-scale, single-axis and two-axis tests, GA design earthquake No. 3 


\section{ERRORS IN TEST DATA}

This section contains estimates of the random errors associated with the various test parameters recorded. The error analysis was conducted as outlined in Ref. 2 by estimating the effect on the response from identified error sources in the test system. These were then compounded by the RSS method to give total errors as shown in Table 8-1. All errors represent one standard deviation.

Since the test apparatus and instrumentation were basically the same as for the single axis test, most component errors were calculated to the same magnitude as in Ref. 2. An exception was the errors induced due to inaccuracies in the rig control since this time two-axis motion was input. The rig control error component, therefore, became larger by the RSS of the errors from separate axes. In addition, the component errors for the new ILMs were estimated. The data acquisition error was obtained from Fig. 8-1 and the calibration error from Table 8-2, which are data obtained from the load verification drop tests described in Ref. 5. The 1/2-scale, twoaxis test was repeated for seven locations of the in-core instrumentation, and the total error in the boundary support forces and core velocities was obtained from statistical analysis as demonstrated in Table 8-3. These errors, represented as one standard deviation, are shown in brackets in Table 8-1. It is seen that the errors obtained by compounding the component errors are very close to these estimates.

The data in Table 8-4 were derived from the resonant frequency plots in Fig. 7-9. The error in the resonant frequency was obtained statistically based on the RMS curve fits. These statistical estimates are also shown in brackets in Table $8-1$. 
TOTAL RANDOM ERRORS IN THE 1/2-SCALE, TWO-DIMENSIONAL, TWO-AXIS TEST DATA

\begin{tabular}{|c|c|c|c|c|c|c|c|c|}
\hline \multirow[b]{2}{*}{$\begin{array}{c}\text { Test } \\
\text { Parameter }\end{array}$} & \multirow[b]{2}{*}{ Instrument } & \multicolumn{7}{|c|}{ Random Error (\%) $(\mathrm{a})$} \\
\hline & & \begin{tabular}{|} 
Rig (b) \\
Control
\end{tabular} & $\begin{array}{c}\mathrm{Rig} \\
\text { Configuration }\end{array}$ & $\begin{array}{c}\text { Element } \\
\text { Properties }\end{array}$ & $\begin{array}{c}\text { Data } \\
\text { Aquisition }\end{array}$ & $\begin{array}{l}\text { Instrument } \\
\text { Calibration }\end{array}$ & Extraneous & $\operatorname{Total}^{(\mathrm{c})}$ \\
\hline Resonance frequency & DC $\propto$ frequency & 0.5 & 4.8 & 0 & 0.3 & - & 0.7 & $4.9(5.9)^{(d)}$ \\
\hline Boundary support force & Load cells & 17.0 & 5.0 & 2.8 & 1.8 & 5.0 & 0.7 & $18.4(20.2)$ \\
\hline Element deflection & Eddy current probe & 8.5 & 2.5 & 0 & 0.6 & 1.7 & 0.7 & 9.1 \\
\hline Element velocity & Eddy current probe & 11.3 & 3.5 & 0 & 0.6 & 2.4 & 0.7 & 12.1 \\
\hline & LVDT & 11.3 & 3.5 & 0 & 0.6 & 0 & 0.7 & $11.9(11.5)$ \\
\hline Element impact force & ILMD & 17.0 & 5.0 & 2.8 & 1.9 & 2.9 & 0.7 & 18.3 \\
\hline
\end{tabular}

\section{(a) $A 11$ errors represent $1 \sigma$ values}

(b) Represent effect of input error from both $X^{\prime}$ and $Y^{\prime}$ axes.

(c) Total obtained by RSS compounding of individual errors.

(d) Numbers in brackets are obtained from repeated test data. 
TABLE 8-2

ERROR IN ILMD LOAD VERIFICATION TEST DATA

\begin{tabular}{c|c|c|c}
\hline $\begin{array}{c}\text { Load } \\
\text { Orientation }\end{array}$ & $\begin{array}{c}\text { Impact } \\
\text { Surface }\end{array}$ & $\begin{array}{c}\text { Drop } \\
\text { Load (1b) }\end{array}$ & $\begin{array}{c}\text { ILMD } \\
\text { Load (1b) }\end{array}$ \\
\hline \multirow{2}{*}{ Flat } & Graphite & 2055 & 2000 \\
& & 1883 & 1900 \\
& \multirow{4}{*}{ Felt } & 3082 & 3000 \\
& & 1883 & 4000 \\
& & 2911 & 1900 \\
& & 3767 & 2850 \\
& & 2740 & 3650 \\
& & 3938 & 2700 \\
& & 1198 & 3850 \\
& & 3596 & 1250 \\
& & 2055 & 3400 \\
& & 2911 & 2000 \\
& & & 2900 \\
\hline
\end{tabular}

Average drop 1 oad $=27661 \mathrm{~b}$

$\hat{\mathrm{S}}=\frac{\left[\frac{1}{\mathrm{n}} \sum_{\mathrm{n}=1}^{\mathrm{n}}\left(\mathrm{u}_{\mathrm{a}}-\mathrm{u}_{\mathrm{m}}\right)\right]^{1 / 2}}{u_{\mathrm{m}}}=2.9 \%$ 
TABLE 8-3
ERRORS IN BOUNDARY SUPPORT FORCE AND CORE VELOCITY DATA (a)

\begin{tabular}{|c|c|c|c|c|c|c|c|c|c|}
\hline Test & 7 & 9 & 20 & 30 & 31 & 40 & 41 & \multirow[t]{2}{*}{ Ave. } & \multirow{2}{*}{$\begin{array}{c}\text { Error } \\
(\%)\end{array}$} \\
\hline Core Position & 1 & $1 \mathrm{a}$ & 2 & 3 & $3 a$ & 4 & $4 a$ & & \\
\hline & \multicolumn{9}{|c|}{$\begin{array}{c}\text { Support Force } \\
\text { (1b) }\end{array}$} \\
\hline LC 002 & 2542 & 2420 & 1860 & 1752 & 1613 & 1608 & 2786 & 2083 & 22.0 \\
\hline LC 019 & 1555 & 1767 & 1688 & 1222 & 1763 & 1602 & 1850 & 1635 & 12.0 \\
\hline LC 055 & 1538 & 1280 & 1102 & 852 & 943 & 1224 & 1632 & 1224 & 22.0 \\
\hline LC 067 & 2959 & 1651 & 2832 & 2319 & 2902 & 1856 & 2564 & 2614 & 20.0 \\
\hline LC 071 & 2327 & 1530 & 1064 & 1392 & 1756 & 1802 & 1285 & 1593 & 24.0 \\
\hline \multirow[t]{2}{*}{ LC 072} & 2535 & 3075 & 2082 & 1717 & 1689 & 2416 & 1990 & 2214 & 21.0 \\
\hline & \multicolumn{9}{|c|}{$\begin{array}{c}\text { Core Velocity } \\
\text { (in./sec) }\end{array}$} \\
\hline $\mathrm{Dx} 003$ & 23.6 & 22.5 & 32.4 & 26.4 & 25.9 & 24.2 & 22.8 & 25.2 & 12.0 \\
\hline Dy 003 & 12.5 & 14.7 & 13.3 & 12.5 & 14.8 & 15.1 & 10.8 & 13.4 & 11.0 \\
\hline
\end{tabular}

(a) Time history test, shock 3, $0.71 \mathrm{~g}$, correlation coefficient 0.25 . (b) A1l error values xepresent one standard deviation. 
TABLE 8-4

ERROR IN CORE RESONANT FREQUENCY

\begin{tabular}{|c|c|c|c|}
\hline \multicolumn{2}{|c|}{ Actual $(\mathrm{Hz})$} & \multicolumn{2}{|c|}{ RMS (Hz) } \\
\hline Sweep-up & Sweep-down & Sweep-up & Sweep-down \\
\hline 6.7 & 6.0 & 6.7 & 5.95 \\
\hline 6.4 & 5.8 & 6.15 & 5.95 \\
\hline 6.2 & 6.0 & 6.1 & 5.6 \\
\hline 6.4 & 5.7 & 6.1 & 5.55 \\
\hline 5.7 & 5.8 & 6.0 & 5.55 \\
\hline 5.8 & 5.0 & 6.0 & 5.55 \\
\hline 5.8 & 5.4 & 5.9 & 5.55 \\
\hline 5.4 & 5.6 & 5.85 & 5.45 \\
\hline 6.4 & 4.8 & 5.85 & 5.40 \\
\hline 5.6 & 5.5 & 5.85 & 5.4 \\
\hline $5: 5$ & 5.3 & 5.8 & 5.4 \\
\hline 5.2 & 5.0 & 5.75 & 5.4 \\
\hline 5.9 & 5.0 & 5.75 & 5.35 \\
\hline 6.0 & 5.7 & 5.75 & 5.35 \\
\hline 5.5 & 5.8 & 5.65 & 5.35 \\
\hline \multirow[t]{2}{*}{6.4} & 5.3 & 5.65 & 5.3 \\
\hline & 5.5 & & 5.3 \\
\hline$\hat{S}=5.9 \%$ & $=5.7 \%$ & ${ }_{m}=5.9$ & $d_{m}=5.5$ \\
\hline
\end{tabular}

$\hat{\mathrm{S}}=\frac{\left[\frac{1}{\mathrm{n}} \sum_{\mathrm{n}=1}^{\mathrm{n}}\left(\mu_{\mathrm{a}}-\mu_{\mathrm{m}}\right)\right]^{1 / 2}}{\mu_{\mathrm{m}}}$ 
By comparison, the two-axis test errors are larger than the errors in the single-axis test by approximately $30 \%$. The main contributing component is the effect of the rig control inaccuracy of the additional excitation axis.

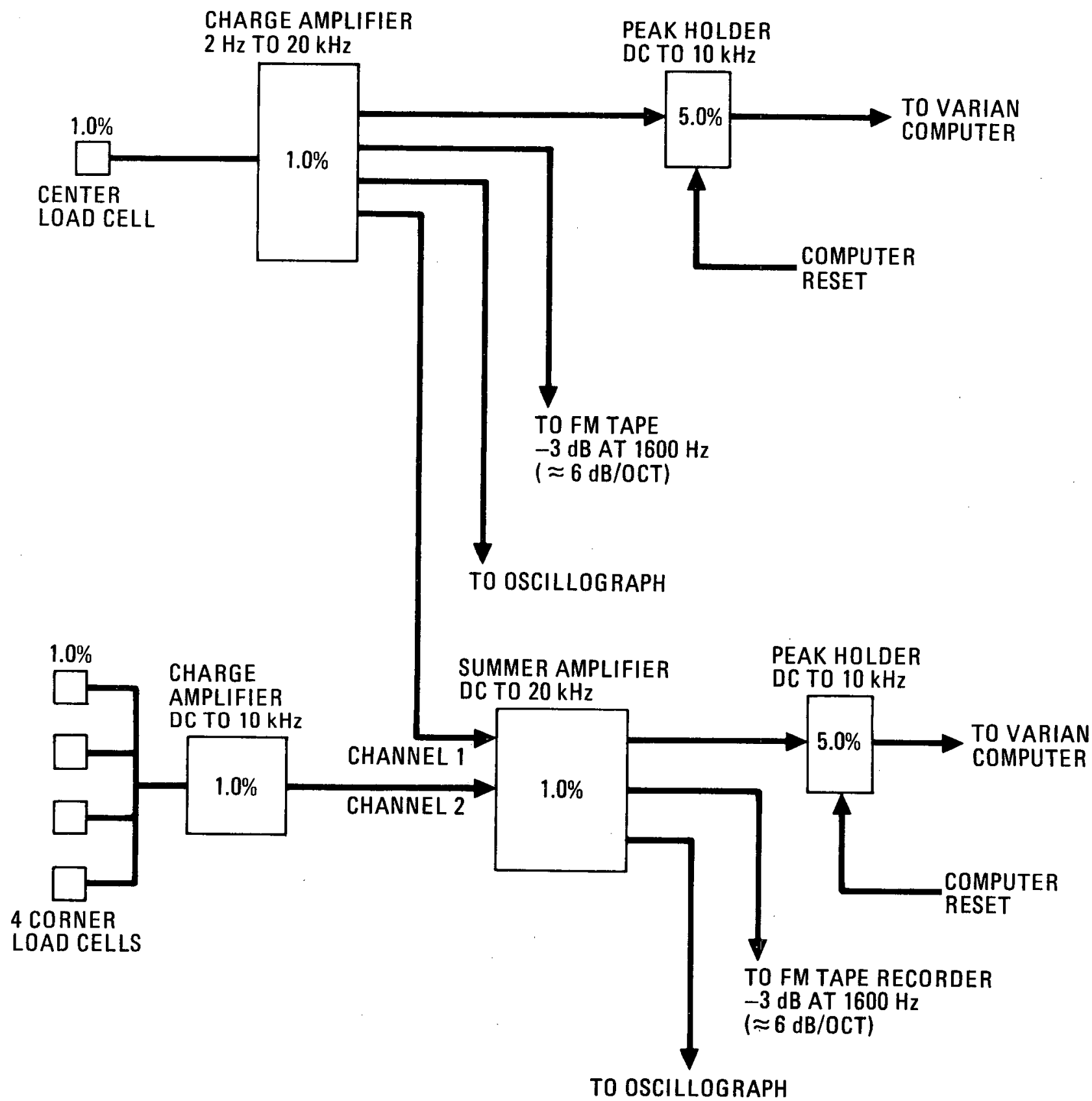

Fig. 8-1. Error diagram for ILMD (element impact force) 


\section{REFERENCES}

1. General Atomic Company, "Test Data for 1/2-scale, Two-Dimensional, TwoAxis Seismic Tests," unpublished data.

2. Peterson, D., and B. E. Olsen, "One-Fifth and One-Half Scale, TwoDimensional Seismic Tests," Department of Energy Report GA-A14087, General Atomic Company, December 1977.

3. "Test Procedure for 2D Seismic Tests on 1/2-Scale Graphite Fuel Elements - Two Axis," Approved Engineering Test Laboratories Report 5486-GGG.*

4. "Final Test Report for Two-Axis Seismic Vibration on 1/2-Scale Graphite Fuel Elements," Approved Engineering Test Laboratories Report 5430-5486FTR. *

5. "Pretest Two-Axis Seismic Test Report on 1/2-Scale Graphite Fuel Elements," Approved Engineering Test Laboratories Report 5430-5486-PTR.*

6. Wonacott, G., B. Hilditch, and B. E. Olsen, General Atomic Company, "HTGR Core Seismic Status Report. 1/5-Scale Full Array Test Results," unpublished data, June 1974.

$*$

* These reports are General Atomic proprietary information. 